University of Massachusetts Amherst

ScholarWorks@UMass Amherst

Masters Theses

Dissertations and Theses

April 2021

\title{
Ground Source Heat Pumps: Considerations for Large Facilities in Massachusetts
}

Eric Wagner

University of Massachusetts Amherst

Follow this and additional works at: https://scholarworks.umass.edu/masters_theses_2

Part of the Energy Systems Commons

\section{Recommended Citation}

Wagner, Eric, "Ground Source Heat Pumps: Considerations for Large Facilities in Massachusetts" (2021).

Masters Theses. 1028.

https://doi.org/10.7275/20019591 https://scholarworks.umass.edu/masters_theses_2/1028

This Open Access Thesis is brought to you for free and open access by the Dissertations and Theses at ScholarWorks@UMass Amherst. It has been accepted for inclusion in Masters Theses by an authorized administrator of ScholarWorks@UMass Amherst. For more information, please contact scholarworks@library.umass.edu. 
University of Massachusetts Amherst

ScholarWorks@UMass Amherst

Ground Source Heat Pumps: Considerations for Large Facilities in Massachusetts

Eric Wagner

Follow this and additional works at: https://scholarworks.umass.edu/masters_theses_2

Part of the Energy Systems Commons 


\title{
GROUND SOURCE HEAT PUMPS: CONSIDERATIONS FOR LARGE FACILITIES IN MASSACHUSETTS
}

\author{
A Thesis Presented \\ by \\ ERIC C. WAGNER
}

\begin{abstract}
Submitted to the Graduate School of the
University of Massachusetts Amherst in partial fulfillment of the requirements for the degree of

MASTER OF SCIENCE IN MECHANICAL ENGINEERING
\end{abstract}

FEBRUARY 2021

Department of Mechanical and Industrial Engineering 
(C) Copyright by Eric C. Wagner 2021

All Rights Reserved 


\title{
GROUND SOURCE HEAT PUMPS: CONSIDERATIONS FOR LARGE FACILITIES IN MASSACHUSETTS
}

\author{
A Thesis Presented \\ by \\ ERIC C. WAGNER
}

Approved as to style and content by:

Dragoljub (Beka) Kosanovic, Chair

Jon McGowan, Member

Ho-Sung Kim, Member

Benjamin McDaniel, Member

Prof. Sundar Krishnamurty, Department Head,

M\&I Engineering Department 


\section{ACKNOWLEDGMENTS}

I would like to first express my sincere thanks and gratitude to my advisor Professor Dragoljub Kosanovic, for the opportunity to learn and study as well as the support provided during my time at University of Massachusetts Amherst. I would like to thank Prof. Jon McGowan, Dr. Ho-Sung Kim, and Benjamin McDaniel for serving on my thesis committee. My thanks also go to my co-workers in the IAC: Akhil Soman, Ritvij Dixit and Kedar Shete who provided feedback and support throughout the course of my research. Finally, I would like to thank my friends and family for supporting me throughout a somewhat unusual time as well as all the other people in my life who helped me build my knowledge and skills up to this point. 


\author{
ABSTRACT \\ GROUND SOURCE HEAT PUMPS: CONSIDERATIONS FOR LARGE FACILITIES \\ IN MASSACHUSETTS \\ FEBRUARY 2021 \\ ERIC C. WAGNER, B.A, GUSTAVUS ADOLPHUS COLLEGE \\ M.S, UNIVERSITY OF MASSACHUSETTS AMHERST \\ Directed by: Prof. Dr. Dragoljub (Beka) Kosanovic
}

There has been a significant increase in the interest and implementations of heat pump systems for HVAC purposes in general and of ground source heat pumps (GSHPs) in particular. Though these systems have existed for decades, primarily in Europe, there has been an upward trend particularly in the United States in recent years. With the world-wide push toward $\mathrm{CO}_{2}$ emissions reduction targets, interest in heat pump systems to reduce $\mathrm{CO}_{2}$ emissions from heating and cooling is likely to only increase in the future. However, more than ever, financial considerations are also key factors in the implementation of any system.

Ground source heat pumps (GSHPs) coupled to vertical borehole heat exchangers (BHEs) have been promoted as a viable heat pump system in climates where traditional air source heat pumps (ASHPs) may operate inefficiently. This type of system claims superior performance to ASHPs due to the relatively consistent temperature of the ground compared to the air, offering a higher temperature heat source in the heating season and a lower temperature sink in the cooling season. Projects designing and installing such a 
GSHP system have been implemented at large scales on several university campuses to provide heating and cooling.

In this study, we aim to test the idea that a GSHP system, as a replacement for an existing $\mathrm{CHP}$ heating and conventional cooling systems, could reduce $\mathrm{CO}_{2}$ emissions, as well as provide a cost benefit to a large energy consumer, in this case the University of Massachusetts. This will be done using the existing heating and cooling loads provided by the conventional system and an established technique of modeling the heat pumps and BHEs. The GSHP system is modeled to follow the parameters of industry standards and sized to provide the best overall lifetime cost. The result on the overall annual costs, emissions, and university microgrid are considered. 


\section{TABLE OF CONTENTS}

Page

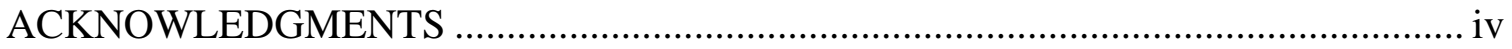

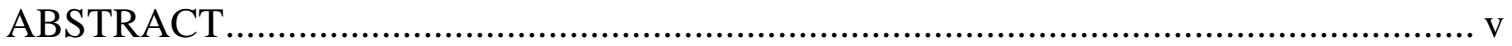

LIST OF TABLES ....................................................................................... ix

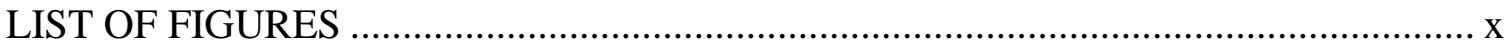

CHAPTER

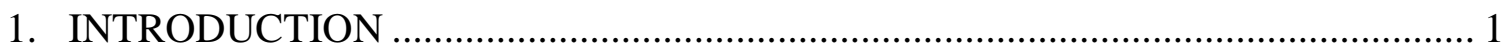

1.1 Introduction to Heat Pumps ..................................................................... 1

1.2 Geothermal Heat Pump Systems ............................................................. 3

1.3 Utility Electric and Heating Costs ............................................................. 5

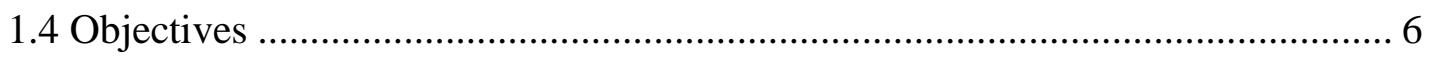

2. REVIEW OF LITERATURE AND PREVIOUS NOTABLE INSTALLATIONS ..... 8

2.1 Research Methodologies ........................................................................ 8

2.2 Heat Pump Simulations......................................................................... 10

2.3 Previous Studies at University of Massachusetts......................................... 12

2.4 Notable Previous Geothermal Installations ................................................ 13

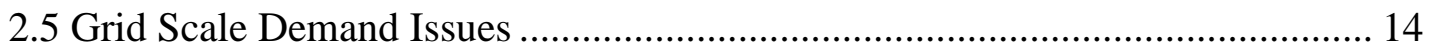

3. HEAT PUMP SIMULATION DESIGN …..................................................... 16

3.1 University Buildings Background........................................................ 16

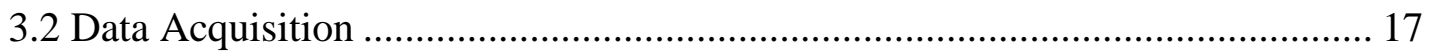

3.3 Heat Pump Performance Characteristics ..................................................... 19

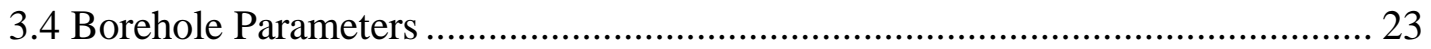




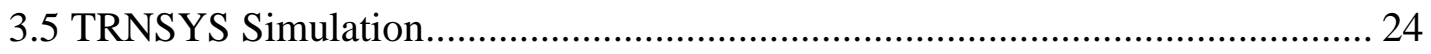

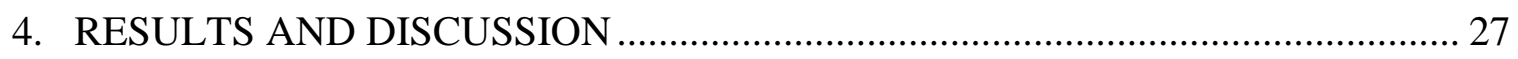

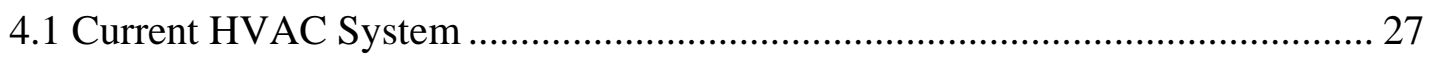

4.2 Proposed Heat Pump System Layout.............................................................. 28

4.3 Comparison of GSHP, ASHP and Conventional Cases..................................... 29

4.4 GSHP System Installation Cost Optimization .................................................... 32

4.5 Ground Source Heat Exchanger System Potential Degradation.......................... 36

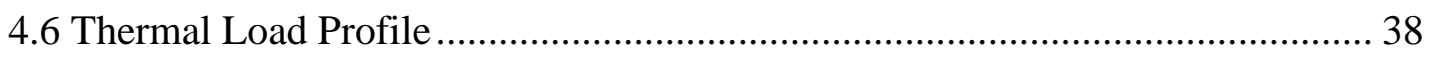

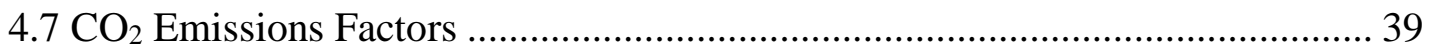

4.8 Building Additional Electric Load................................................................ 40

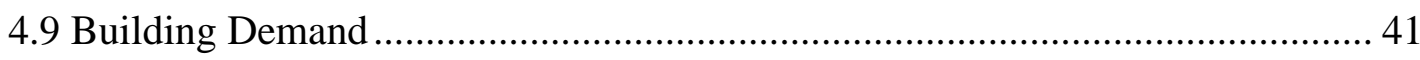

4.10 Overall Cost and Emissions Comparison .......................................................... 44

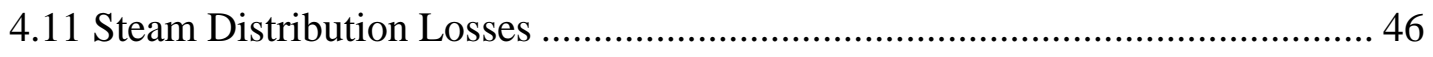

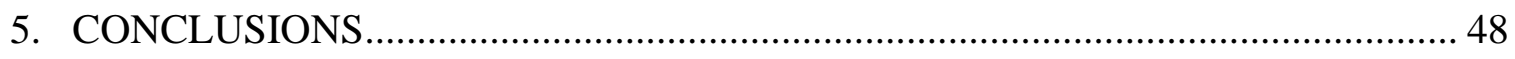

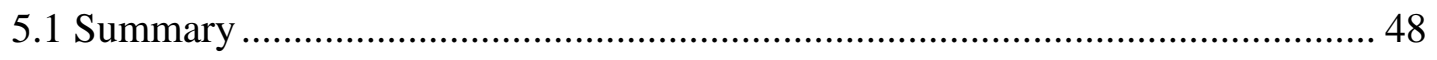

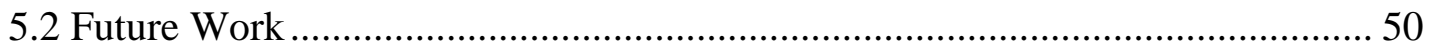

APPENDICES

A. CONVENTIONAL CHILLER PERFORMANCE DATA (kW/Ton) ....................... 53

B. GROUND SOURCE HEAT PUMP PERFORMANCE DATA ………………........ 54

C. AIR SOURCE HEAT PUMP PERFORMANCE DATA ........................................... 57

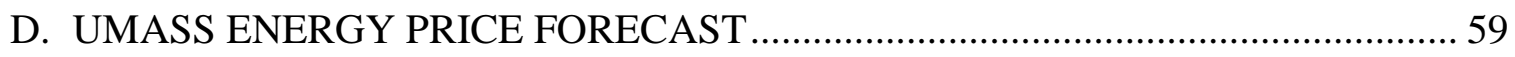

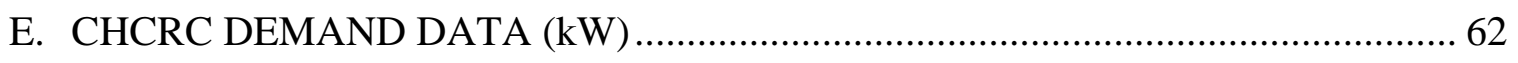

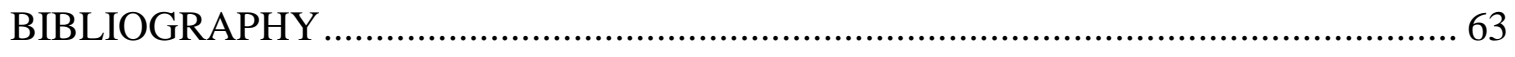




\section{LIST OF TABLES}

TABLE 1: THEORETICAL CARNOT COP OF A HEAT PUMP AT VARIOUS

TEMPERATURES 3

TABLE 2: MONTHLY ENERGY CONSUMPTION OF THE HEATING AND COOLING COMPONENTS IN THE GSHP, ASHP AND CONVENTIONAL CASES 31 TABLE 3: MONTHLY ELECTRICITY AND FUEL CONSUMPTION IN THE GSHP,

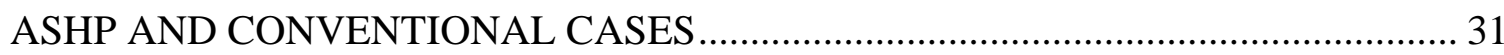

TABLE 4: HEAT PUMP AND BOREHOLE DRILLING COSTS .................................. 33

TABLE 5: AVERAGE EMISSIONS FACTORS FOR GRID PURCHASED

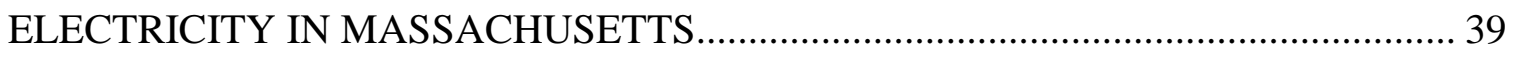
TABLE 6: EMISSIONS FACTORS OF THE CHP CTG PER MMBTU OF FUEL

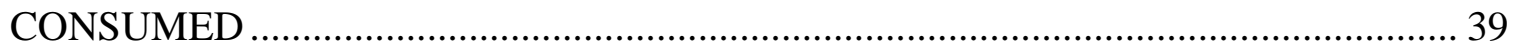

TABLE 7: EMISSIONS FACTORS OF THE CHP BOILERS PER MMBTU OF FUEL

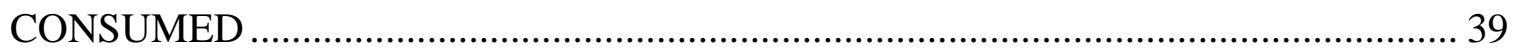

TABLE 8: MONTHLY DEMAND PEAK HOURS FOR 2019 ……………………..... 42

TABLE 9: SUMMARY OF ANNUAL UTILITY COSTS ............................................ 45

TABLE 10: SUMMARY OF GSHP, ASHP AND CONVENTIONAL CASE

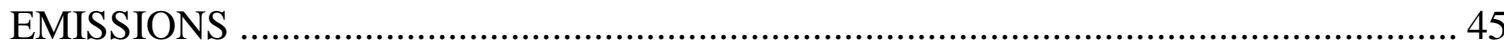

TABLE 11: ANNUAL COST INCREASES BETWEEN HEAT PUMP AND CONVENTIONAL CASES OVER 10 YEARS............................................................. 46 


\section{LIST OF FIGURES}

Page

FIGURE 1: A SIMPLIFIED DIAGRAM OF A HEAT PUMP CYCLE ........................... 1 FIGURE 2: DIAGRAM OF VERTICAL GROUND HEAT EXCHANGER (SANNER

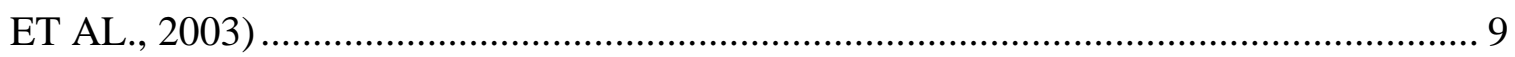

FIGURE 3: CONVENTIONAL CHILLER PERFORMANCE DATA ............................ 18 FIGURE 4: HEATING AND COOLING LOADS FOR THE HONORS COLLEGE

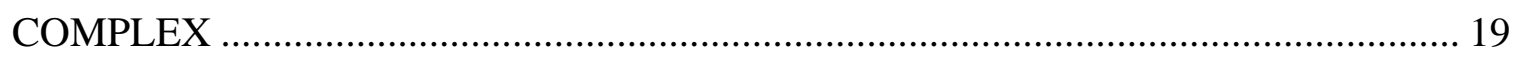
FIGURE 5: GROUND SOURCE, WATER-TO-WATER HEAT PUMP COOLING (TOP) AND HEATING (BOTTOM) PERFORMANCE DATA..................................... 21

FIGURE 6: AIR SOURCE HEAT PUMP COOLING (TOP) AND HEATING

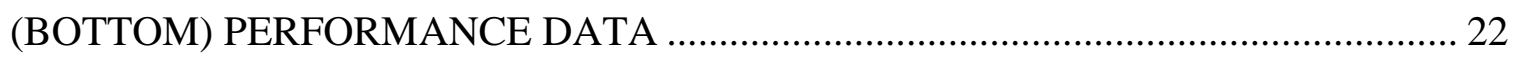
FIGURE 7: PERFORMANCE OF EACH COOLING SYSTEMS AT 75 $\mathrm{F}$

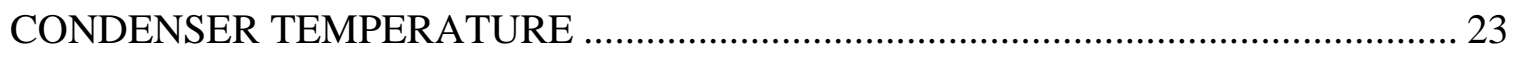

FIGURE 8: TRNSYS PROJECT USED TO MODEL GSHPS ……………………..... 25 FIGURE 9: FLOW CHART SHOWING SIMULATION PROCESS FOR GSHP AND

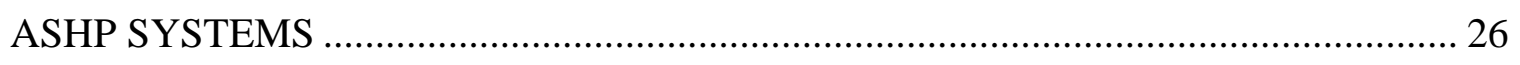
FIGURE 10: ELECTRICAL USAGE OF CONVENTIONAL COOLING COMPARED

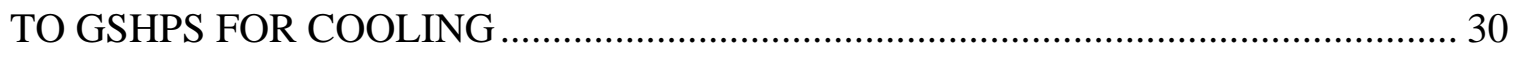
FIGURE 11: HEATING ENERGY INPUT TO THE CONVENTIONAL SYSTEM (MMBTU) COMPARED TO ELECTRICAL CONSUMPTION OF GSHPS FOR

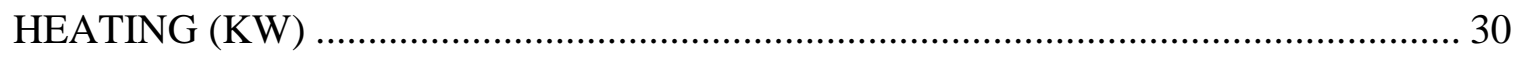
FIGURE 12: INSTALLED GSHP SYSTEM COST ……….......................................... 34 
FIGURE 13: COST OF ELECTRICITY FOR GSHP SYSTEM ................................. 34

FIGURE 14: LIFETIME COST OF GSHP SYSTEM OVER 40 YEAR PERIOD ......... 35

FIGURE 15: THE AVERAGE GROUND TEMPERATURE IN THE GROUND

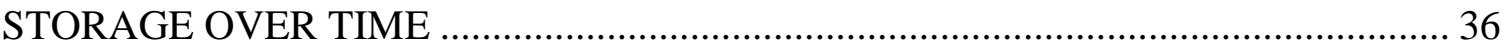

FIGURE 16: CHCRC BUILDING ELECTRIC LOAD AND ELECTRIC POWER

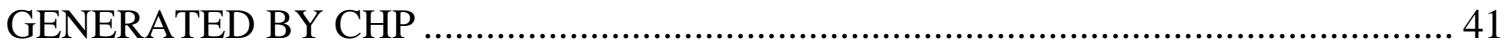

FIGURE 17: ELECTRICAL POWER PURCHASED FROM THE GRID BY THE

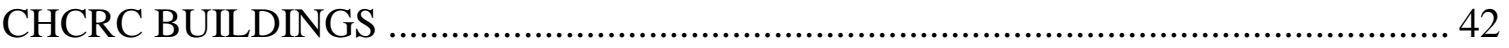

FIGURE 18: MONTHLY DEMAND OF THE HONORS COLLEGE COMPLEX....... 43 


\section{CHAPTER 1 \\ INTRODUCTION}

\subsection{Introduction to Heat Pumps}

A heat pump is essentially a heat engine operated in reverse, such that mechanical work is done to move heat from a cold reservoir to a hot reservoir. This is done by evaporation of a working fluid on the cooling side, then this vapor is compressed, and condensation of the vapor occurs on the heating side. The condensed fluid is then moved through an expansion valve and the process is repeated. This process is illustrated in the following figure.

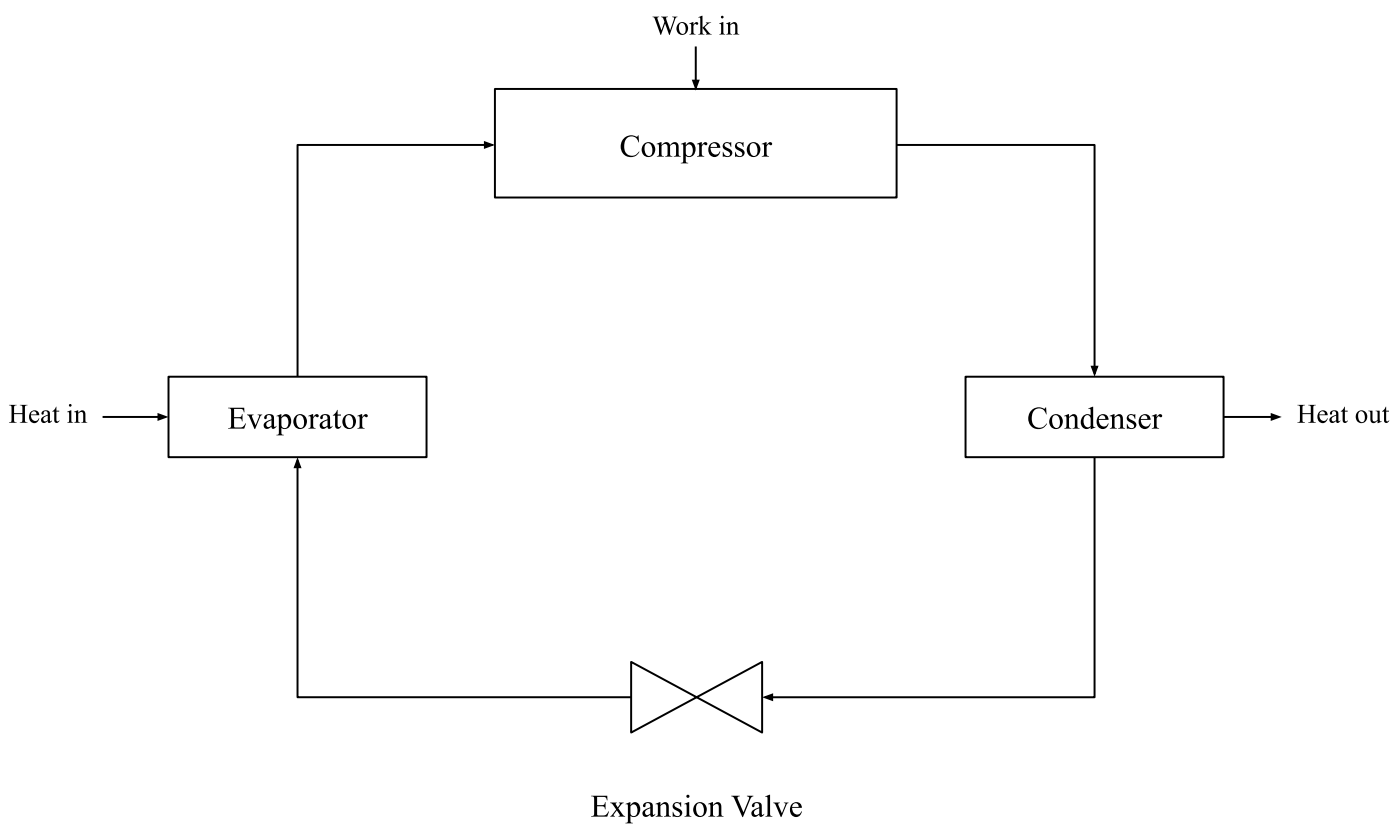

Figure 1: A simplified diagram of a heat pump cycle

This process is employed in many common refrigerant systems. As compared to a simple air conditioner however, a reversible heat pump uses a reversing valve to allow the cycle to operate in reverse. Practically speaking, this means that a reversible heat pump can operate both in a typical refrigerant cycle, where the outdoor refrigerant coil is 
used for condensing the refrigerant and the indoor coil is used evaporating the refrigerant, and also in the reverse cycle, where the outdoor coil is used to evaporate the refrigerant and the indoor coil is used to condense the refrigerant. In the reverse cycle, this allows for the heat pump to heat a building using heat from a lower temperature heat source, such as outdoor air, even when the outdoor air temperature is lower than the desired building temperature.

A heat pump's efficiency is defined as the ratio of heat supplied or removed by the heat pump (Q) to the amount of work required (W). This is also called the coefficient of performance (COP) as defined in the equation below.

$$
\mathrm{COP}=\frac{\mathrm{Q}}{\mathrm{W}}
$$

The COP is physically determined by the operation of the compression and expansion as well as the temperature of the hot and cold reservoirs. In an ideal case, the expansion and compression are done isentropically (adiabatically, and reversibly) and the heat transfer during the evaporation and condensation is done isothermally. This would result in a Carnot cycle, for which the $\mathrm{COP}$ of heating and cooling provided are as follows:

$$
\begin{aligned}
\operatorname{COP}_{\text {Carnot,Heat }} & =\frac{\mathrm{T}_{\mathrm{H}}}{\left(\mathrm{T}_{\mathrm{H}}-\mathrm{T}_{\mathrm{C}}\right)} \\
\mathrm{COP}_{\text {Carnot,Cool }} & =\frac{\mathrm{T}_{\mathrm{C}}}{\left(\mathrm{T}_{\mathrm{H}}-\mathrm{T}_{\mathrm{C}}\right)}
\end{aligned}
$$

Where, $\mathrm{T}_{\mathrm{C}}$ is the temperature of the cold side reservoir and $\mathrm{T}_{\mathrm{H}}$ is the temperature of the hot side reservoir. The Carnot COP of a theoretical heat pump at several temperatures is shown in Table 1. 


\begin{tabular}{|c|c|c|c|}
\hline Typical Use Case: & $\mathrm{T}_{\mathrm{C}}\left({ }^{\circ} \mathrm{C}\right)$ & $\mathrm{T}_{\mathrm{H}}\left({ }^{\circ} \mathrm{C}\right)$ & Carnot COP \\
\hline Heating from a cold $\left(-10^{\circ} \mathrm{C}\right)$ source & -10 & 40 & 5.78 \\
\hline source & 10 & 40 & 9.09 \\
\hline Cooling from a moderate $\left(+10^{\circ} \mathrm{C}\right)$ & 5 & 10 & 55.6 \\
\hline source & 5 & 30 & 11.1 \\
\hline
\end{tabular}

Table 1: Theoretical Carnot COP of a heat pump at various temperatures

This Carnot efficiency forms an upper-bound of the maximum possible efficiency of any refrigeration device. In reality, the efficiency of a real-world heat pump is lower than the Carnot efficiency due to non-adiabatic, non-reversible compression and expansion. However, the trend of higher efficiencies when moving heat from a higher temperature cold side or to a lower temperature hot side reservoir remains true in practice. (Mustafa Omer, 2008)

\subsection{Geothermal Heat Pump Systems}

In a geothermal or ground source heat pump (GSHP) system, the ground itself is used as a heat source in the heating season and a heat sink in the cooling season. This is done through the use of geothermal heat exchangers. Several types of geothermal systems exist. Four common types are: horizontal loop, vertical loop, pond loop, and open loop. The first three main types fall into the category of closed loop systems while the fourth would be an open loop system. Hybrid systems combining two or more types of systems also are possible. (Lanahan \& Tabares-Velasco, 2017) 
In a closed loop system, the heat exchanging fluid flows from the heat pump, through the ground source system, and back to the heat pump in a closed loop. As a result of the closed loop design, an antifreeze solution containing glycol or ethanol may be used to prevent freezing of the fluid in the loop.

In an open loop system, water is pumped from a well in the ground to the heat pump system and then after exchanging heat, can be pumped back into the ground using a second well. Another open loop design is a standing column well design where a single well is used. In this design, water fills the well to the height of the water table and water is pumped to and from the single well in a process promoting recirculating flow in the nearby groundwater. This type of system is particularly common in regions such as the Pacific Northwest and Northeastern United States, however, requires suitable hydrological and geological conditions. (Rees et al., 2004)

Of these systems, a closed loop vertical borehole type system is commonly used for large-scale, commercial geothermal systems. This type of system consists of a large area, into which, a field of boreholes is drilled, typically several hundred feet until bedrock is reached. Cross-linked polyethylene (PEX) tubing forming the closed loop is used, running down and up each borehole in a "U-bend" shape. The boreholes are finished by adding a thermally conductive grout and backfilling to maintain the structural integrity of the boreholes. This type of vertical borehole system has been implemented effectively in large-scale geothermal installations as will be discussed further in Chapter 2. 


\subsection{Utility Electric and Heating Costs}

For small energy consumers, such as a typical residential home, utility costs are charged based mainly on usage of electricity or fuel. For example, a consumer may pay a certain rate in \$ per kilowatt-hour for electricity and a rate in $\$$ per MMBtu, $\mathrm{ft}^{3} \mathrm{or} \mathrm{m}^{3}$ for heating fuel. In such a situation, comparison of a conventional heating and cooling system to an electrified heat pump system for heating and cooling is relatively straight forward. Most heat pumps sold in the United States, especially "Energy Star” rated products, estimate the Heating Seasonal Performance Factor (HSPF) defined as the amount of heating delivered in BTU divided by the amount of electricity consumed in Wh over the course of a typical heating season. A Seasonal Energy Efficiency Ratio (SEER) is also given as the cooling delivered in BTU divided by electricity consumed in Wh. A simple comparison of the SEER of the heat pump to a conventional air conditioner provides an indication of the cooling efficiency, where a higher SEER indicates greater efficiency and thus potential savings in electric consumption for cooling. The HSPF can be used as follows to estimate potential cost saving from heating:

$$
\text { Savings Factor }=\frac{\left(\operatorname{HSPF}\left[\frac{\mathrm{BTU}}{\mathrm{Wh}}\right]\right) \times\left(\operatorname{Cost}_{\mathrm{Fuel}}\left[\frac{\$}{\mathrm{BTU}}\right]\right)}{\eta_{\text {conventional }} \times\left(\operatorname{Cost}_{\text {electricity }}\left[\frac{\$}{\mathrm{kWh}}\right]\right) \times\left(1,000\left[\frac{\mathrm{kWh}}{\mathrm{Wh}}\right]\right)}
$$

Where, $\eta_{\text {conventional }}$ is the efficiency of the conventional heating system. A savings factor greater than 1 would indicate potential savings for the heat pump over the conventional heating system at the current fuel and electricity prices.

While this holds true for a small energy consumer, where utilities are billed based mainly on usage, larger energy consumers such as large commercial or industrial customers may have a more complex energy rate structure. For most large energy 
consumers, particularly those in deregulated markets, it is common for electricity to be charged based mainly on three metrics:

1. Total electricity usage in $\mathrm{kWh}$

2. Monthly demand in $\mathrm{kW}$

3. Annual capacity charge in $\mathrm{kW}$ used at a yearly peak time for the regional grid

This makes analysis of the effect of installing electric heat pumps more complex, as the increase in electric demand must be calculated on a sub-hourly basis to determine the resulting cost increase due to increased demand.

Further, the case of a facility using a combined heat and power (CHP) plant to satisfy both heating and electricity needs introduces yet another complexity. In analyzing a replacement of the entire heating load by electric heat pumps, the loss in electrical generation must also be considered. As many CHP plants are operated to primarily satisfy the required heating, this could mean loss of all generated electricity.

The University of Massachusetts in one such example of a large energy consumer that is billed based on the three electricity metrics listed above and also currently operates a CHP for heating and electricity generation.

\subsection{Objectives}

Unlike previous research into GSHPs, which mainly uses generalized loads applied to large scale networks (Veldman et al., 2011), or very small residential systems (Safa et al., 2015). By comparison, this research focuses on the effect of transitioning the known, measured heating and cooling loads at the University of Massachusetts (UMass) campus to electric heat pumps. As noted in Section 1.3, the utility costs and presence of a CHP make this a unique challenge. Thus, the following will be done in this thesis: 
- Measured data for heat transfer and electric power will be obtained from the current campus Building Automation System.

- MATLAB will be used to pre-process this raw data into useful heating and cooling load and electrical consumption data.

- Ground source and air source heat pumps providing this load will be simulated using a combination of TRNSYS Type557 Duct Storage modeling and MATLAB using manufacturer provided performance specifications.

- The resulting energy usage and $\mathrm{CO}_{2}$ emissions will be analyzed.

- Costs will be compared between the GSHP, ASHP and current conventional cases using utility and installation costs typical for a large consumer in the New England region.

This aims to test the idea that a GSHP system, as a replacement for an existing CHP heating and conventional cooling systems, could reduce $\mathrm{CO}_{2}$ emissions and also provide a cost benefit to a large energy consumer, in this case the University of Massachusetts. 


\section{CHAPTER 2}

\section{REVIEW OF LITERATURE AND PREVIOUS NOTABLE INSTALLATIONS}

\subsection{Research Methodologies}

Borehole and well drilling have a long history reaching back millennia as a method of extracting water as well as other resources such as oil and natural gas. Geothermal boreholes are defined as those drilled for the specific purpose of harnessing geothermal energy. This can be done by directly extracting heat from the ground; however, this requires specific geology with active geologic activity to produce high enough temperatures to be useful. In addition, many boreholes for this application require drilling thousands of meters resulting in high drilling costs. As a result, these types of systems are limited in their application to places such as Iceland where such systems have proven highly effective. Since the 1980's, research has focused on a second approach to harnessing the power of geothermal energy. This second method relies on borehole heat exchangers (BHE) connected to ground source heat pumps (GSHPs). In this type of installation, the ground itself is used as a heat source or sink for the GSHPs. 


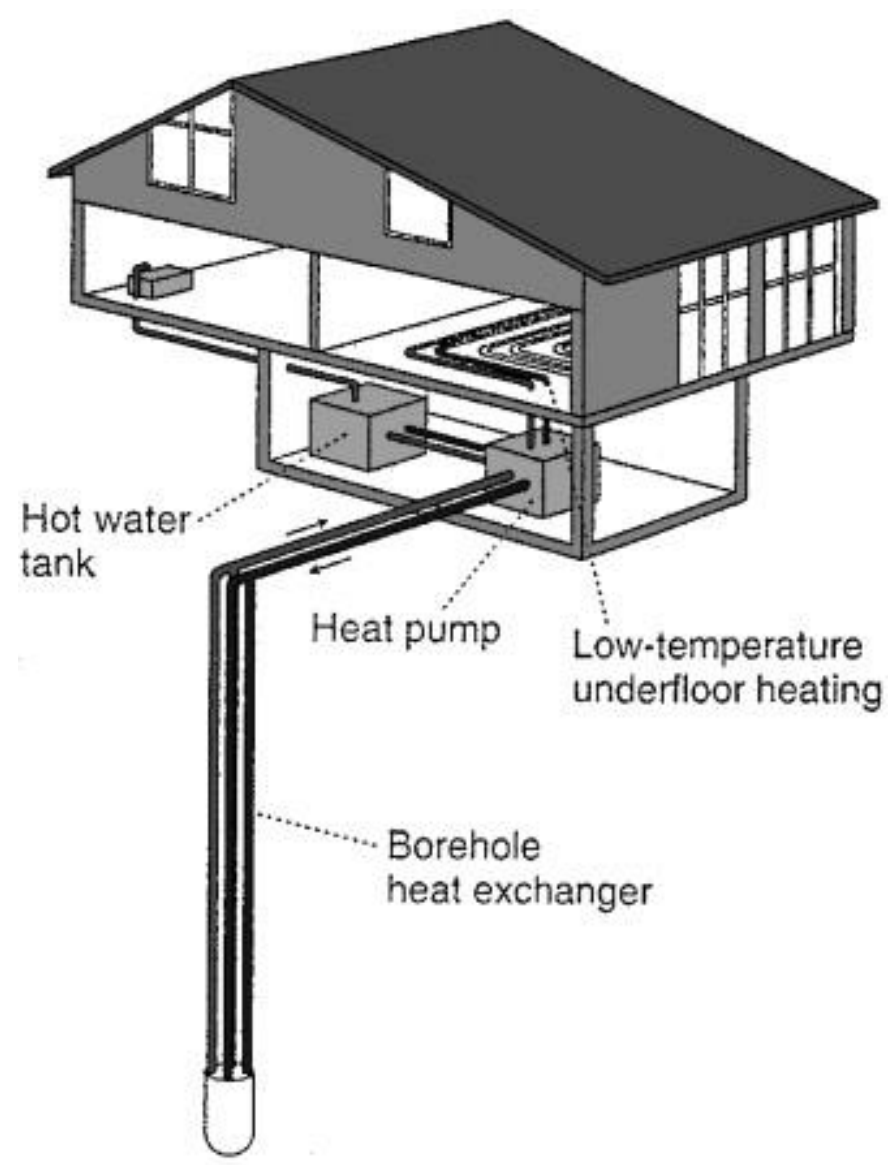

Figure 2: Diagram of vertical ground heat exchanger (Sanner et al., 2003)

Through pumping of a heat transfer fluid through the BHEs, the GSHPs can extract heat from the ground and "boost" it to a usable temperature for typical building heating needs or cool a building by rejecting heat from the building to the ground. As will be discussed further, the average ground temperature remains fairly consistent throughout the year, resulting in significantly better efficiencies for a GSHP as opposed to an air source heat pump.

Broadly speaking, research into heat pump systems for heating and cooling can be divided into two categories. First is simulation of heat pump systems using varying amounts of data from real world sources. The second would be post installation analyses 
on real world system, varying in size from single home systems to commercial systems using thousands of boreholes.

\subsection{Heat Pump Simulations}

The simulation of GSHPs requires simulation of two main components: the heat pumps themselves, and the GHEs. Simulation of the heat pumps can be done simply by following data provided by the manufacturer for the capacity and power requirements of the particular heat pump model used at the specific operating conditions such as entering water temperature, flowrate, and fraction load if a variable speed model is used. On the other hand, simulation of the GHEs is much more complex. The simulation must take into account the full heat transfer from the heat transfer fluid to the ground and through the ground over time.

The duct ground heat storage model is a well-regarded method for simulation of the borehole heat transfer process. Hellstrom, 1989, presents the physical background of the model and numerical method as implemented in TRNSYS Type557. In this process, the heat exchangers are assumed to be uniformly placed in the ground storage region with homogeneous thermal properties and the temperature at any given point in the storage volume is calculated based on a superposition of three separate solutions for the heat flow: the global solution, a steady heat-flux solution that occurs around the GHE pipes, and a local solution dependent on the radial component only. This gives the equation:

$$
\mathrm{C} \frac{\partial \mathrm{T}}{\partial \mathrm{t}}=\nabla \cdot(\lambda \nabla \mathrm{T})+\mathrm{q}_{\mathrm{sf}}+\mathrm{q}_{\mathrm{l}}
$$

Where, $\mathrm{q}_{\mathrm{sf}}$ is the source term for the steady-flux solution and $\mathrm{q}_{1}$ is the source term transferring heat from the local solution. $\mathrm{C}$ represents the volumetric heat capacity and $\lambda$ represents the thermal conductivity. 
Thus, this equation can be solved stepwise for the ground storage region to model the effect of the GHEs and heating and cooling loads on the ground temperature and the resulting fluid temperature entering and leaving the GHEs.

Previous studies have used the duct ground heat storage model, as given in TRNSYS Type557, to model a GHE system. For example, Safa et al., 2015 applied the model to a GSHP system using load and performance data from an existing GSHP system, gathered from two model experimental houses in Kortright Centre, CA. The results were used to optimize pump and temperature controls, indicating potential efficiency gains. The heating and cooling demand were extrapolated based on only 23 days of experimental data and stipulated separate discrete heating and cooling seasons with no overlap.

Similarly, Cacabelos et al., 2015 used TRNSYS and GenOpt to calibrate a model of an existing building with GSHPs. A physically based model of the building's dimensions and materials was applied, and TRNSYS was used to simulate the heating and cooling of the building using the GSHPs. The energy consumption of the simulated heat pumps was found to have a root mean squared error (RMSE) of $11.78 \%$ relative to the real energy consumption. This was accepted to be within the $\pm 15 \%$ recommended by ASHRAE Guideline 14.

These studies demonstrate the established ability of the duct ground heat storage model in TRNSYS Type557 to simulate BHEs in a GSHP system. 


\subsection{Previous Studies at University of Massachusetts}

At the University of Massachusetts in particular, there have been several previous studies considering geothermal boreholes for seasonal heat storage (Elhasnaoui, 1991; McDaniel \& Kosanovic, 2016).

First, Elhasnaoui, 1991, studied the potential for a central solar heating plant with seasonal storage using BHEs. This included study of the efficiency, performance and

control of such as system. A storage volume of $60,000 \mathrm{~m}^{3}$ with 850 boreholes was used to provide $83 \%$ of a 3,306 MWh annual heat load using a solar collector area of 7,500 $\mathrm{m}^{2}$. The first law efficiency of the system was found to be $65 \%$. As part of this research, the simulation method for modeling vertical, U-tube, borehole heat exchangers was also analyzed and advanced. A comparison of a finite element method to the duct storage method allowed the U-tubes to be modeled using a calculated thermal resistance with a maximum deviation of <5\% (Breger et al., 1996).

Second, seasonal thermal energy storage was also studied by McDaniel \& Kosanovic, 2016 using excess heat generated during the summer by the CHP plant. This study used generated steam and power data from the CHP plant as an input to a TRNSYS model using the duct ground storage model for the thermal energy storage simulation. This model comprising 6,000 boreholes was run over 5 years to reach steady state, at which point the efficiency of the borehole system reached 90\%. Cost and emissions savings were found when the heat from the thermal energy storage system was used instead of burning ultra-low sulfer diesel fuel during the winter months when natural gas shortages occur. 
This thesis builds upon the collected data from these previous studies on the geological feasibility of a ground source heat exchanger system at UMass in particular and the simulation methods for such a system. As well, these studies have demonstrated a desire to implement a geothermal system at UMass in the future.

\subsection{Notable Previous Geothermal Installations}

Geothermal heat pump systems for large scale heating and cooling have been implemented in several areas, with Europe having by far the most. In the United States, one noteworthy project was implemented at Ball State University in Muncie, Indiana (Lowe et al., 2010). Ball State installed a campus wide geothermal heat pump system in two phases with three borehole fields totaling 3,400 boreholes in total, which heats and cools 47 buildings. The cost of the completed system was $\$ 83,000,000$ and is said to save $\$ 2.2-2.5$ million per year over their previous coal fired boilers. This project was completed between 2009 and 2014 and has since generated significant interest in GSHPs at other campuses. However, it should be noted that this case study compares the GSHPs to steam generation by coal fired boilers and chilled water from conventional chillers. Thus, in this case there was a larger potential for savings over the initial state due to the relative inefficiency of coal fired boilers as compared to a more state of the art conventional heating system such as natural gas fired boilers.

There has been one installation of GSHPs at the University of Massachusetts in particular. The campus police station building is a three story, $25,700 \mathrm{ft}^{2}$ building using a primary-secondary GSHP loop with 16 vertical boreholes and 41 independent locally zoned heat pumps. This is a system where fluid is circulated by a set of primary pumps from the BHEs to a set of secondary pumps, which are then used to circulate fluid 
through the building to the heat pumps. This building was the subject of a retro-

commissioning study (Marmaras, 2014) as energy consumption of the building was much higher than originally projected. The space heating and cooling load were originally projected to total $96,585 \mathrm{kWh}$ annually, however actual consumption was $192,900 \mathrm{kWh}$ over the 2011-2012 year-long period. After retro-commissioning, this was reduced to $149,332 \mathrm{kWh}$. Pump and fan power consumption was also reduced, from 152,800 kWh to $105,334 \mathrm{kWh}$. In addition to methods such as fault detection, power consumption was reduced through optimizations to the primary and secondary pumping system. This optimization compared relative heat pump performance to fluid pump power in order to minimize total power consumption.

\subsection{Grid Scale Demand Issues}

A problematic issue with GSHPs and electrified heating in general is the effect of large-scale adoption of these technologies on grid demand. Electrified heating by heat pumps has been previously shown to potentially increase variability and peak demand when simulated at a grid scale (Quiggin \& Buswell, 2016). Quiggin \& Buswell present a system model for the UK grid to examine the impact of 6 different scenarios ranging from $24.5 \%$ to $90 \%$ adoption of electrified heating by 2050 . The model simulates the electricity supply side with both dispatchable and non-dispatchable generation. The electricity demand side is also simulated with the demand from traditional electricity, space and water heating, electric vehicles and heat pumps considered. Two heating demand profiles for the heat pumps were considered: one "flat" profile where heating was provided at a constant rate throughout a 24 hour period, and an unrestricted profile where the heat pump demand was allowed to vary to meet the hourly heating load. It was 
found that the heat pump demand increased by $\sim 50 \%$ when using the unrestricted profile compared to the flat profile and heat pump demand constituted the majority of increased grid demand. This demonstrates a potential need for thermal storage as a method of reducing the electrical demand from heat pumps.

These issues are particularly a concern for large electricity consumers such as the University of Massachusetts that need to consider the effect of such technologies on the resiliency of their microgrid as well as the financial impact of increased electricity demand. 


\section{CHAPTER 3}

\section{HEAT PUMP SIMULATION DESIGN}

\subsection{University Buildings Background}

As simulation of GSHPs using TRNSYS and related methods is an established technique (Cacabelos et al., 2015; Hellstrom, 1989; Safa et al., 2015), we will apply this type of simulation to a building complex on the UMass campus using the existing heating and cooling loads. The Commonwealth Honors College Residential Complex (CHCRC) on the University of Massachusetts Amherst campus was chosen as the study location for several reasons. First, the residential complex was completed in 2013 as a LEED Silver certified green building and as a result is a good candidate for further energy efficiency projects. Second, the complex includes 512,000 $\mathrm{ft}^{2}\left(47,600 \mathrm{~m}^{2}\right)$ of building area with 1,500 student beds, 9 classrooms and a 24/7 café and is occupied during all months out of the year, thus it is a smaller complex that can be representative of the larger campus as a whole. Finally, unlike many buildings on the UMass campus that use steam for heating directly, the Honors College buildings use a dual water system to deliver hot water for heating and cold water for cooling to the buildings. Lower temperature heating distribution systems are more conducive to heat pump replacement than higher temperature heating distribution systems, thus the CHCRC is an example of buildings that could utilize heat pumps with their current heat distribution system. By comparison, a building currently utilizing steam for heating directly would require a retrofit or replacement of the heat distribution system in order to use heat pumps for heating. 


\subsection{Data Acquisition}

Heating and cooling load data for the Honors College complex was obtained from data collected by a building automation system (BAS). The UMass campus uses Johnson Controls' Metasys BAS for control and data acquisition of HVAC systems. This system measures the heating and cooling water system's total fluid flow rate, as well as the water temperature at the source and return. The fluid flow rate is measured using Venturi flow meters and the temperatures using temperature sensors. The data is measured and recorded at a 15-minute interval. This data can be used to estimate the total heating and cooling load required by the building by the following equation:

$$
\dot{\mathrm{Q}}=\rho \times \dot{\mathrm{V}} \times \mathrm{c}_{\mathrm{p}} \times \Delta \mathrm{T}
$$

Where, $\rho$ is the density of water, $\dot{V}$ is the flowrate of the heating or cooling water, $\mathrm{c}_{\mathrm{p}}$ is the specific heat of water, and $\Delta \mathrm{T}$ is the temperature change in the water from the source to return.

While both heating and cooling load can be measured in this manner, the cooling load can be measured more directly in this case by measuring the total electrical load of the chillers. This electrical power measurement was obtained from the same Metasys BAS and used to calculate the total cooling load, based on manufacturer provided performance data. This performance data is also listed in Appendix A. 


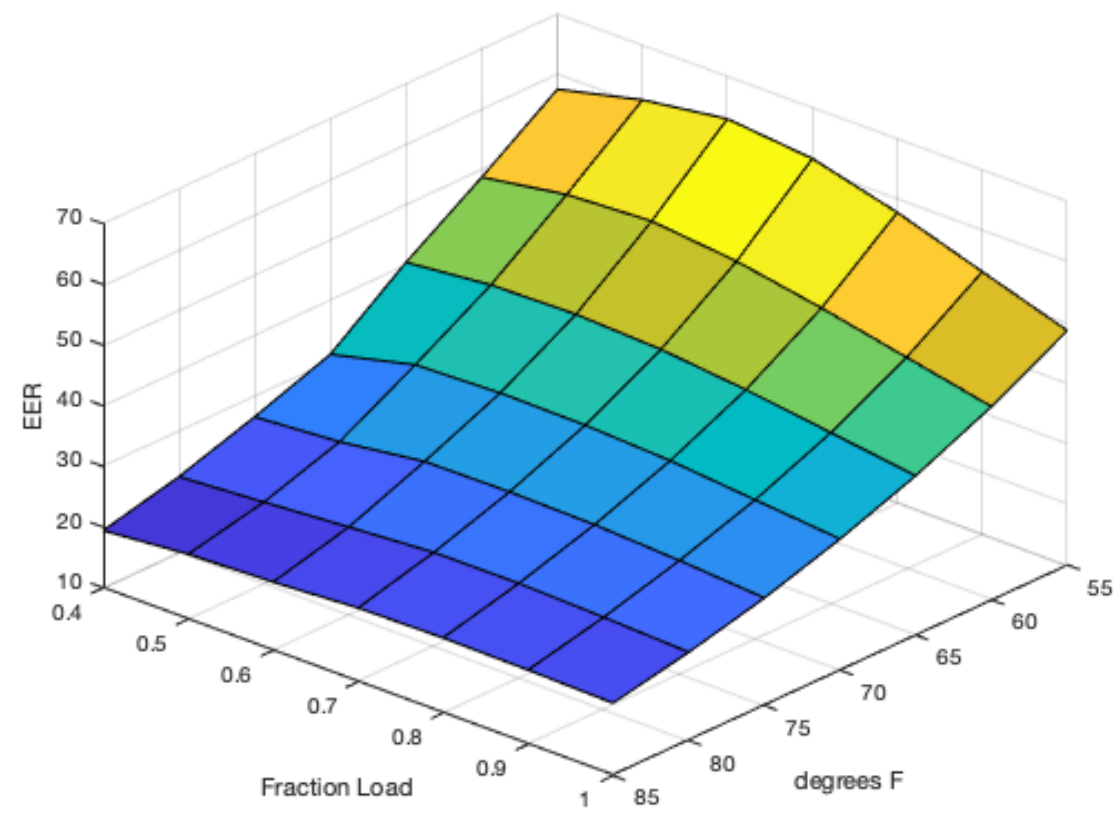

Figure 3: Conventional chiller performance data

Figure 3 above shows the performance of the conventional chiller as EER (BTU/Wh) as a function of condenser water temperature and fraction load. Figure 4 below shows the resulting heating and cooling loads in BTUh for the Honors College complex over the course of one year. The total heating load over the course of the year is 19,490 MMBtu and the total cooling load over the course of the year is 16,440 MMBtu.

In addition to the electric load from conventional cooling, the CHCRC buildings have additional electric load due to ventilation, lighting, and plug load. This will be referred to in this thesis as the "building load" and is assumed to remain the same whether heating or cooling is done with heat pumps or conventional means. The total annual building load is 3,586,209 $\mathrm{kWh}$. 


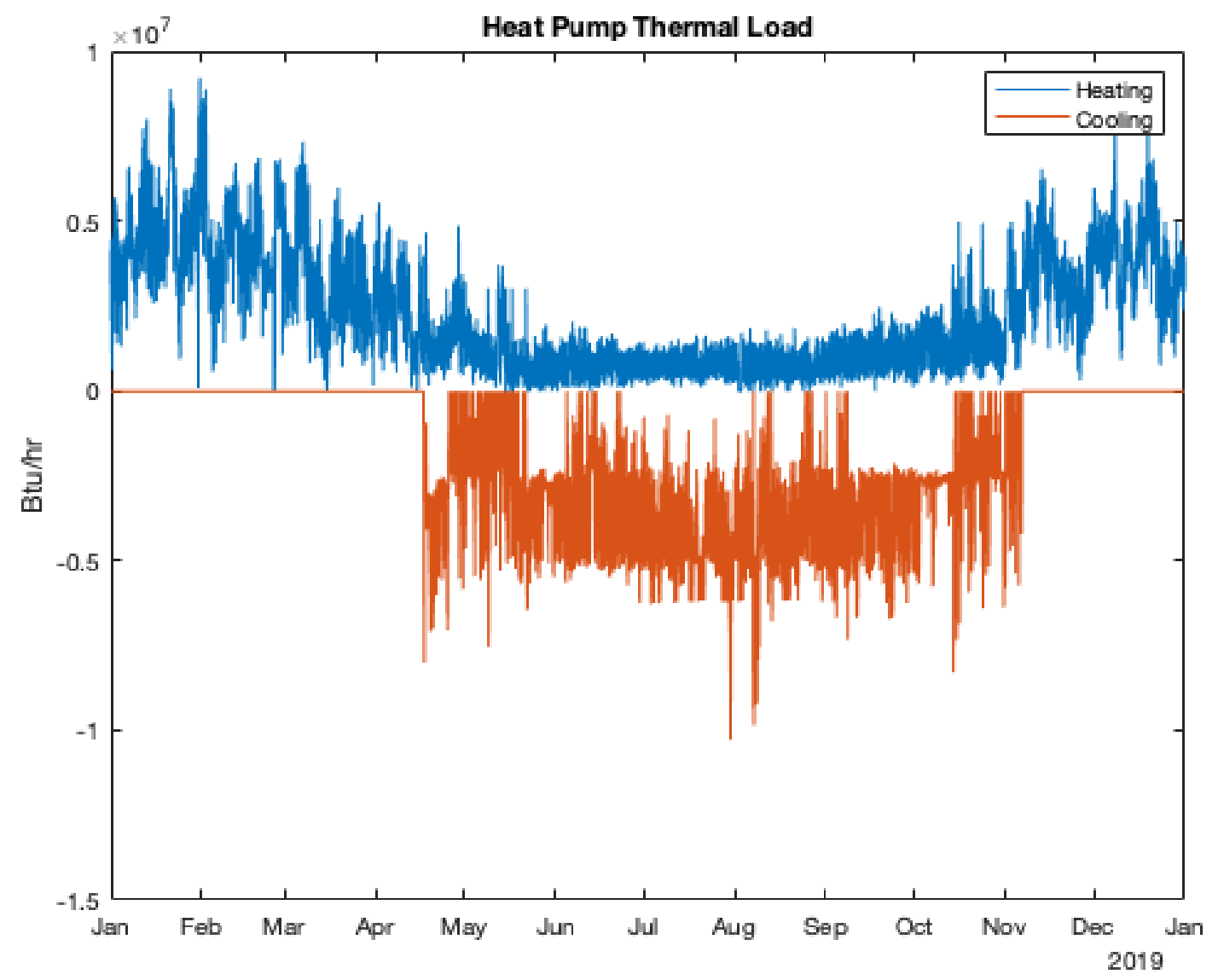

Figure 4: Heating and Cooling loads for the Honors College complex

\subsection{Heat Pump Performance Characteristics}

Heat pumps were simulated to provide the heating and cooling load. This was done using manufacturer provided performance data, linearly interpolated to match the temperature and load conditions of the heat pumps. Figure 5 shows the heating and cooling performance of the chosen Waterfurnace Versatec 180 water-to-water heat pump. Figure 6 shows the heating and cooling performance of an air source heat pump, a Carrier 25VNA060. This data is also listed in a tabular form in Appendices B and C. The heat pump performance is a function of load fraction and borehole fluid temperature in the case of the water-to-water heat pump. In the case of the air source heat pump the 
performance is a function of load fraction and outside air temperature. The recommended heat pumps can run at a variable speed and variable capacity, as this greatly improves the efficiency of a heat pump at part load. The efficiency of the heat pumps increases uniformly up to a maximum efficiency at the minimum part load. The optimal percentage load of the heat pumps is the minimum percentage load that satisfies the current heating and cooling load. Thus, the load fraction is calculated as:

$($ Heating Load + Cooling Load $)=($ Load Fraction $) \times($ Installed Heat Pump Capacity $)$ 

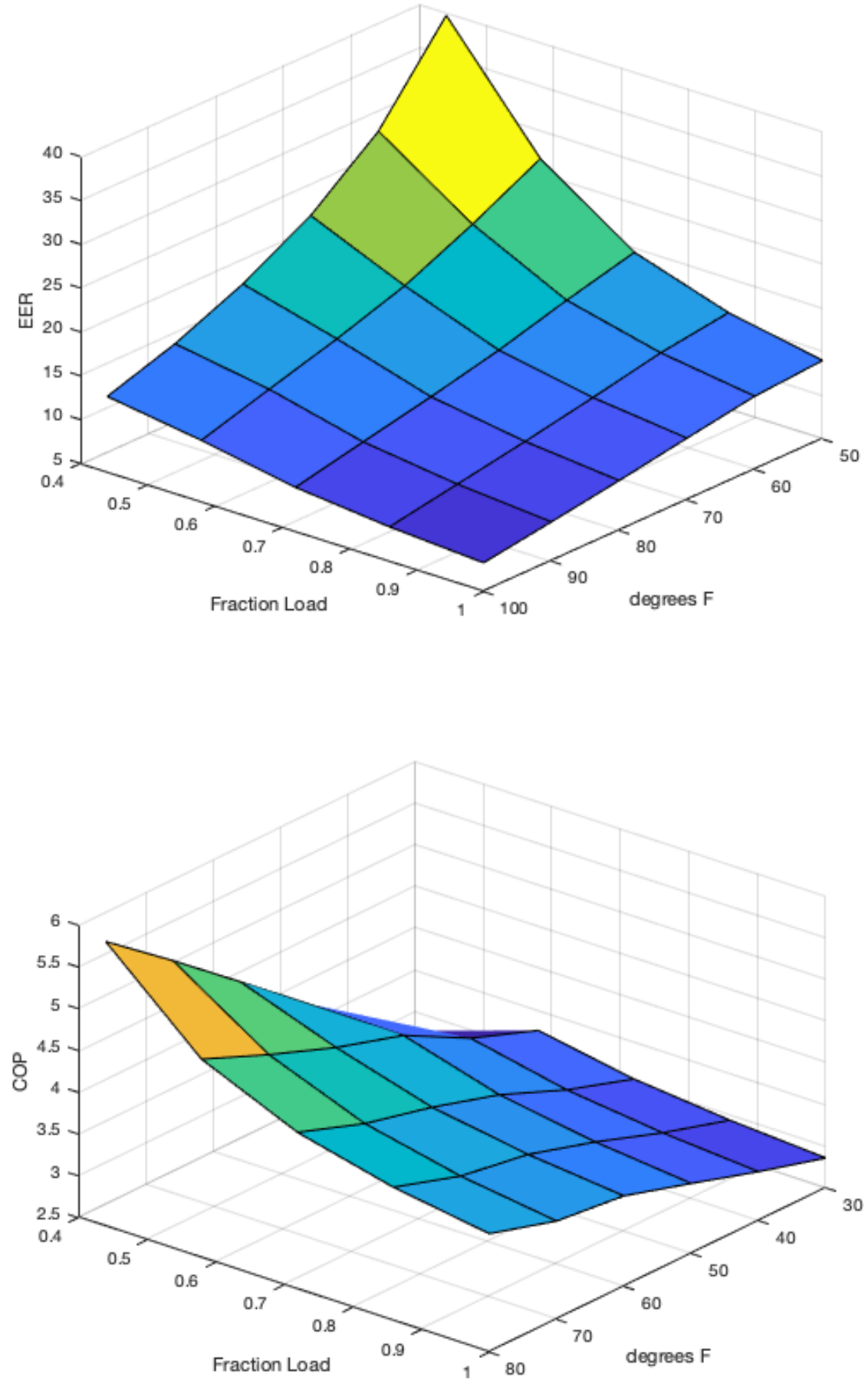

Figure 5: Ground source, water-to-water heat pump cooling (top) and heating (bottom) performance data 

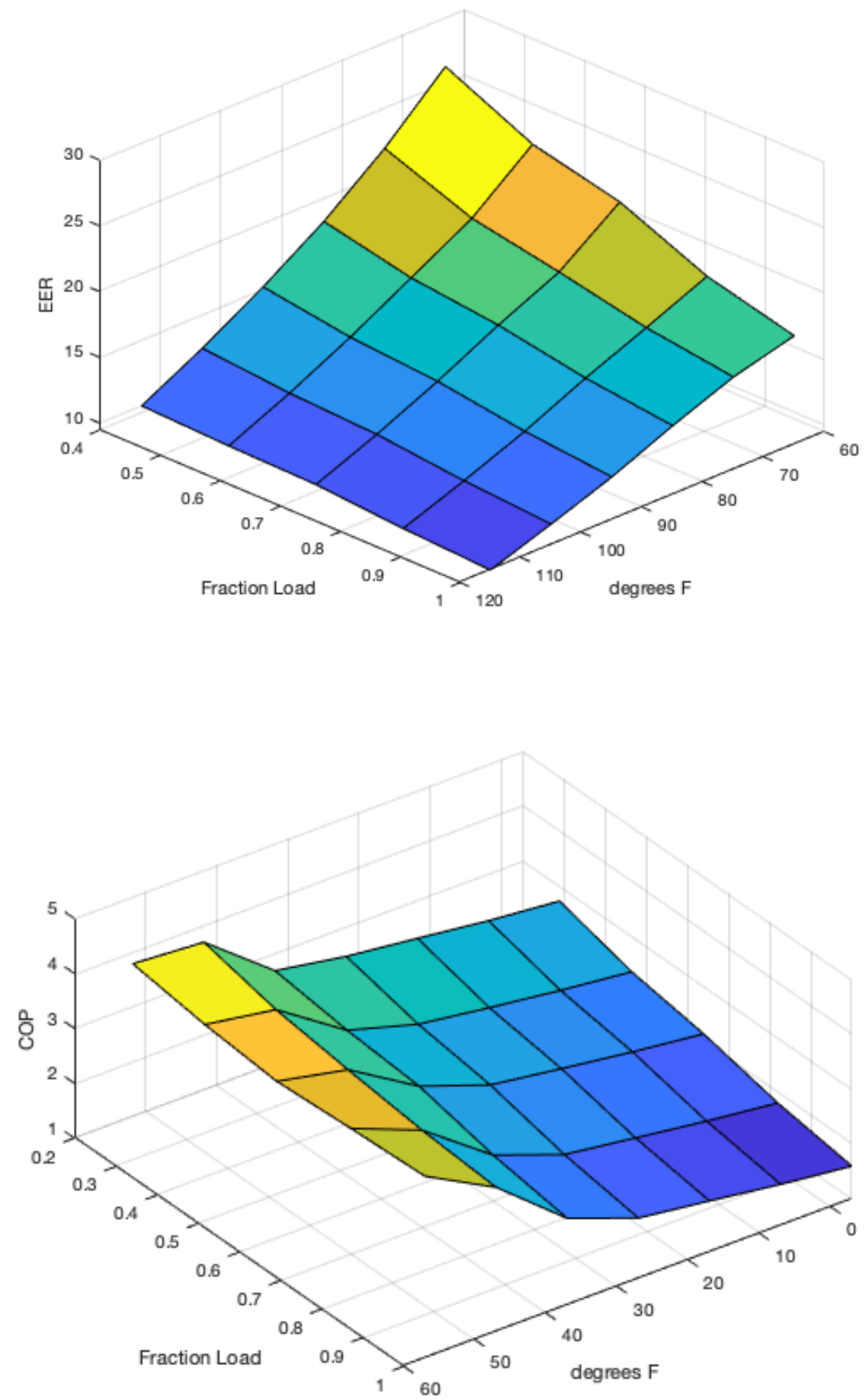

Figure 6: Air source heat pump cooling (top) and heating (bottom) performance data 


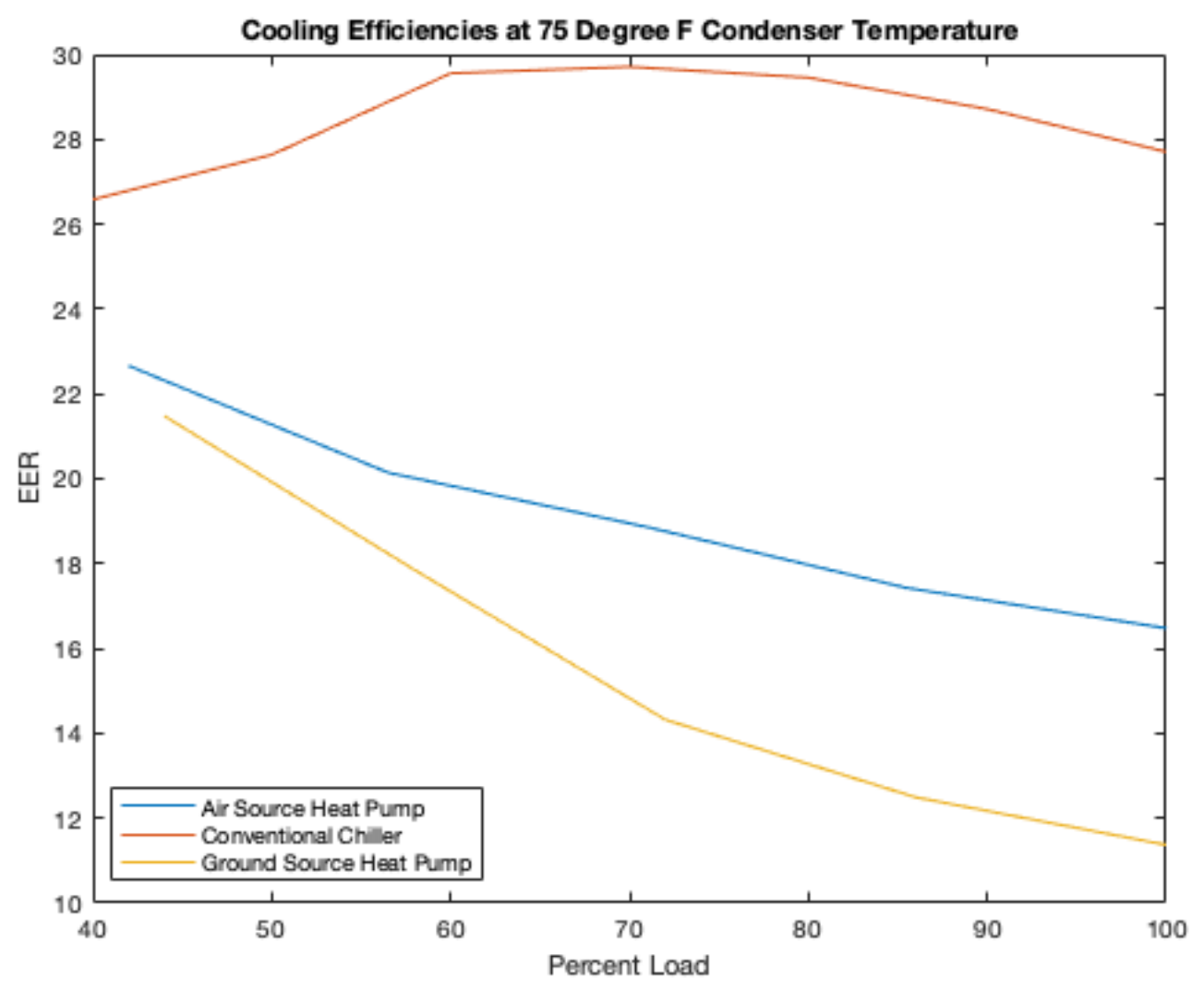

Figure 7: Performance of each cooling systems at $75^{\circ} \mathrm{F}$ condenser temperature

From Figure 7, it can be seen that the efficiency of the particular GSHP model chosen is lower at the same condenser temperature compared to the current chillers. However, the actual condenser temperature when operating in the GSHP case is expected be lower than that of the conventional chillers or ASHPs.

\subsection{Borehole Parameters}

The parameters of the GHEs were set to be within the International Ground Source Heat Pump Association (IGSHPA) Closed-Loop/Geothermal Heat Pump Systems, Design and Installation Standards (IGSHPA Standards Committee 2017, 2017). This requires a pipe material of cross-linked polyethylene (PEX) and a U-tube pipe nominal diameter of $6.033 \mathrm{~cm}$ (2.371 in). Given a dimension ratio of 9 to 1 , thus the minimum 
wall thickness is $6.7 \mathrm{~mm}(0.26 \mathrm{in})$. The minimum pressure rating of the pipe is $160 \mathrm{psi}$ and the classification is PEX 1006 or PEX 1008. The borehole radius used is $12 \mathrm{~cm}(4.7$ in).

A thermal grout with thermal conductivity of $6.2303 \frac{\mathrm{kJ}}{\mathrm{hr} \mathrm{m} \mathrm{K}}\left(1 \frac{\mathrm{BTU}}{\mathrm{hr} \mathrm{ft}^{\circ} \mathrm{F}}\right)$ was used. This is representative of a medium grade thermally enhanced bentonite grout used for modern borehole systems. The ground thermal conductivity and volumetric heat capacity of the soil in the area has been studied as part of the previous thermal energy storage studies (Elhasnaoui, 1991; McDaniel \& Kosanovic, 2016). Thus, the previously found ground thermal conductivity of $4.4 \frac{\mathrm{kJ}}{\mathrm{hrm} \mathrm{K}}\left(0.71 \frac{\mathrm{BTU}}{\mathrm{hr} \mathrm{ft}^{\circ} \mathrm{F}}\right)$ and volumetric heat capacity of $3,960 \frac{\mathrm{kJ}}{\mathrm{m}^{3} \mathrm{~K}}\left(59.05 \frac{\mathrm{BTU}}{\mathrm{ft}^{3}{ }^{\circ} \mathrm{F}}\right)$ are used here.

The fluid used for the geothermal loop of vertical boreholes was a $10 \%$ by weight ethylene glycol to water mixture. The addition of an antifreeze such as ethylene glycol is necessary in cold climates to prevent freezing of the liquid during the heating season. A direct exchange geothermal system using a refrigerant such as R-410a could alternatively be used, however this was not considered in this analysis.

\subsection{TRNSYS Simulation}

In the case of the ground source heat pumps, a TRNSYS project with unit Type557 was used to calculate the ground temperature and the resulting water temperature to and from the ground heat exchangers. This simulates the GHEs through a duct ground heat storage model as described previously in Chapter 2.2. This water was then provided to the water-to-water heat pumps. The performance data for a variable speed water source heat pump was given. In sum, this results in a MATLAB and 
TRNSYS program that was able to simulate the operation of water-to-water heat pumps with vertical boreholes used to provide ground temperature water.

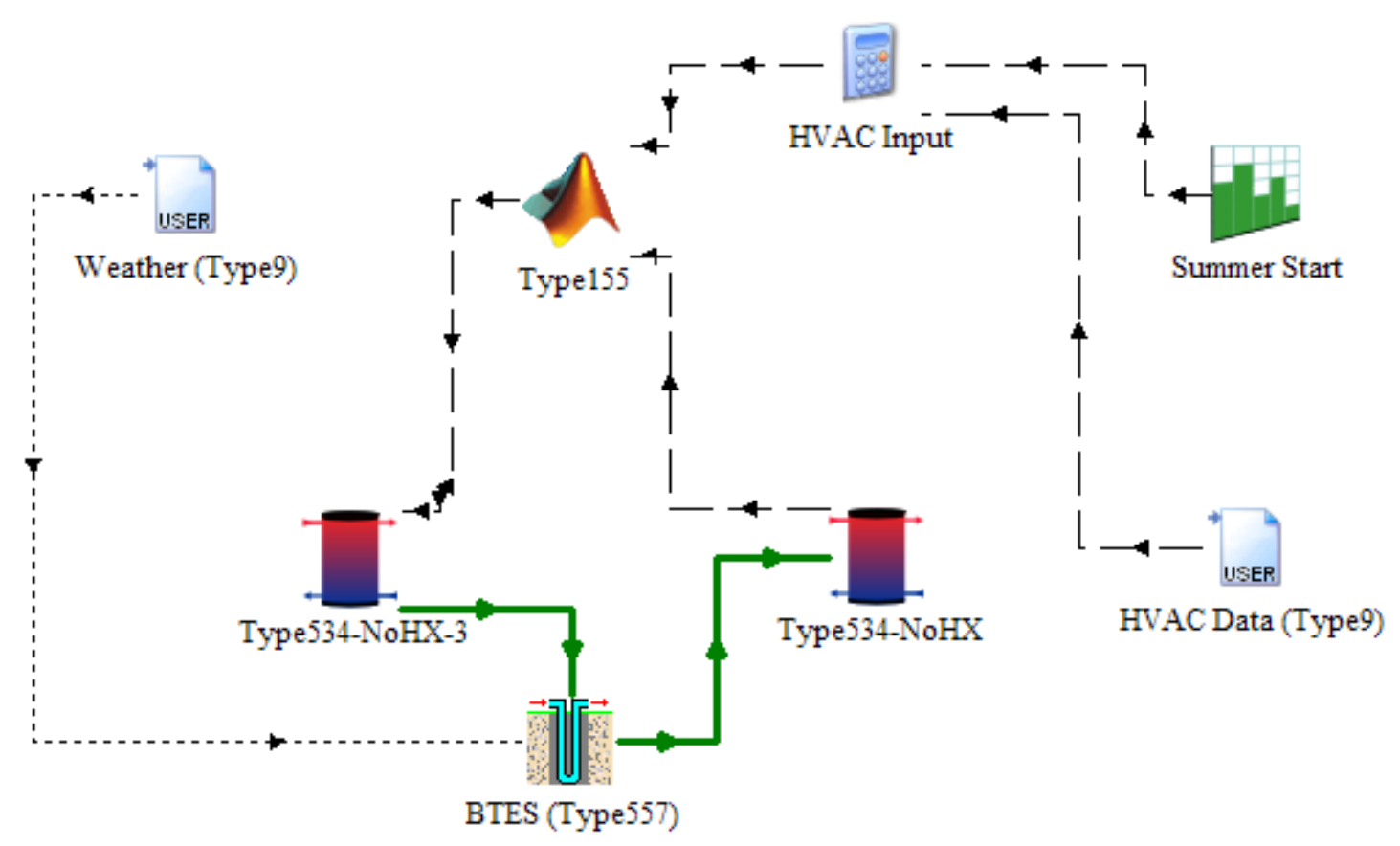

\section{Figure 8: TRNSYS Project Used to Model GSHPs}

In the case where air source heat pumps are considered, the outside air temperature from typical meteorological year (TMY) data for Amherst, MA was used to simulate the outside air temperature provided to the heat pumps. Again, a MATLAB program was used to calculate the performance of the heat pumps at the required load and outside air conditions. The heating and cooling capacities and power consumption of the heat pumps was provided from the manufacturer as a table of capacity and power consumption values at specific outdoor coil entering air temperature and percent load. These values were then linearly interpolated as specified by the manufacturer's data sheets to obtain values at the exact load and temperatures required by the simulation. The 
process of running the GSHP and ASHP simulations is visualized in the flow chart,

Figure 9, below.

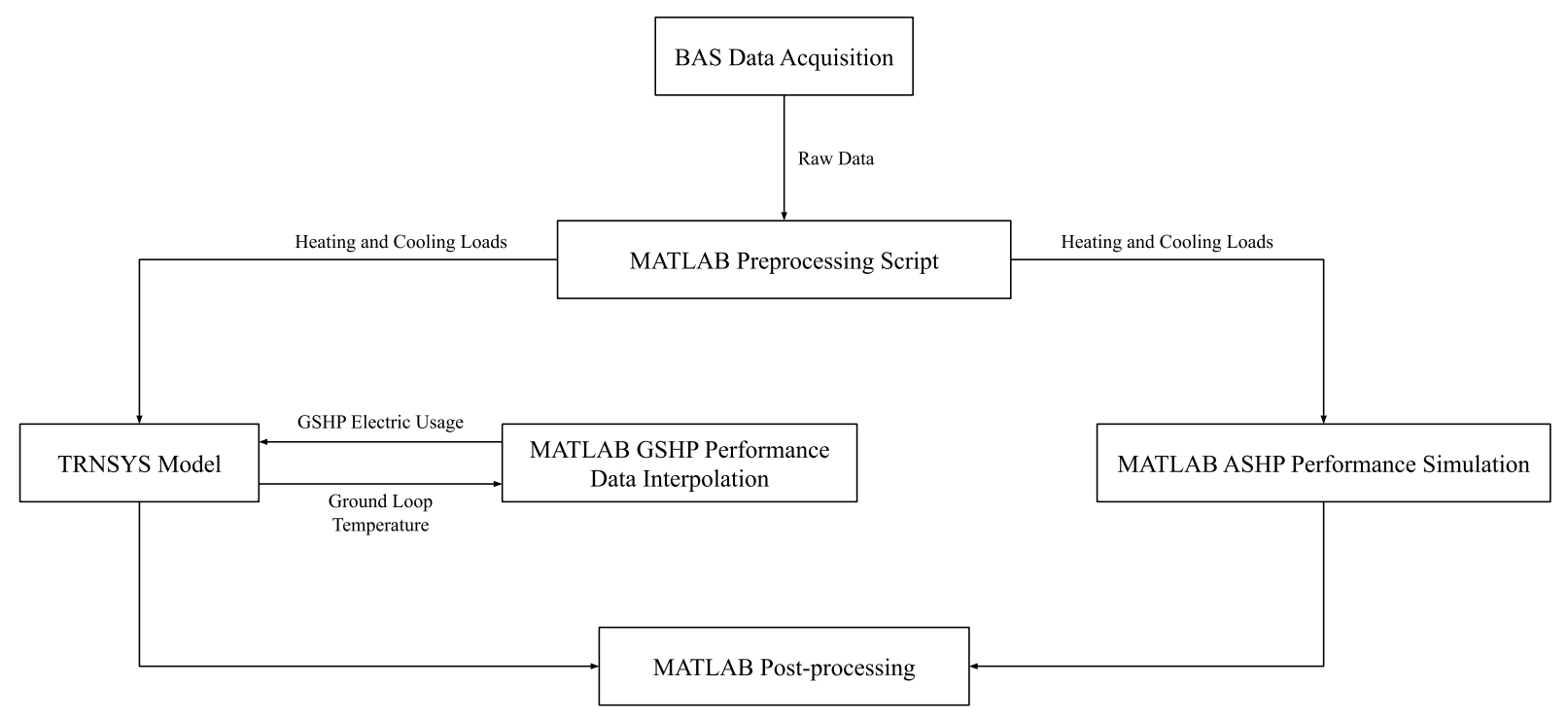

Figure 9: Flow chart showing simulation process for GSHP and ASHP systems 


\section{CHAPTER 4}

\section{RESULTS AND DISCUSSION}

\subsection{Current HVAC System}

The base case of the current HVAC system is used to compare to the heat pumps performance. This current system provides cooling by 2 York YK centrifugal variable speed 400 ton chillers cooled using 2 cooling towers. Heating is provided by steam distribution from a CHP plant burning natural gas, as well as liquefied natural gas and ultra-low sulfur diesel occasionally during winter shortages. The plant simultaneously generates electrical power as well as heating. The CHP plant provides heating and electricity using a combustion gas turbine (CTG), heat recovery steam generator (HRSG), high pressure steam turbine, high pressure boiler, low pressure steam turbine, and 2 low pressure boilers. Generated electricity from the CHP constitutes $66 \%$ of the annual total electricity consumed by the full UMass campus. Thus, generated electricity from the CHP proportionally also constitutes $66 \%$ of the current electric usage of the CHCRC. As a result of the electrical generation from the CTG component of the CHP, heat is produced as a byproduct. Some of this heat is recovered by the HRSG. The heat recovered as a byproduct of the electrical generation for the CHCRC provides a portion of the heating load, however, additional heating is needed, particularly in the winter months. Additional heating beyond the heat recovered from the CTG is provided by additional firing of duct burners on the HRSG as well as production of steam by the high and low pressure boilers. Fuel is required as an input to the CTG to produce electricity and as an input to the HRSG and boilers to provide additional heating. The efficiencies of these components are defined as follows. (Suresh, 2012) 


$$
\begin{aligned}
\eta_{\mathrm{CTG}} & =\frac{E_{\text {electricity,CTG }}}{Q_{\text {fuel,CTG }}} \\
\eta_{\text {heat }} & =\frac{Q_{\text {additional heat }}}{Q_{\text {fuel,heat }}}
\end{aligned}
$$

Where, $\eta_{\text {СтG }}$ is the electrical generation efficiency of the CTG, $E_{\text {electricity,CTG is the }}$ electrical energy produced, $\mathrm{Q}_{\text {fuel,CTG }}$ is the energy content of fuel consumed by the CTG, $\eta_{\text {heat }}$ is the efficiency of the heating components, $Q_{\text {additional heat }}$ is the additional heating needed beyond the heat energy recovered by the HRSG from the CTG, and $\mathrm{Q}_{\text {fuel,heat }}$ is the energy content of the fuel consumed by the additional heating components.

Using production data for the CHP from 2019, these efficiencies were calculated. The annual average efficiencies were $\eta_{\text {СтG }}=29.1 \%$ and $\eta_{\text {heat }}=86.6 \%$. Using these efficiencies, along with the quantities of electricity generated for the CHCRC, heat recovered as a byproduct of that generation, and total heating load of the $\mathrm{CHCRC}$, the fuel required by the CHP components to provide electrical generation and heat to the CHCRC are obtained and are given in Table 2.

\subsection{Proposed Heat Pump System Layout}

In the case of the heat pumps, it is assumed that a distributed, terminal heat pump system will be used, wherein multiple smaller heat pumps are used to provide heating and cooling to specific HVAC zones. This is the type of system used for the existing geothermal system at the UMass Police Station using ground source heat pumps. As a result, to provide the full heating and cooling capacity necessary, a system of 100 heat pumps each with a 10 ton nominal capacity are used to deliver the heating and cooling load to the Commonwealth Honors College Complex. This system size is based on the peak 15-minute cooling load required by the complex. Note that in terms of MMBtu of 
heating or cooling required per day, the maximum system load is determined by the heating load. However, as the current system is designed to provide the peak 15 minute load, this is determined by the maximum peak cooling load.

\subsection{Comparison of GSHP, ASHP and Conventional Cases}

From the simulation of the heat pumps, the electrical energy required to meet the current heating and cooling load is obtained. This is a 15-minute data series following the data for the heating and cooling loads. From this, the total annual electricity consumption can be calculated for a variety of GSHP systems as well as an air source heat pump (ASHP) system and compared to the conventional energy usage.

In the first case, a heat pump system with ground source heat pumps and electricity purchased from the grid at typical prices will be considered. In the second case, a heat pump system with air source heat pumps and electricity purchased from the grid at typical prices will be considered. These two cases will be compared to the conventional system with heating provided by a CHP plant and cooling provided by variable speed chillers cooled by cooling towers. In comparing the different systems, typically one of the most important criteria is the total energy usage and resulting cost of operation. Also, of importance for a new system is the cost of installation. Finally, the total $\mathrm{CO}_{2}$ emissions are an important factor for considering the environmental impacts.

Figures 10 and 11 show the energy usage of the GSHPs as well as the conventional system for heating and cooling. The annual totals for energy usage in each case are given in Table 2. 

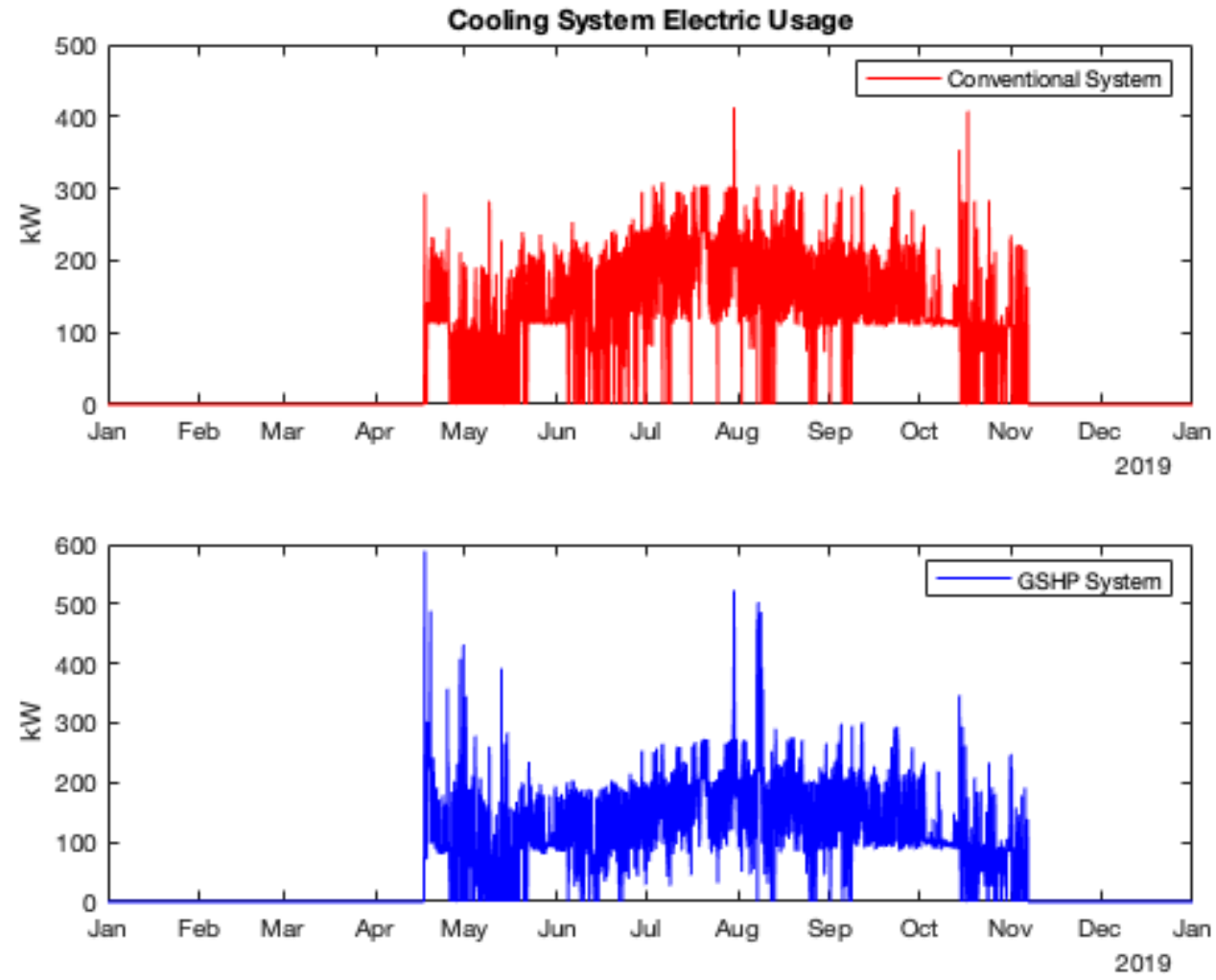

Figure 10: Electrical usage of conventional cooling compared to GSHPs for cooling
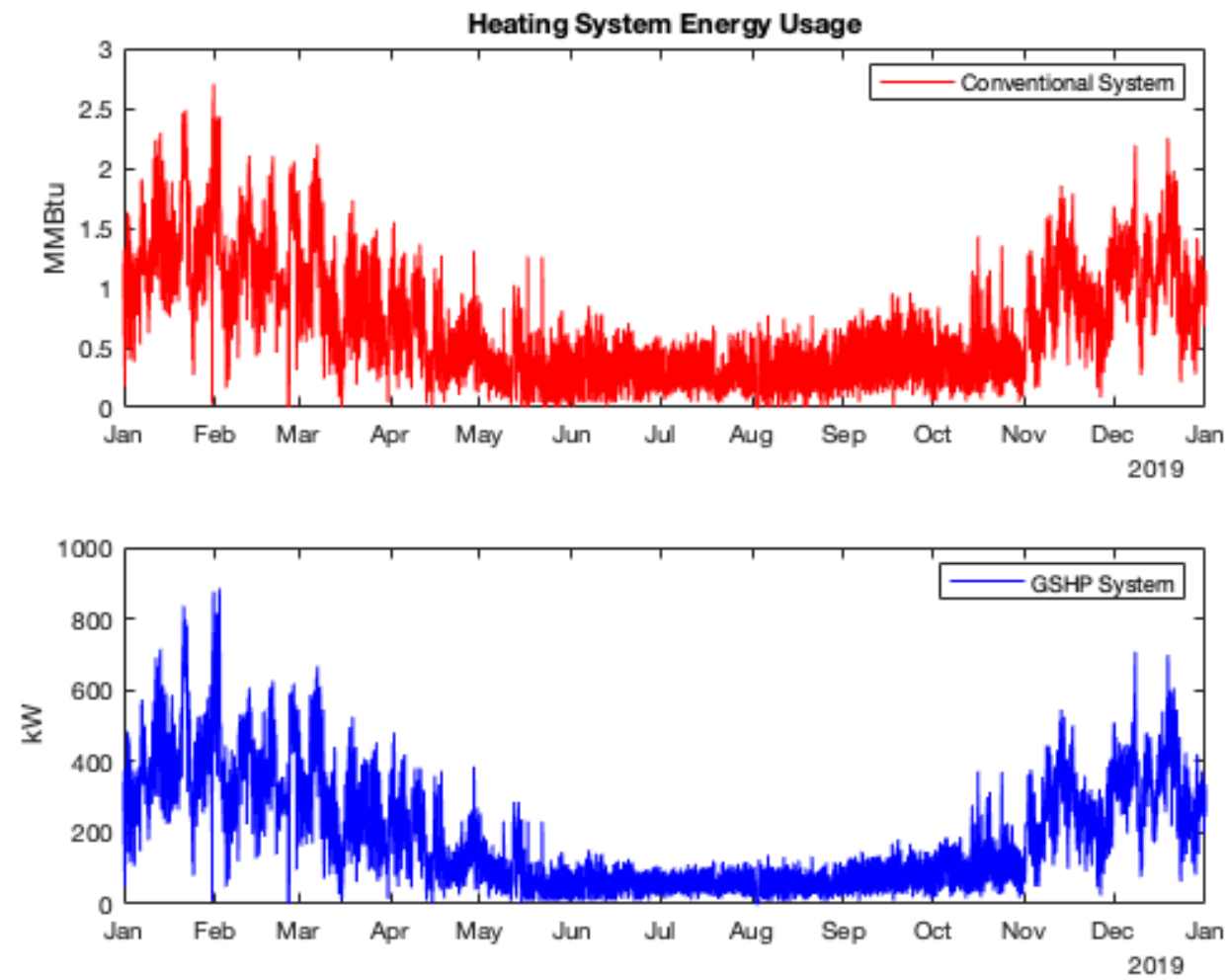

Figure 11: Heating energy input to the conventional system (MMBtu) compared to electrical consumption of GSHPs for heating $(\mathrm{kW})$ 


\begin{tabular}{|c|c|c|c|c|c|c|c|c|c|c|}
\hline \multirow{3}{*}{ Month } & \multirow{3}{*}{$\begin{array}{c}\text { Heating } \\
\text { Load } \\
\text { (MMBtu) }\end{array}$} & \multicolumn{5}{|c|}{ Heating Energy Input (kWh) } & \multirow{3}{*}{$\begin{array}{c}\text { Cooling } \\
\text { Load } \\
\text { (MMBtu) }\end{array}$} & \multicolumn{3}{|c|}{ Cooling Electricity (kWh) } \\
\hline & & \multirow[b]{2}{*}{ GSHP } & \multirow[b]{2}{*}{ ASHP } & \multicolumn{3}{|c|}{ Conventional } & & \multirow[b]{2}{*}{ GSHP } & \multirow[b]{2}{*}{ ASHP } & \multirow[b]{2}{*}{ Conventional } \\
\hline & & & & $\begin{array}{c}\text { Heating } \\
\text { Fuel } \\
\end{array}$ & $\begin{array}{c}\text { Heat } \\
\text { Recovery }\end{array}$ & $\begin{array}{l}\text { Extra } \\
\text { Heat } \\
\end{array}$ & & & & \\
\hline 1 & 3,371 & 295,352 & 355,901 & 786,332 & 312,429 & -504 & 0 & 0 & 0 & 0 \\
\hline 2 & 3,118 & 275,904 & 319,932 & 606,015 & 399,021 & $-6,602$ & 0 & 0 & 0 & 0 \\
\hline 3 & 2,327 & 201,735 & 224,503 & 370,824 & 371,793 & $-11,301$ & 0 & 0 & 0 & 0 \\
\hline 4 & 1,452 & 119,619 & 124,476 & 200,335 & 292,731 & $-43,312$ & $-1,027$ & 51,666 & 70,111 & 39,478 \\
\hline 5 & 676 & 53,596 & 51,282 & 24,384 & 300,492 & $-123,178$ & $-1,931$ & 73,586 & 127,695 & 78,910 \\
\hline 6 & 529 & 41,544 & 43,967 & 574 & 329,053 & $-174,444$ & $-2,453$ & 89,230 & 151,710 & 109,073 \\
\hline 7 & 542 & 42,172 & 46,942 & 1,063 & 358,357 & $-200,346$ & $-3,277$ & 133,114 & 195,719 & 155,486 \\
\hline 8 & 479 & 37,140 & 41,466 & 115 & 357,769 & $-217,369$ & $-2,918$ & 121,779 & 181,759 & 127,622 \\
\hline 9 & 752 & 56,863 & 60,327 & 470 & 414,402 & $-194,316$ & $-2,633$ & 104,677 & 166,700 & 113,217 \\
\hline 10 & 1,048 & 79,142 & 82,965 & 40,847 & 410,232 & $-137,399$ & $-1,930$ & 70,964 & 132,686 & 82,339 \\
\hline 11 & 2,343 & 187,544 & 190,076 & 308,538 & 431,127 & $-16,973$ & -271 & 9,239 & 19,164 & 11,733 \\
\hline 12 & 2,852 & 242,992 & 274,314 & 485,652 & 416,508 & $-2,821$ & 0 & 0 & 0 & 0 \\
\hline Total: & 19,490 & $1,633,603$ & $1,816,153$ & $2,825,148$ & $4,393,913$ & $-1,128,563$ & $-16,440$ & 654,256 & $1,045,544$ & 717,858 \\
\hline
\end{tabular}

Table 2: Monthly energy consumption of the heating and cooling components in the GSHP, ASHP and conventional cases

\begin{tabular}{|c|c|c|c|c|c|c|c|}
\hline \multirow[b]{2}{*}{ Month } & \multirow{2}{*}{$\begin{array}{c}\text { Building } \\
\text { Fixed Electric } \\
\text { Load (kWh) }\end{array}$} & \multirow{2}{*}{$\begin{array}{c}\text { CHP Generated } \\
\text { Electricity } \\
(\mathbf{k W h})\end{array}$} & \multirow{2}{*}{$\begin{array}{l}\text { CHP Fuel Used } \\
\text { for Electric } \\
\text { Generation }(\mathbf{k W h})\end{array}$} & \multicolumn{3}{|c|}{ Total Purchased Electricity (kWh) } & \multirow{2}{*}{$\begin{array}{l}\text { Total Conventional } \\
\text { Case Fuel Usage } \\
\text { (MMBtu) }\end{array}$} \\
\hline & & & & GSHP & ASHP & Conventional & \\
\hline 1 & 288,010 & 181,434 & 672,519 & 583,362 & 643,911 & 106,576 & 4,975 \\
\hline 2 & 367,041 & 236,396 & 863,591 & 642,945 & 686,973 & 130,645 & 4,989 \\
\hline 3 & 335,600 & 217,082 & 801,478 & 537,335 & 560,103 & 118,518 & 3,957 \\
\hline 4 & 342,679 & 187,733 & 647,858 & 513,964 & 537,267 & 194,424 & 2,715 \\
\hline 5 & 237,707 & 193,161 & 665,483 & 364,889 & 416,683 & 123,456 & 1,732 \\
\hline 6 & 217,283 & 231,263 & 748,479 & 348,056 & 412,960 & 95,093 & 1,564 \\
\hline 7 & 247,210 & 257,839 & 821,117 & 422,496 & 489,870 & 144,856 & 1,770 \\
\hline 8 & 241,810 & 256,283 & 818,637 & 400,729 & 465,035 & 113,148 & 1,578 \\
\hline 9 & 332,450 & 295,134 & 946,505 & 493,990 & 559,478 & 150,534 & 2,137 \\
\hline 10 & 333,722 & 254,132 & 898,948 & 483,828 & 549,373 & 161,929 & 2,681 \\
\hline 11 & 328,042 & 260,822 & 938,481 & 524,825 & 537,281 & 78,953 & 4,192 \\
\hline 12 & 314,656 & 257,204 & 911,884 & 557,648 & 588,970 & 57,452 & 4,757 \\
\hline Total: & $3,586,209$ & $2,828,483$ & $9,734,979$ & $5,874,068$ & $6,447,906$ & $1,475,585$ & 37,047 \\
\hline
\end{tabular}

Table 3: Monthly electricity and fuel consumption in the GSHP, ASHP and conventional cases 
The heating system energy input in the conventional case includes two parts: the heat recovered from the CTG as a byproduct of the electricity generated for the CHCRC, and the energy content of the fuel used, measured in $\mathrm{kWh}$, to provide additional heating. At times, there is extra heat resulting from generation that is not used for heating immediately at the CHCRC. This heat is provided to the district heating system and is used to provide heating elsewhere on campus, offsetting heat that would otherwise be provided by the boilers. In the heat pump cases, the energy input is simply the electricity usage of the heat pumps to provide heating.

In addition to the total electricity consumption, another factor in the cost effectiveness of an electrical heating and cooling system is the electrical demand. For a large electricity consumer such as the University of Massachusetts, electricity purchased from the grid is charged based on total usage, monthly demand, and a yearly capacity charge. All three of these charges will be considered in the cost analysis, as these are typical factors for many large electricity consumers in many areas in the United States.

\subsection{GSHP System Installation Cost Optimization}

The financial cost and benefit depend heavily on the price of the components and cost of energy. As a result, these costs were tailored to those typical of Massachusetts and the University in particular. For this analysis, month-by-month electricity and fuel cost forecasts for the University were used, shown in full in Appendix D. The 2020 average volumetric cost of electricity is $\$ 0.0766 / \mathrm{kWh}$. Monthly demand was $\$ 11.53 / \mathrm{kW}$ and yearly capacity charges were $\$ 95.40 / \mathrm{kW}$ per year based on the year's designated ISO-NE peak hour. The costs of fuel for the CHP (primarily pipeline natural gas, with occasional use of liquified natural gas and ultra-low sulfur diesel) resulted in a weighted average of 
$\$ 7.97 / M M B t u$ for 2020 . These costs can then be used to calculate the annual cost of operation for the GSHP system given several borehole system parameters.

In analyzing the viability of such a system, the cost of installing the system is a significant barrier. In estimating the installed cost of the GSHP system, the national averages published by (Battocletti \& Glassley, 2013) for vertical geothermal loops and heat pumps were considered, as well as regional residential system installation costs reported by MassCEC (Massachusetts Clean Energy Center, 2020) and previous studies investigating large installations at other institutions (Integral Group, 2019). These costs are summarized in Table 4 below:

\begin{tabular}{|c|c|c|}
\hline Source: & $\begin{array}{c}\text { Vertical } \\
\text { Borehole Total } \\
\$ / f t\end{array}$ & $\begin{array}{c}\text { Water-to-Water } \\
\text { Heat Pump Total } \\
\$ / \text { ton }\end{array}$ \\
\hline $\begin{array}{c}\text { 2020 MassCEC Residential } \\
\text { and Small-Scale GSHP } \\
\text { Projects }\end{array}$ & $\$ 13.43$ & $\$ 3,643.87$ \\
\hline $\begin{array}{c}\text { 2019 Amherst College } \\
\text { Integral Group Report }\end{array}$ & $\$ 15.94$ & $\$ 3,391.42$ \\
\hline $\begin{array}{c}\text { 2013 GHPSUS National } \\
\text { Survey }\end{array}$ & $\$ 16.03$ & $\$ 3,248.00$ \\
\hline $\begin{array}{c}\text { Average of 2019 and 2020 } \\
\text { Costs: }\end{array}$ & $\$ 14.68$ & $\$ 3,517.65$ \\
\hline
\end{tabular}

Table 4: Heat Pump and Borehole Drilling Costs

This data indicates heat pump costs have risen slightly between 2013 and 2020, while borehole drilling costs seem to have fallen over the same period. The average of the 2020 MassCEC Residential and 2019 Amherst College Integral Group Report costs are used to provide up-to-date, regional cost data. The 2013 GHPsRUS costs are given for reference, but not used as they are based on older, national-level cost data. This results in total installation costs of $\$ 14.68 / \mathrm{ft}$ for the vertical borehole loop and $\$ 3,517.65 /$ ton for the water-to-water heat pumps. Using these costs, the installation and electricity costs of the 
proposed 1,000 nominal ton GSHP system with 550 to 800 boreholes each to a depth of 100 meters $(328 \mathrm{ft}$.$) with a spacing of 5.886 \mathrm{~m}(19.31 \mathrm{ft})$ are given in Figures 12 and 13.

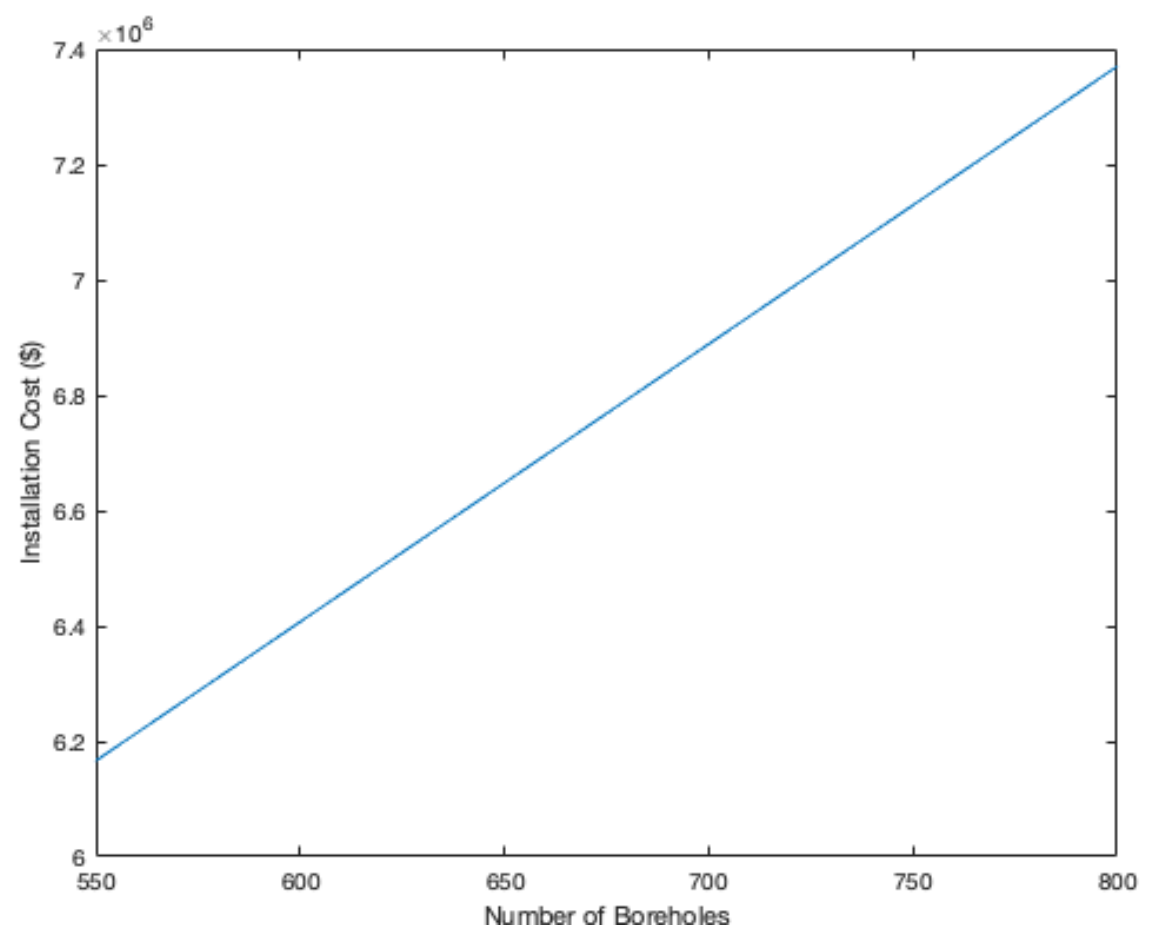

Figure 12: Installed GSHP system cost

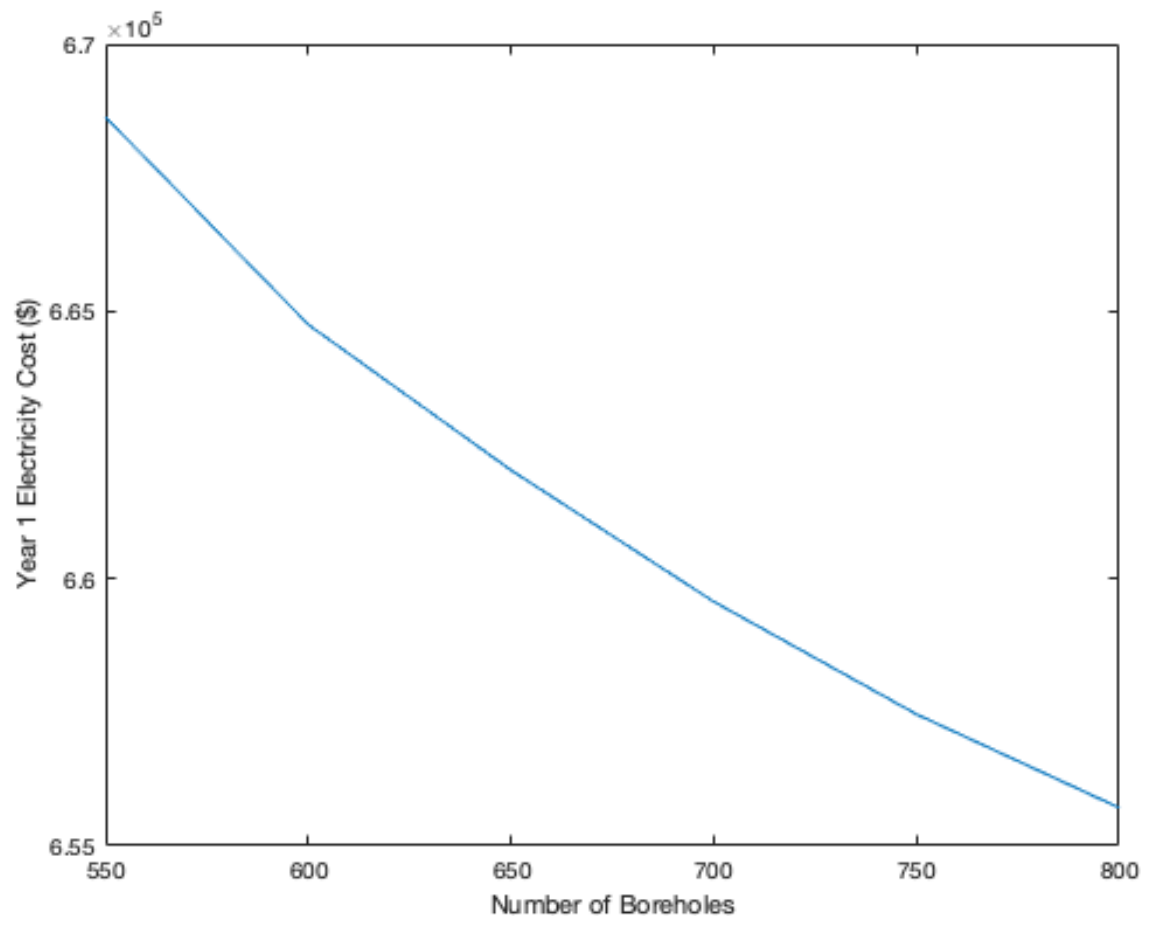

Figure 13: Cost of Electricity for GSHP system 
Thus, the financially most beneficial system can be assessed assuming a lifespan of 40 years for the GSHP system with a replacement of the heat pumps midway through the system's lifetime. From 2020 to 2050, electricity costs from the UMass 30-year energy price forecast (Appendix D) were used. Beyond 2050, a 2.2\% increase in energy costs per year, as projected by the U.S. Energy Information Administration's Annual Energy Outlook, was used. This results in a total lifetime cost as follows:

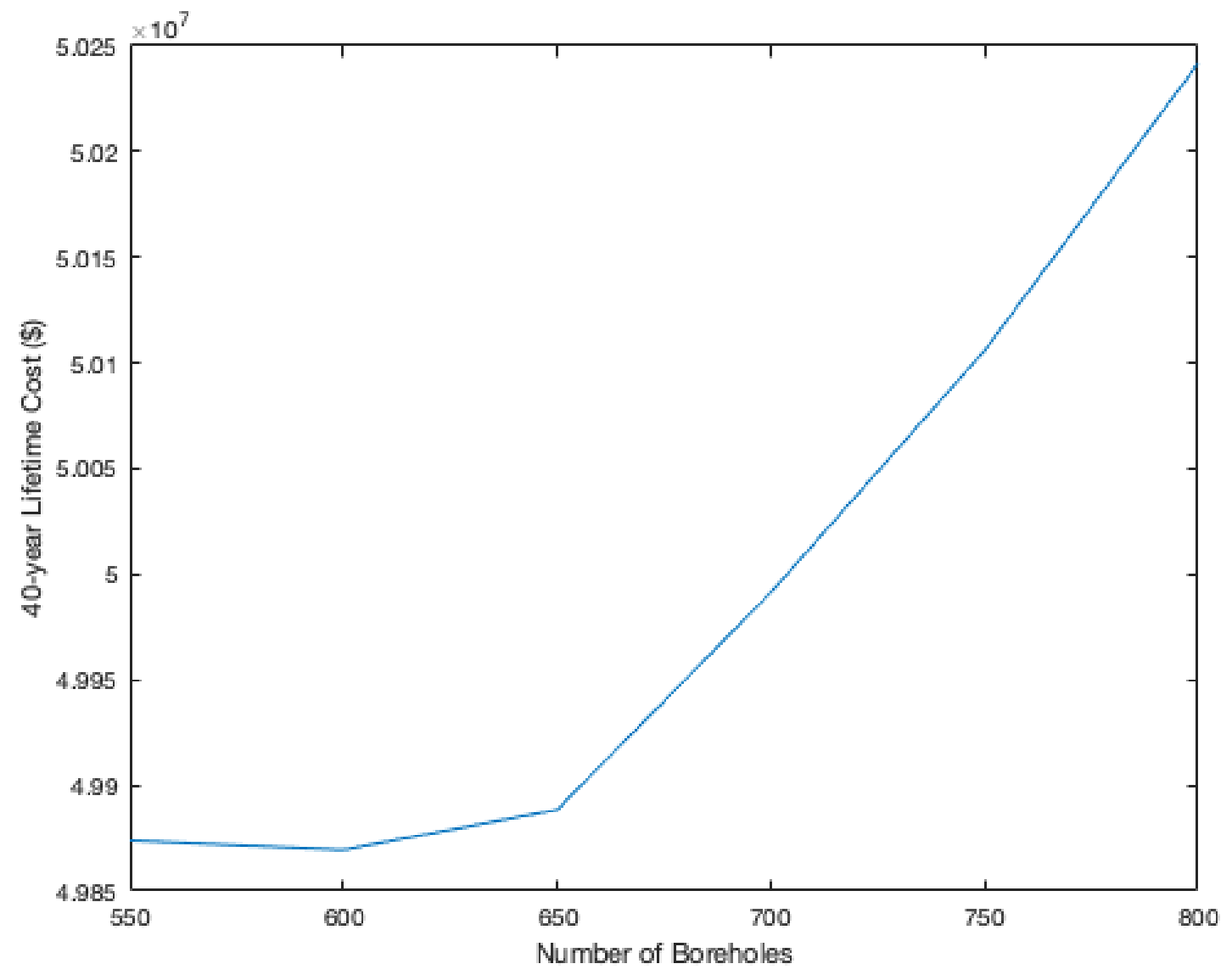

Figure 14: Lifetime cost of GSHP system over 40 year period

This makes the 600 borehole system the most optimal system from this financial perspective. This system has a total installed cost of $\$ 6,407,024$ and an annual electricity 
cost of $\$ 664,744$ to power the system at 2020 electricity prices. Comparison of GSHP annual costs to the ASHP and conventional systems follows in Section 4.10.

\subsection{Ground Source Heat Exchanger System Potential Degradation}

In a ground source heat pump system, the temperature of the ground can change over the course of several years if there is a significantly greater amount of heating required over the course of one year compared to the amount of cooling or vice versa. If this ground temperature change occurs, it will affect the water temperature being delivered to the heat pumps, and in turn this will affect the heating and cooling performance. In the building case studied, the heating load was slightly larger than the cooling load, thus the average ground temperature slightly decreased from one point in one year to the same time in the next year as shown in the figure below.

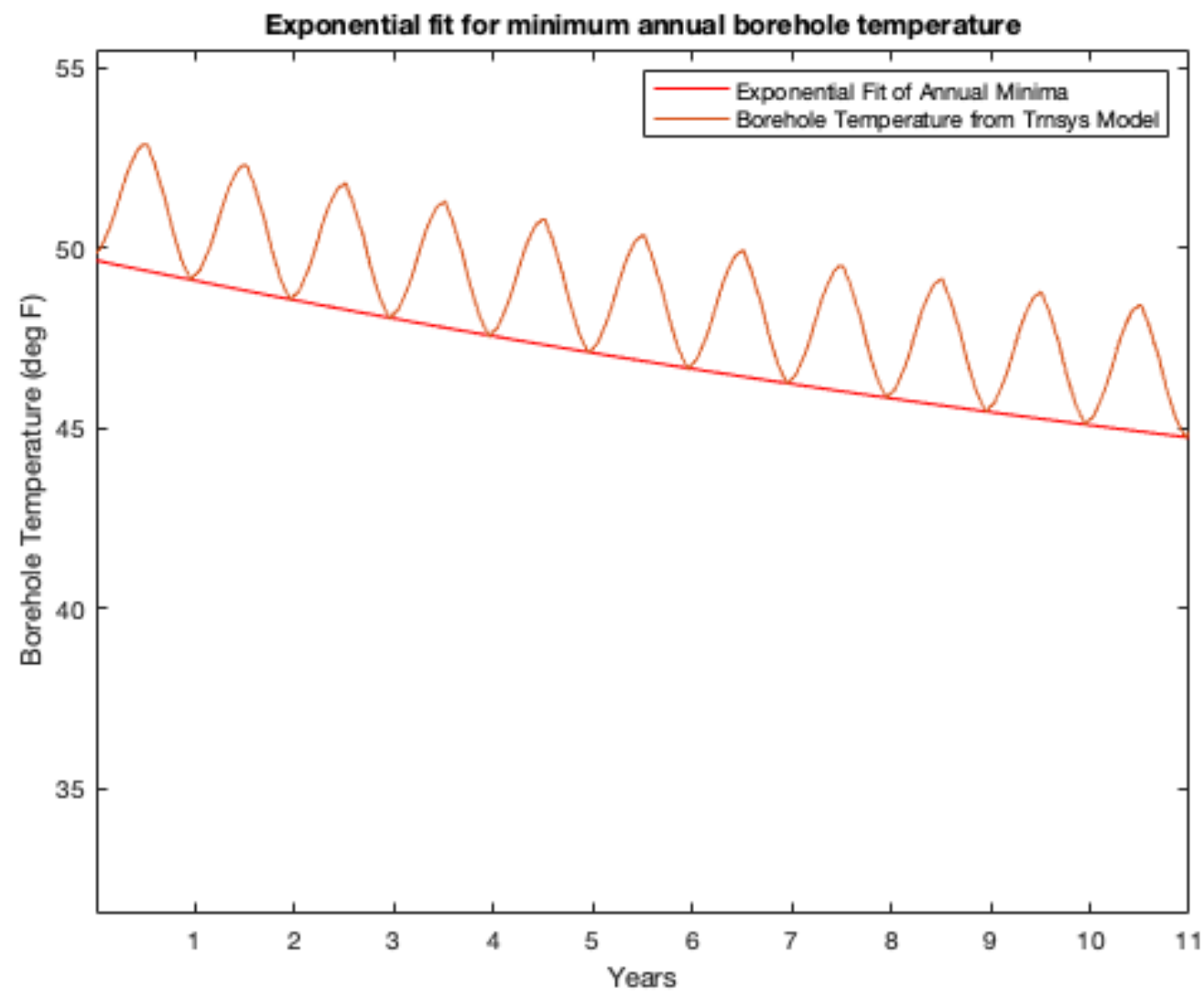

Figure 15: The average ground temperature in the ground storage over time 
Note year to year temperature can be fit to an exponential function. Given an exponential function of the form:

$$
y=\mathrm{A} e^{\mathrm{B} x}+\mathrm{C}
$$

A non-linear least squares curve fit of this function to the borehole temperature data gives coefficients: $\mathrm{A}=11.8, \mathrm{~B}=-0.049, \mathrm{C}=37.9$. This gives an approximation of the annual minimum temperature at steady-state of $37.9^{\circ} \mathrm{F}$.

In the event that a building load is heating dominated, the ground temperature would be lower in the following year as the heat pump extracts more heat from the ground to the building in the heating season than is rejected from the building to the ground in the cooling season. Without mitigation, this would result in lower water temperatures from the ground source heat pumps and thus decreased heating performance from the heat pumps. One technique for mitigating this ground temperature decrease is to install solar thermal collectors to deliver additional heat to the ground storage.

In the case that the building load is cooling dominated, the ground temperature would be higher in the following year as the heat pump would reject more heat to the ground in the cooling season than is extracted during the heating season. In this case, a purely ground source system would result in higher water temperatures over the course of several years, and thus experience decreased cooling performance. One mitigation for this would be a hybrid ground-source and air source system where the condenser water for the heat pumps can be delivered by either the geothermal heat exchangers or an air cooled cooling tower system. This would allow for a balance between the heating and cooling energy extracted and rejected from the ground, allowing for a stable temperature without degraded performance. This would also allow for the use of the lowest 
temperature condenser water from either the air cooled cooling towers or the ground heat exchangers. A second possible mitigation for a cooling dominated system would be to use a desuperheater on the heat pump to recover excess heat during the cooling season. Such a desuperheating system is common on some heat pumps as it allows excess heat to be used to provide hot water heating production.

Following the heating and cooling loads provided by the 2019 BAS data, the Honors College Complex has a slightly greater heating load than cooling load, making it slightly "heating dominated". However, due to external factors such as building occupancy, climate change, and individual behavior the load in the future could vary from the previous year's load. As a result, previous research (Garber et al., 2013) has suggested that a full-size GSHP system with auxiliary backup such as cooling towers for potential additional cooling and solar collectors for potential additional heating has potential for the greatest economic benefit.

\subsection{Thermal Load Profile}

In this simulation, the heat pumps were operated such that they provide the same heating and cooling load, during the same time periods, as is currently used by the UMass Honors College building. This is done to provide an equal comparison to the current operation of the building, however, the current heating production from the CHP does not have any associated demand costs and thus the heating load profile has not been optimized to reduce demand. As a result, peaks in the heating and cooling load profiles will result in significantly increased demand if an electrified heating system such as heat pumps are installed. A mechanism for shifting these thermal load peaks would be needed to minimize electrical demand of the heat pumps. An established method for peak 
shifting is a thermal energy storage system allowing the heating or cooling load profile to be "smoothed out" to reduce excess demand. Thermal storage is one possible technology to help shift peaks, however usage of such a technology would require additional research to optimize the control of the heating and cooling systems with the thermal storage. This will be discussed further in the "Further Work" Section 5.2.

\section{7 $\mathrm{CO}_{2}$ Emissions Factors}

The pollutant emissions from an electrified heat pump system depend on the primary energy source used to generate the electricity used to run them. As a result, for a heat pump using electricity from the grid, the emissions can change as the electricity sources for the grid change. For this analysis, the following average emissions factors for Massachusetts provided by ISO-NE were used to calculate the emissions from the electrical energy used from the grid (ISO New England, 2018).

\begin{tabular}{|l|c|c|c|}
\hline & $\mathrm{CO}_{2}(\mathrm{lb} / \mathrm{kWh})$ & $\mathrm{NO}_{\mathrm{x}}(\mathrm{lb} / \mathrm{kWh})$ & $\mathrm{SO}_{2}(\mathrm{lb} / \mathrm{kWh})$ \\
\hline ISO-NE Electricity & 0.81700 & 0.00048 & 0.00012 \\
\hline
\end{tabular}

Table 5: Average emissions factors for grid purchased electricity in Massachusetts

To compare to the current conventional system, emissions factors for the UMass CHP plant for the 2019 Massachusetts Greenhouse Gas reporting were used. The CHP plant operates a selective catalytic reduction system to reduce $\mathrm{NO}_{\mathrm{x}}$ emissions.

\begin{tabular}{|l|c|c|c|}
\hline & $\mathrm{CO}_{2}(\mathrm{lb} / \mathrm{MMBtu})$ & $\mathrm{NO}_{\mathrm{x}}(\mathrm{lb} / \mathrm{MMBtu})$ & $\mathrm{SO}_{2}(\mathrm{lb} / \mathrm{MMBtu})$ \\
\hline CTG Fuel Input & 111.48 & 0.00943 & 0.00216 \\
\hline
\end{tabular}

Table 6: Emissions factors of the CHP CTG per MMBtu of fuel consumed

\begin{tabular}{|l|c|c|c|}
\hline & $\mathrm{CO}_{2}(\mathrm{lb} / \mathrm{MMBtu})$ & $\mathrm{NO}_{\mathrm{x}}(\mathrm{lb} / \mathrm{MMBtu})$ & $\mathrm{SO}_{2}(\mathrm{lb} / \mathrm{MMBtu})$ \\
\hline Boiler Fuel Input & 120.44 & 0.00681 & 0.00068 \\
\hline
\end{tabular}

Table 7: Emissions factors of the CHP boilers per MMBtu of fuel consumed 
The total emissions from the heat pump system are simply the emissions resulting from the total purchased electricity. The total emissions from the conventional CHP system are the sum of the emissions from the fuel combustion in the conventional boilers for heating, the emissions from the fuel consumption of the CTG for electrical generation and heat, as well as the emission from the purchased electricity. Comparisons of the emissions of the GSHP, ASHP and conventional systems follows in Table 9.

\subsection{Building Additional Electric Load}

In addition to the energy used for heating and cooling, the Commonwealth Honors College buildings also have an additional electric load including lighting, ventilation, and plug load, which would be the same despite any change between GSHP, ASHP or conventional heating and cooling sources. This "building load" is 3,586,209 $\mathrm{kWh}$ annually. In the current conventional system case where the CHP generates electricity, the total combined system and building electricity usage is 4,304,068 $\mathrm{kWh}$. Of this usage, 2,828,483 $\mathrm{kWh}$ are generated by the CHP and 1,475,585 $\mathrm{kWh}$ are purchased from the grid. In a case where all heating and cooling on campus has been electrified, there would be no CHP generating power. Thus, without any additional installed power generation capability, the campus would need to purchase all of this electricity from the grid. Using the electricity usage prices previously defined, this results in an annual additional cost of $\$ 214,690$ due to the increased usage of electricity purchased from the grid. This increased usage will also affect demand costs, which will be discussed in Section 4.9. The building additional load and generated electricity throughout 2019 are shown in Figure 16 below. Refer to Table 3 above for annual total generation and load. 


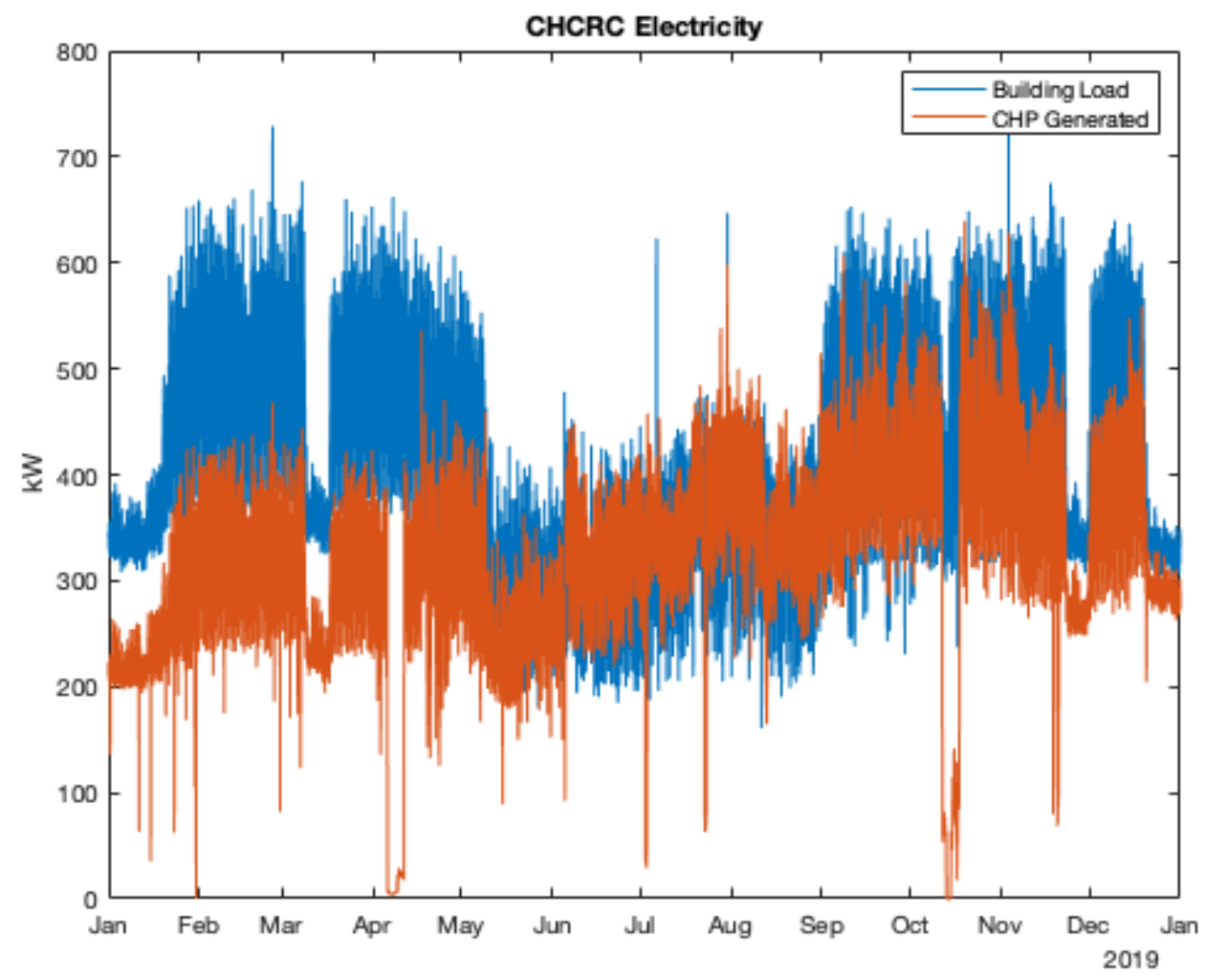

Figure 16: CHCRC building electric load and electric power generated by CHP

\subsection{Building Demand}

As previously stated, for this research it is assumed the GSHP system uses

electricity for heating and cooling and eliminates the electricity generated by the CHP. As a result, all the electricity for the Honors College complex is shifted to the grid. In addition, the electric requirements of the heat pumps also increase the electrical load. The change in electrical power purchased from the grid can be seen in Figure 17 below: 


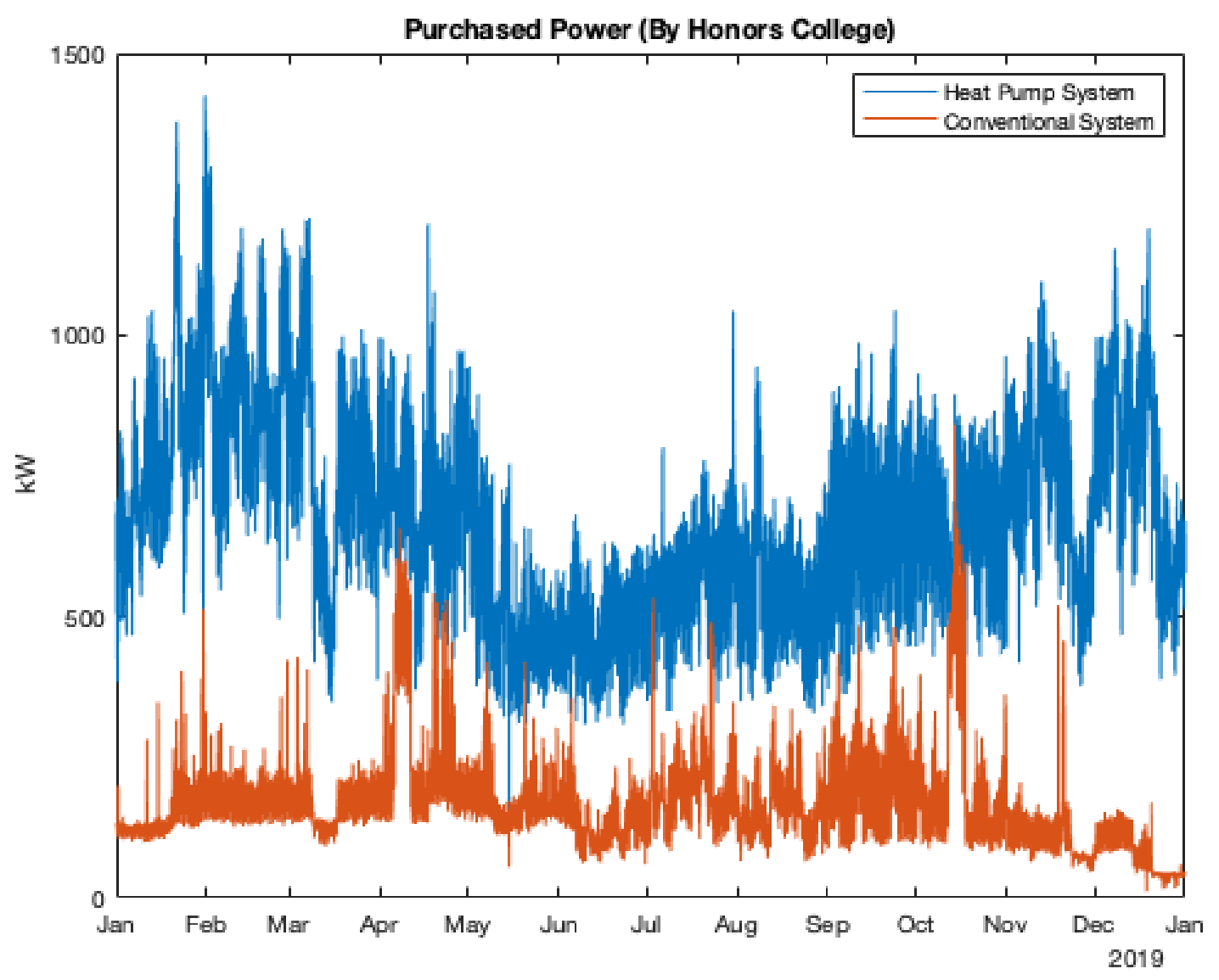

Figure 17: Electrical power purchased from the grid by the CHCRC buildings

There is a significant increase overall due to the lack of power generation previously provided by the CHP. There is also a seasonal shift in the overall yearly peak from the summer to the winter due to the use of heat pumps to provide heating.

In the case of UMass, monthly demand charges are based on the electricity usage during a peak hour each month, defined by the utility. For 2019, these peak hours are:

\begin{tabular}{|c|c|c|c|c|c|c|c|c|c|c|c|c|}
\hline Month: & 1 & 2 & 3 & 4 & 5 & 6 & 7 & 8 & 9 & 10 & 11 & 12 \\
\hline Day: & 21 & 1 & 6 & 1 & 20 & 28 & 21 & 19 & 11 & 2 & 13 & 19 \\
\hline Hour: & 18 & 19 & 19 & 20 & 18 & 18 & 18 & 16 & 18 & 15 & 18 & 19 \\
\hline
\end{tabular}

Table 8: Monthly demand peak hours for 2019 
Thus, the monthly demand at the grid peak hours is shown in Figure 18 and included in tabular form in Appendix E.
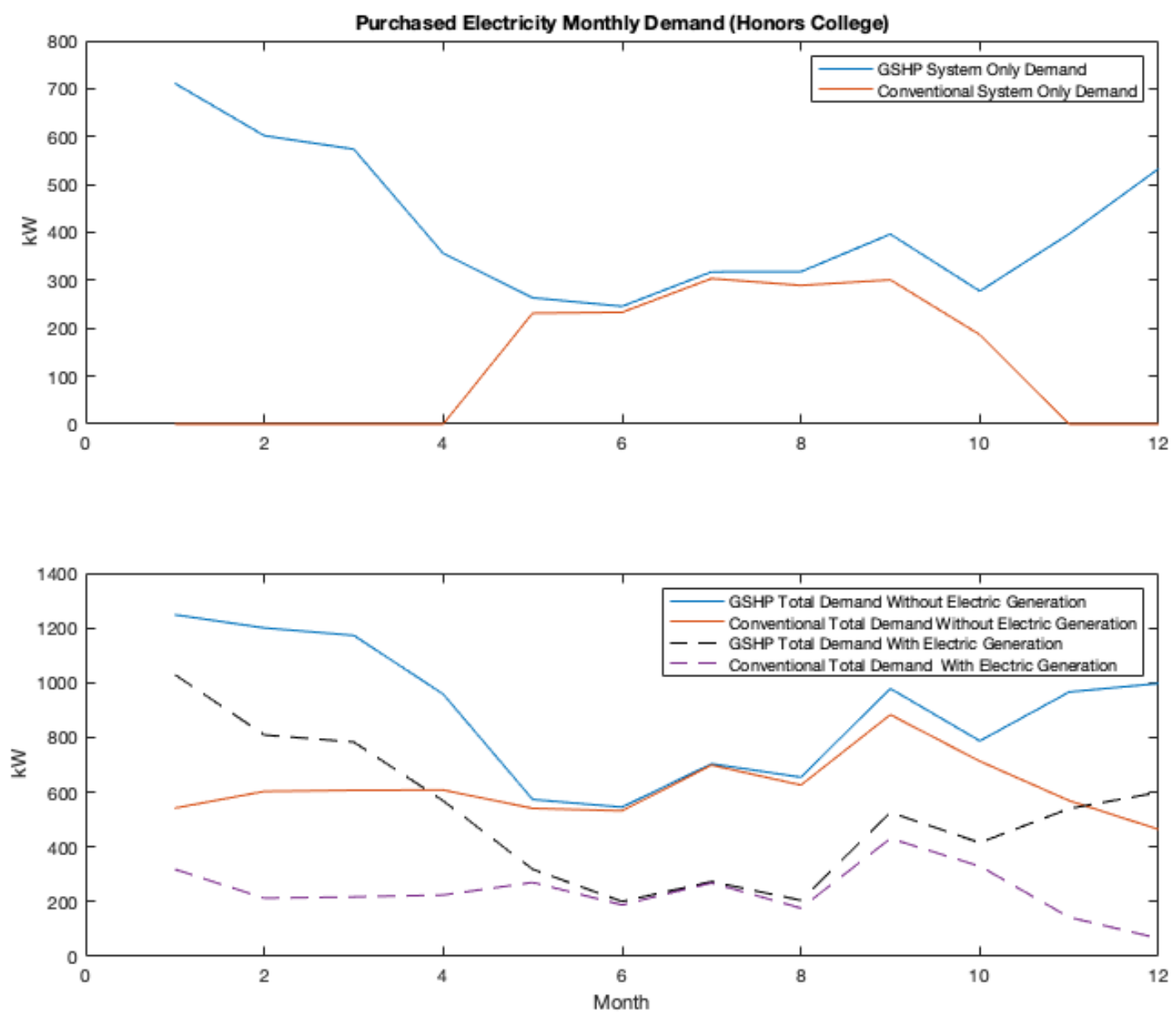

Figure 18: Monthly Demand of the Honors College complex

The portion of the demand due to the heating and cooling systems only is shown above, as well as the total demand when including the building electric demand, with and without generated electricity in each case below. In both cases, the inclusion of generated electricity results in lower demand throughout the year. It can be seen in all cases that the GSHP system significantly increases demand during the winter months due to usage of the electric heat pumps for heating. Comparing the conventional case with generation to the GSHP case without generation, demand in the GSHP case is increased in the summer 
due to the lack of electric generation. Moreover, demand increases by an even greater amount during the winter due to the compounding effects of both a lack of generation and usage of the heat pumps for heating. Overall, the GSHP case results in a greater reliance on the grid in general, as well as a significantly higher peak load during the winter. The overall maximum peak shifts from $431 \mathrm{~kW}$ in September in the conventional case to $1,248 \mathrm{~kW}$ in January in the GSHP case.

Additionally, a yearly capacity charge is accessed based on the electricity usage during the annual peak hour of the regional grid. In 2019, this peak hour was July $30^{\text {th }}$, 5:00PM to 6:00PM. Thus, the capacity charge in the GSHP system case is $846 \mathrm{~kW}$ and in the conventional case is $213 \mathrm{~kW}$.

At a monthly demand cost of $\$ 11.53 / \mathrm{kW}$ and a capacity charge of $\$ 95.40 / \mathrm{kW} / \mathrm{year}$, this overall increase in demand adds an additional total of $\$ 151,904$ to the annual cost of the GSHP system over the current conventional system.

\subsection{Overall Cost and Emissions Comparison}

Utility costs in the heat pump cases result from: electricity usage of the heat pump system, additional electricity usage of the CHCRC building, and additional demand costs from the grid purchased electricity. This compares to the conventional case, in which heat and electricity are generated by the CHP and cooling is provided by electric chillers, where utility costs result from: the fuel usage cost and electricity usage cost of the cooling system, the additional usage cost of the building electric load, and additional demand costs. As noted in the previous sections, building electricity and demand costs are greater in the heat pump cases compared to the conventional case due to generation of 
electricity by the CHP. The utility costs over a period of 10 years for each case are given in Table 9 and emissions results are summarized in Table 10.

\begin{tabular}{|c|c|c|c|c|c|c|c|c|c|c|c|c|}
\hline \multirow{2}{*}{ Year } & \multicolumn{3}{|c|}{$\begin{array}{c}\text { System Energy Use Cost } \\
(\$)\end{array}$} & \multicolumn{3}{|c|}{$\begin{array}{c}\text { Additional Demand Cost } \\
(\$)\end{array}$} & \multicolumn{3}{|c|}{$\begin{array}{l}\text { Additional Building } \\
\text { Electricity Cost }(\$)\end{array}$} & \multicolumn{3}{|c|}{ Total Cost (\$) } \\
\hline & GSHP & ASHP & Conventional & GSHP & ASHP & Conventional & GSHP & ASHP & Conventional & GSHP & ASHP & Conventional \\
\hline 2020 & 182,199 & 225,100 & 323,221 & 205,094 & 232,238 & 53,190 & 277,451 & 277,451 & 62,761 & 664,744 & 734,789 & 439,171 \\
\hline 2021 & 194,158 & 239,123 & 328,271 & 196,061 & 221,915 & 51,098 & 294,804 & 294,804 & 64,974 & 685,023 & 755,842 & 444,343 \\
\hline 2022 & 205,803 & 251,283 & 306,067 & 187,686 & 210,735 & 48,793 & 309,428 & 309,428 & 68,157 & 702,916 & 771,446 & 423,017 \\
\hline 2023 & 213,999 & 259,565 & 314,108 & 166,263 & 185,169 & 43,396 & 319,657 & 319,657 & 70,293 & 699,919 & 764,391 & 427,797 \\
\hline 2024 & 217,286 & 261,803 & 323,808 & 201,767 & 226,600 & 52,416 & 321,958 & 321,958 & 71,100 & 741,011 & 810,361 & 447,324 \\
\hline 2025 & 220,712 & 264,679 & 336,850 & 219,949 & 247,309 & 56,983 & 324,634 & 324,634 & 72,408 & 765,294 & 836,621 & 466,242 \\
\hline 2026 & 221,592 & 265,598 & 340,296 & 237,009 & 267,172 & 61,349 & 325,839 & 325,839 & 72,642 & 784,440 & 858,609 & 474,288 \\
\hline 2027 & 218,944 & 262,431 & 340,211 & 267,761 & 303,208 & 69,200 & 321,971 & 321,971 & 71,763 & 808,675 & 887,610 & 481,174 \\
\hline 2028 & 221,383 & 265,408 & 343,704 & 273,276 & 309,399 & 70,630 & 325,733 & 325,733 & 72,545 & 820,393 & 900,539 & 486,879 \\
\hline 2029 & 216,230 & 259,179 & 344,426 & 279,027 & 315,848 & 72,121 & 317,977 & 317,977 & 70,884 & 813,234 & 893,004 & 487,431 \\
\hline
\end{tabular}

Table 9: Summary of Annual Utility Costs

\begin{tabular}{|c|c|c|c|c|c|c|}
\hline System Case & $\begin{array}{c}\text { Heating } \\
\text { System CO } \\
\text { (tons) }\end{array}$ & $\begin{array}{c}\text { Cooling } \\
\text { System CO } \\
\text { (tons) }\end{array}$ & $\begin{array}{c}\text { Additional } \\
\text { Building } \\
\text { Electricity } \\
\mathbf{C O}_{2} \text { (tons) }\end{array}$ & $\begin{array}{c}\text { Total } \\
\text { System + } \\
\text { Building } \\
\mathbf{C O}_{2} \text { (tons) }\end{array}$ & $\begin{array}{c}\text { Total } \\
\text { System + } \\
\text { Building } \\
\text { NO }_{\mathbf{x}} \text { (lbs) }\end{array}$ & $\begin{array}{c}\text { Total } \\
\text { System + } \\
\text { Building } \\
\mathbf{S O}_{2} \text { (lbs) }\end{array}$ \\
\hline GSHP & 667 & 267 & 1,465 & 2,400 & 2,820 & 705 \\
\hline ASHP & 742 & 427 & 1,465 & 2,634 & 3,095 & 774 \\
\hline Conventional & 1,626 & 293 & 847 & 2,767 & 1,048 & 251 \\
\hline
\end{tabular}

Table 10: Summary of GSHP, ASHP and conventional case emissions

The cost comparison of the conventional system to the heat pump systems depends on the relative cost of natural gas compared to electricity. An increase in electrical or demand costs relative to the cost of natural gas would make the current CHP system more financially viable, whereas an increase in natural gas costs relative to electricity costs would further increase the cost savings of the heat pump systems. Using the electricity and natural gas price forecasts from Appendix D, changes in total annual 
costs from 2020, and cost increases between the heat pump and conventional cases are summarized in Table 11 below.

\begin{tabular}{|c|c|c|c|c|c|}
\hline \multirow{2}{*}{ Year } & \multicolumn{2}{|c|}{ Total Cost Increase from 2020 (\%) } & \multicolumn{2}{c|}{$\begin{array}{c}\text { Cost Increase Over } \\
\text { Conventional (\%) }\end{array}$} \\
\cline { 2 - 6 } & GSHP & ASHP & Conventional & GSHP & ASHP \\
\hline $\mathbf{2 0 2 0}$ & $0 \%$ & $0 \%$ & $0 \%$ & $51 \%$ & $67 \%$ \\
\hline $\mathbf{2 0 2 1}$ & $3 \%$ & $3 \%$ & $1 \%$ & $54 \%$ & $70 \%$ \\
\hline $\mathbf{2 0 2 2}$ & $6 \%$ & $5 \%$ & $-4 \%$ & $66 \%$ & $82 \%$ \\
\hline $\mathbf{2 0 2 3}$ & $5 \%$ & $4 \%$ & $-3 \%$ & $64 \%$ & $79 \%$ \\
\hline $\mathbf{2 0 2 4}$ & $11 \%$ & $10 \%$ & $2 \%$ & $66 \%$ & $81 \%$ \\
\hline $\mathbf{2 0 2 5}$ & $15 \%$ & $14 \%$ & $6 \%$ & $64 \%$ & $79 \%$ \\
\hline $\mathbf{2 0 2 6}$ & $18 \%$ & $17 \%$ & $8 \%$ & $65 \%$ & $81 \%$ \\
\hline $\mathbf{2 0 2 7}$ & $22 \%$ & $21 \%$ & $10 \%$ & $68 \%$ & $84 \%$ \\
\hline $\mathbf{2 0 2 8}$ & $23 \%$ & $23 \%$ & $11 \%$ & $69 \%$ & $85 \%$ \\
\hline $\mathbf{2 0 2 9}$ & $22 \%$ & $22 \%$ & $11 \%$ & $67 \%$ & $83 \%$ \\
\hline
\end{tabular}

Table 11: Annual cost increases between heat pump and conventional cases over 10 years

\subsection{Steam Distribution Losses}

The conventional fuel usages in Tables 2 and 3 and the resulting conventional system costs and emissions in Tables 9 and 10 are calculated based on the thermal energy needed to satisfy the CHCRC buildings' heating load as measured by the hot water heating system as stated in Section 3.2. Implicitly, in the conventional case this assumes that there are no thermal energy losses between steam production by the CHP and the CHCRC hot water system. The UMass campus uses a steam district heating system, where steam produced by the CHP is distributed at 20 psig or 200 psig to the campus through steam pipes. Distribution losses in the system vary based on distribution temperature and pressure, length and cross-sectional area of steam pipes used for distribution, and thermal conductivity between the steam pipes and the surroundings. At 
the CHCRC, steam is used to provide heat to the hot water loop using a heat exchanger, which may incur additional thermal energy losses.

Steam is metered at various points in the district heating network. Annual production data records the measured steam output of the HRSG and boilers in the CHP. The total steam output in 2019 was 1,062,955,027 lbs of steam with 1,316,613 MMBtu of energy. Steam usage of each building on campus is measured using an orifice plate steam meter recording data to the campus Metasys BAS. While accurate data for steam usage is available for some buildings on campus, the measured steam usage of the CHCRC could not be accurately confirmed using the available data. If a distribution efficiency of $67 \%$ and a steam to hot water heat exchanger efficiency of $94 \%$ are used, this would increase total fuel usage by $13,359 \mathrm{MMBtu}$ and costs by $\$ 103,226$ in the conventional case. Such distribution losses would not be present in the heat pump cases as the heat pumps provide the heating or cooling needed directly to the hot or cold water loops at the buildings where it's required. 


\section{CHAPTER 5}

\section{CONCLUSIONS}

\subsection{Summary}

As opposed to a small energy consumer, who is billed mainly based on usage, large consumers such as the University of Massachusetts have a more complicated rate structure with significant costs associated with demand. This makes the analysis of replacing a conventional heating system with an electrified heat pump system much more complex. The addition of a CHP plant generating electricity and heat simultaneously further adds complexity. In this thesis, the established technique of ground heat exchanger simulation with the duct storage model provided in Type557 by TRNSYS, is combined with real world heating and cooling load data and manufacturer provided heat pump performance specifications to find the resulting electrical energy required by a GSHP or ASHP system for the University of Massachusetts Commonwealth Honors College complex. Application of the electrical rate structure including electricity usage costs, monthly demand and annual capacity charges gives the resulting cost of each of the GSHP, ASHP and current conventional systems. These results, given in Table 9, show the clear energy usage cost benefit to a GSHP system or an ASHP system over the conventional system using a CHP plant for heating and a set of tower cooled chillers. For the usage costs of natural gas and purchased electricity defined, in year 1 corresponding to 2020, it was found that for heating and cooling alone, the GSHP system saved $\$ 141,022$ over the conventional system. However, due to the additional cost of demand and the unrestricted thermal load profile of the heat pumps without thermal energy storage, the system savings are reduced by $\$ 151,904$ when considering electrical demand 
of the GSHP over the current system. Additionally, the combined nature of the heat and electricity production by the CHP plant means the cost of heating and cooling is not the only relevant expense. The cost of electricity to replace the electricity that would have been generated by the CHP also becomes a factor, further adding $\$ 214,690$ to the cost of the GSHP over the conventional system. This combines to a total cost deficit of $\$ 225,572$. This cost difference, however, is relatively small compared to the installation cost of the system of $\$ 6,407,024$. An ASHP system was also found to not result in savings over the conventional system, as net annual costs increased by $\$ 295,617$.

The $\mathrm{CO}_{2}$ emissions of the GSHP system are found to be 367 short tons (333 metric tons) lower than that of the conventional system, with potentially greater emissions savings as more renewable energy production is added to the grid. $\mathrm{NO}_{\mathrm{x}}$ emissions increased by $1,772 \mathrm{lbs}(804 \mathrm{~kg})$ when comparing the GSHP to the conventional system, while $\mathrm{SO}_{2}$ emissions also rose slightly by $453 \mathrm{lbs}(206 \mathrm{~kg})$. This increase in $\mathrm{NO}_{\mathrm{x}}$ and $\mathrm{SO}_{2}$ emissions is due to use of more sulfur containing fossil fuels such as coal and oil in power generation by the electrical grid and use of a selective catalytic reduction system in the CHP plant, which significantly reduces current $\mathrm{NO}_{\mathrm{x}}$ emissions and is required due to its proximity to the campus. Purchased electricity increased significantly, a total annual increase of 4,398,483 $\mathrm{kWh}$ resulting in 5,874,068 $\mathrm{kWh}$ purchased per year from the current 1,475,585 kWh per year. The Massachusetts State Senate bill S.2477 currently before the legislature proposes a "Market-based compliance mechanism" (i.e. "carbontax"). While this bill has not yet passed and does not specify an exact cost, it is estimated by others (Integral Group, 2019) that a $\$ 40 /$ ton tax could be applied to all emissions, with a carbon offset sale cost of $\$ 18 /$ ton. In such a scenario, the potential savings of the GSHP 
system over the conventional system would increase by $\$ 14,696$ annually through the avoidance of additional carbon taxes.

In summary, using established techniques for simulation, it is found that either an ASHP system or a GSHP system would result in a net utility cost increase when compared to the current conventional system without changes to the current energy costs. Though a GSHP system would result in pure heating and cooling energy savings over the conventional system due to the higher efficiency of ground source heat pumps, the cost of increased demand and purchased electricity outweigh these savings. This highlights a need for energy storage and on-site generation to mitigate these issues. However, there is a significant reduction in $\mathrm{CO}_{2}$ emissions from a heat pump system utilizing electricity purchased from the grid over the current CHP system. The heat pump system would also see further emissions reductions if more carbon-neutral electricity generation sources were used. As a result, it could be beneficial to install a GSHP system when the current CHP system reaches its end of life and requires a replacement and if a large financial cost to ongoing $\mathrm{CO}_{2}$ emissions, such as a carbon tax, were introduced.

\subsection{Future Work}

As noted in Section 4.6, the thermal load profile of the heat pump system remains the same for the conventional and heat pump systems in this analysis. This is a factor in the increased electrical demand costs. Such a system could use thermal energy storage to shift the demand peaks, however, the operation and control of such a system has not been modeled and would require further work to optimize the heating and cooling load profiles for greatest financial benefit. 
Thermal energy losses due to steam distribution, as noted in Section 4.11, are a factor in the current district heating system that would be avoided in cases where heat pumps provide heating directly to each building. Fully accounting for these losses requires accurate metering of steam energy from the CHP plant and of steam energy delivered to each building. Distribution losses in the current system could be mitigated through additional insulation of steam pipes or identification of any leaks or poorly performing components. Additionally, lower temperature distribution strategies such as hot water district heating would lower distribution losses and also allow incorporation of GSHPs or solar thermal heating directly into the district heating system. In such a system, a centralized GSHP system could be used to supply a portion of the total heating load required to the entire campus rather than a single building complex.

This study compares the current conventional system to a system that fully replaces the conventional system with a GSHP system and purchases electricity from the grid to replace the lost generation capacity. While such a system is typical of previous installations, this is only one of multiple strategies for integration of heat pumps into an existing HVAC system. Other implementations of a GSHP system could use on site electrical generation to reduce the cost of electricity and potentially increase the financial viability of such a system. Electrical generation done through renewable technologies such as photovoltaics (PV) or wind would also have the benefit of reducing the overall $\mathrm{CO}_{2}$ emissions compared to grid purchased electricity generated from fossil fuel sources. Another method for heat pump integration could be a hybrid approach where both the conventional system and a GSHP system are utilized to provide heating and cooling. A method of marginally adding heat pumps to the existing system could be one of 
significant interest, as a smaller, marginal system would have a smaller installation cost and therefore may be easier to afford and implement. Such a system would allow use of heat pumps for heating during high heating and low electric demand periods, such as on cold winter nights, and use of the heat pumps for cooling as well to improve cooling efficiency during the summer. This could allow the current CHP plant to maximize the amount of useful work extracted from its fuel. This would require analysis of both the current CHP system, as well as a GSHP system, at a component level as load on the individual boilers and steam turbines would be affected, changing the fuel consumption and efficiency of the plant. 


\section{APPENDIX A}

\section{CONVENTIONAL CHILLER PERFORMANCE DATA (kW/Ton)}

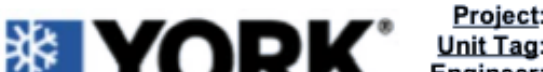 \\ Engineer: \\ Customer:}

Rating Program: LTC v1 195.idd Software Version: YW $20 . \overline{0} 3$

Date: 08/19/20 14:20:20

\begin{tabular}{|c|c|c|c|c|c|c|c|c|c|c|}
\hline \multicolumn{11}{|c|}{ Partload Data (Minimum Condenser Water Temperature) } \\
\hline \multirow{2}{*}{ CEFT $\left({ }^{\circ} \mathrm{F}\right)$} & \multicolumn{10}{|c|}{$\%$ LOAD } \\
\hline & $100 \%$ & $90 \%$ & $80 \%$ & $70 \%$ & $60 \%$ & $50 \%$ & $40 \%$ & $30 \%$ & $20 \%$ & $15 \%$ \\
\hline $85.00^{\circ}$ & 0.5463 & 0.5390 & 0.5358 & 0.5411 & 0.5642 & 0.5795 & 0.6173 & 0.6847 & 0.8128 & 0.9289 \\
\hline $80.00^{\circ}$ & 0.4887 & 0.4770 & 0.4689 & 0.4701 & 0.4890 & 0.5109 & 0.5329 & 0.5904 & 0.7028 & 0.8041 \\
\hline $75.00^{\circ}$ & 0.4331 & 0.4179 & 0.4074 & 0.4039 & 0.4060 & 0.4342 & 0.4514 & 0.4987 & 0.5943 & 0.6838 \\
\hline $70.00^{\circ}$ & 0.3793 & 0.3646 & 0.3506 & 0.3438 & 0.3422 & 0.3474 & 0.3858 & 0.4144 & 0.4951 & 0.5712 \\
\hline $65.00^{\circ}$ & 0.3308 & 0.3142 & 0.2991 & 0.2884 & 0.2842 & 0.2863 & 0.2965 & 0.3498 & 0.4043 & 0.4682 \\
\hline $60.00^{\circ}$ & 0.2866 & 0.2677 & 0.2511 & 0.2384 & 0.2317 & 0.2352 & 0.2464 & 0.2734 & 0.3372 & 0.3798 \\
\hline $55.00^{\circ}$ & 0.2469 & 0.2258 & 0.2078 & 0.1952 & 0.1909 & 0.1973 & 0.2090 & 0.2338 & 0.2899 & 0.3500 \\
\hline $54.00^{\circ}$ & 0.2398 & 0.2182 & 0.1996 & 0.1883 & 0.1869 & 0.1912 & 0.2037 & 0.2270 & 0.2845 & 0.3402 \\
\hline $53.00^{\circ}$ & 0.2333 & 0.2107 & 0.1915 & 0.1832 & 0.1817 & 0.1872 & 0.2006 & 0.2228 & 0.2765 & 0.3342 \\
\hline $52.00^{\circ}$ & - & - & 0.1835 & 0.1785 & 0.1787 & 0.1835 & 0.1955 & 0.2192 & 0.2720 & 0.3276 \\
\hline $51.00^{\circ}$ & - & - & - & - & - & 0.1800 & 0.1927 & 0.2150 & 0.2669 & 0.3216 \\
\hline $50.00^{\circ}$ & - & - & - & - & - & - & - & - & 0.2621 & 0.3139 \\
\hline \multicolumn{11}{|c|}{ "Values are in $\mathrm{kW} / \mathrm{T}$ on. $R$} \\
\hline & \multicolumn{10}{|c|}{ Rated point is $60 \%$ or higher efficiency compared to design operation point. } \\
\hline & \multicolumn{10}{|c|}{ Rated point is $70 \%$ or higher efficiency compared to design operation point. } \\
\hline & - & & +0 & $n$ & - & n ope & ion point. & & & \\
\hline
\end{tabular}

Certified in accordance with the AHRI Water-Cooled Water Chilling and Heat Pump WaterHeating Packages Using Vapor Compression Cycle Certification Program, which is based on AHRI Standard 550/590 (I-P) and AHRI Standard 551/591 (SI). Certified units may be found in the AHRI Directory at www.ahridirectory.org.

Compliant with ASHRAE 90.1 - 2004.

Compliant with ASHRAE 90.1 - 2007.

Compliant with ASHRAE 90.1 - 2010.

Compliant with ASHRAE 90.1 - 2013.

Compliant with ASHRAE 90.1 - 2016.

Materials and construction per mechanical specifications - Form 160.75-EG1.

Auxiliary components included in total $\mathrm{KW}$ - oil pump \& heater, chiller controls. IECC 2012 and IECC 2015/2018 Compliant 
GROUND SOURCE HEAT PUMP PERFORMANCE DATA

VERSATEC VARIABLE SPEED SERIES SPECIFICATION CATALOG

\section{0 - Min Load - Performance Data}

\section{Low Speed (2460 CFM)}

\begin{tabular}{|c|c|c|c|c|c|c|c|c|c|c|c|c|c|c|}
\hline \multirow{2}{*}{$\begin{array}{c}\text { EWT } \\
\text { of }\end{array}$} & \multirow{2}{*}{$\begin{array}{l}\text { Flow } \\
\text { gpm }\end{array}$} & \multicolumn{2}{|c|}{ WPD } & \multicolumn{5}{|c|}{ HEATING - EAT 70 OF } & \multicolumn{6}{|c|}{ COOLING - EAT $80 / 67$ oF } \\
\hline & & PSI & FT & $\begin{array}{c}\mathrm{HC} \\
\text { Mbtu/h }\end{array}$ & $\begin{array}{l}\text { Power } \\
\text { (kW) }\end{array}$ & $\begin{array}{c}\mathrm{HE} \\
\mathrm{Mbtu} / \mathrm{h}\end{array}$ & LAT & COP & $\begin{array}{c}\text { TC } \\
\text { Mbtu/h }\end{array}$ & $\begin{array}{c}\text { SC } \\
\text { Mbtu/h }\end{array}$ & $S / T$ & $\begin{array}{c}\text { POWER } \\
\text { (kW) }\end{array}$ & $\begin{array}{c}\text { HR } \\
\text { Mbtu/h }\end{array}$ & EER \\
\hline \multirow{3}{*}{30} & 12 & 0.57 & 1.32 & 22.6 & 2.68 & 15.3 & 74.2 & 2.47 & \multirow{6}{*}{\multicolumn{6}{|c|}{ Operation not recommended }} \\
\hline & 16 & 0.99 & 2.28 & 23.5 & 2.71 & 16.0 & 75.6 & 2.54 & & & & & & \\
\hline & 20 & 1.51 & 3.48 & 24.0 & 2.74 & 16.4 & 76.4 & 2.57 & & & & & & \\
\hline \multirow{3}{*}{40} & 12 & 0.55 & 1.26 & 29.1 & 2.72 & 22.3 & 76.6 & 3.14 & & & & & & \\
\hline & 16 & 0.94 & 2.18 & 30.2 & 2.74 & 23.2 & 78.1 & 3.23 & & & & & & \\
\hline & 20 & 1.44 & 3.32 & 30.9 & 2.77 & 23.9 & 78.8 & 3.27 & & & & & & \\
\hline \multirow{3}{*}{50} & 12 & 0.53 & 1.22 & 35.8 & 2.75 & 29.5 & 79.1 & 3.82 & 60.5 & 51.6 & 0.85 & 1.57 & 67.7 & 38.5 \\
\hline & 16 & 0.92 & 2.11 & 37.2 & 2.77 & 30.7 & 80.6 & 3.93 & 60.4 & 51.2 & 0.85 & 1.55 & 67.5 & 39.0 \\
\hline & 20 & 1.40 & 3.24 & 38.1 & 2.80 & 31.6 & 81.4 & 3.98 & 60.7 & 51.0 & 0.84 & 1.53 & 67.7 & 39.6 \\
\hline \multirow{3}{*}{60} & 12 & 0.51 & 1.18 & 42.3 & 2.78 & 36.6 & 81.6 & 4.47 & 57.9 & 50.5 & 0.87 & 1.99 & 66.5 & 29.1 \\
\hline & 16 & 0.89 & 2.05 & 44.0 & 2.81 & 38.1 & 83.1 & 4.60 & 57.9 & 50.2 & 0.87 & 1.96 & 66.3 & 29.5 \\
\hline & 20 & 1.37 & 3.16 & 45.0 & 2.84 & 39.2 & 83.9 & 4.66 & 58.1 & 49.9 & 0.86 & 1.94 & 66.4 & 29.9 \\
\hline \multirow{3}{*}{70} & 12 & 0.49 & 1.13 & 48.7 & 2.81 & 43.4 & 83.9 & 5.08 & 55.5 & 49.5 & 0.89 & 2.39 & 65.3 & 23.2 \\
\hline & 16 & 0.86 & 1.99 & 50.6 & 2.84 & 45.2 & 85.5 & 5.23 & 55.4 & 49.1 & 0.89 & 2.36 & 65.0 & 23.5 \\
\hline & 20 & 1.33 & 3.07 & 51.8 & 2.87 & 46.5 & 86.4 & 5.29 & 55.7 & 48.9 & 0.88 & 2.34 & 65.2 & 23.8 \\
\hline \multirow{3}{*}{80} & 12 & 0.47 & 1.08 & 55.0 & 2.84 & 50.2 & 86.3 & 5.67 & 53.0 & 48.4 & 0.91 & 2.80 & 64.1 & 19.0 \\
\hline & 16 & 0.83 & 1.91 & 57.2 & 2.87 & 52.3 & 87.9 & 5.84 & 53.0 & 48.1 & 0.91 & 2.76 & 63.8 & 19.2 \\
\hline & 20 & 1.29 & 2.97 & 58.5 & 2.90 & 53.9 & 88.8 & 5.92 & 53.2 & 47.9 & 0.90 & 2.73 & 64.0 & 19.5 \\
\hline \multirow{3}{*}{90} & 12 & 0.45 & 1.03 & 61.6 & 2.87 & 57.3 & 88.8 & 6.28 & 50.5 & 47.3 & 0.94 & 3.22 & 62.8 & 15.7 \\
\hline & 16 & 0.79 & 1.83 & 64.0 & 2.90 & 59.7 & 90.4 & 6.47 & 50.5 & 47.0 & 0.93 & 3.17 & 62.6 & 15.9 \\
\hline & 20 & 1.24 & 2.86 & 65.5 & 2.93 & 61.5 & 91.3 & 6.55 & 50.7 & 46.8 & 0.92 & 3.14 & 62.8 & 16.1 \\
\hline \multirow{3}{*}{100} & 12 & 0.43 & 0.98 & \multirow{9}{*}{\multicolumn{5}{|c|}{ Operation not recommended }} & 48.0 & 46.3 & 0.96 & 3.62 & 61.6 & 13.3 \\
\hline & 16 & 0.76 & 1.76 & & & & & & 48.0 & 46.0 & 0.96 & 3.58 & 61.4 & 13.4 \\
\hline & 20 & 1.19 & 2.76 & & & & & & 48.2 & 45.8 & 0.95 & 3.54 & 61.5 & 13.6 \\
\hline \multirow{3}{*}{110} & 12 & 0.42 & 0.97 & & & & & & 45.5 & 45.2 & 0.99 & 4.04 & 60.3 & 11.3 \\
\hline & 16 & 0.75 & 1.74 & & & & & & 45.5 & 44.9 & 0.99 & 3.99 & 60.1 & 11.4 \\
\hline & 20 & 1.18 & 2.73 & & & & & & 45.7 & 44.7 & 0.98 & 3.94 & 60.3 & 11.6 \\
\hline \multirow{3}{*}{120} & 12 & 0.42 & 0.96 & & & & & & 43.0 & 43.6 & 1.01 & 4.45 & 59.1 & 9.7 \\
\hline & 16 & 0.75 & 1.72 & & & & & & 43.0 & 43.3 & 1.01 & 4.40 & 58.9 & 9.8 \\
\hline & 20 & 1.17 & 2.70 & & & & & & 43.1 & 43.1 & 1.00 & 4.35 & 59.0 & 9.9 \\
\hline
\end{tabular}




\section{0 - Part Load - Performance Data}

\section{Mid Speed (3250 CFM)}

\begin{tabular}{|c|c|c|c|c|c|c|c|c|c|c|c|c|c|c|}
\hline \multirow{2}{*}{$\begin{array}{c}\text { EWT } \\
\text { OF }\end{array}$} & \multirow{2}{*}{$\begin{array}{l}\text { Flow } \\
\text { gpm }\end{array}$} & \multicolumn{2}{|c|}{ WPD } & \multicolumn{5}{|c|}{ HEATING - EAT 70 oF } & \multicolumn{6}{|c|}{ COOLING - EAT $80 / 67$ oF } \\
\hline & & PSI & FT & $\begin{array}{c}\text { HC } \\
\text { Mbtu/h }\end{array}$ & $\begin{array}{l}\text { Power } \\
\text { (kW) }\end{array}$ & $\underset{\text { Mbtu/h }}{\mathrm{HE}}$ & LAT & COP & $\begin{array}{c}\text { TC } \\
\text { Mbtu/h }\end{array}$ & $\begin{array}{c}\mathrm{SC} \\
\mathrm{Mbtu} / \mathrm{h}\end{array}$ & $S / T$ & $\begin{array}{c}\text { POWER } \\
(\mathrm{kW})\end{array}$ & $\begin{array}{c}\mathrm{HR} \\
\mathrm{Mbtu} / \mathrm{h}\end{array}$ & EER \\
\hline \multirow{3}{*}{30} & 24 & 2.12 & 4.90 & 77.1 & 7.26 & 58.0 & 90.5 & 3.11 & \multirow{6}{*}{\multicolumn{6}{|c|}{ Operation not recommended }} \\
\hline & 28 & 2.86 & 6.61 & 78.0 & 7.15 & 58.9 & 89.8 & 3.20 & & & & & & \\
\hline & 32 & 3.66 & 8.45 & 79.1 & 7.12 & 60.1 & 89.7 & 3.25 & & & & & & \\
\hline \multirow{3}{*}{40} & 24 & 2.04 & 4.71 & 84.4 & 7.16 & 65.2 & 91.8 & 3.45 & & & & & & \\
\hline & 28 & 2.74 & 6.33 & 86.2 & 7.11 & 67.5 & 91.3 & 3.56 & & & & & & \\
\hline & 32 & 3.52 & 8.13 & 88.7 & 7.31 & 69.2 & 93.3 & 3.55 & & & & & & \\
\hline \multirow{3}{*}{50} & 24 & 1.98 & 4.57 & 93.8 & 7.34 & 74.8 & 94.1 & 3.75 & 130.0 & 84.2 & 0.65 & 5.10 & 151.6 & 25.5 \\
\hline & 28 & 2.65 & 6.12 & 98.2 & 7.51 & 92.5 & 96.5 & 3.83 & 131.4 & 84.3 & 0.64 & 5.09 & 153.6 & 25.8 \\
\hline & 32 & 3.42 & 7.90 & 101.4 & 7.46 & 82.1 & 96.4 & 3.98 & 131.9 & 87.9 & 0.67 & 4.93 & 153.3 & 26.7 \\
\hline \multirow{3}{*}{60} & 24 & 1.91 & 4.41 & 104.0 & 7.51 & 85.1 & 96.9 & 4.06 & 125.6 & 79.8 & 0.64 & 5.71 & 149.1 & 22.0 \\
\hline & 28 & 2.58 & 5.96 & 108.1 & 7.58 & 88.7 & 98.7 & 4.18 & 125.8 & 80.4 & 0.64 & 5.61 & 149.0 & 22.4 \\
\hline & 32 & 3.35 & 7.74 & 110.6 & 7.66 & 91.3 & 99.7 & 4.23 & 125.8 & 81.1 & 0.64 & 5.53 & 148.6 & 22.7 \\
\hline \multirow{3}{*}{70} & 24 & 1.88 & 4.34 & 116.1 & 7.76 & 96.9 & 100.8 & 4.38 & 118.1 & 84.0 & 0.71 & 6.37 & 143.6 & 18.5 \\
\hline & 28 & 2.54 & 5.87 & 120.9 & 7.95 & 101.3 & 103.6 & 4.46 & 119.5 & 82.5 & 0.69 & 6.27 & 144.7 & 19.1 \\
\hline & 32 & 3.3 & 7.62 & 123.0 & 7.94 & 104.2 & 103.7 & 4.57 & 118.9 & 83.7 & 0.70 & 6.19 & 143.9 & 19.2 \\
\hline \multirow{3}{*}{80} & 24 & 1.87 & 4.32 & 128.6 & 8.08 & 108.9 & 104.6 & 4.67 & 115.3 & 80.5 & 0.70 & 7.14 & 142.8 & 16.1 \\
\hline & 28 & 2.5 & 5.78 & 133.0 & 8.16 & 113.3 & 106.2 & 4.78 & 115.5 & 81.3 & 0.70 & 7.04 & 143.1 & 16.4 \\
\hline & 32 & 3.25 & 7.51 & 136.7 & 8.21 & 117.2 & 107.3 & 4.88 & 115.8 & 82.0 & 0.71 & 6.96 & 143.0 & 16.7 \\
\hline \multirow{3}{*}{90} & 24 & 1.87 & 4.32 & 140.4 & 8.22 & 121.3 & 107.6 & 5.00 & 110.7 & 77.0 & 0.70 & 7.91 & 140.1 & 14.0 \\
\hline & 28 & 2.46 & 5.68 & 144.6 & 8.28 & 125.3 & 108.7 & 5.11 & 110.6 & 76.5 & 0.69 & 7.81 & 139.6 & 14.2 \\
\hline & 32 & 3.2 & 7.39 & 148.4 & 8.31 & 129.4 & 109.7 & 5.56 & 111.1 & 76.1 & 0.68 & 7.73 & 140.0 & 14.4 \\
\hline \multirow{3}{*}{100} & 24 & 1.7 & 3.93 & \multirow{9}{*}{\multicolumn{5}{|c|}{ Operation not recommended }} & 102.0 & 79.7 & 0.78 & 8.71 & 133.9 & 11.7 \\
\hline & 28 & 2.33 & 5.38 & & & & & & 103.2 & 79.5 & 0.77 & 8.63 & 134.7 & 12.0 \\
\hline & 32 & 3.04 & 7.02 & & & & & & 102.7 & 78.7 & 0.77 & 8.54 & 133.5 & 12.0 \\
\hline \multirow{3}{*}{110} & 24 & 1.67 & 3.86 & & & & & & 97.6 & 73.3 & 0.75 & 9.61 & 131.6 & 10.2 \\
\hline & 28 & 2.3 & 5.31 & & & & & & 96.8 & 74.2 & 0.77 & 9.52 & 130.9 & 10.2 \\
\hline & 32 & 3.02 & 6.98 & & & & & & 97.1 & 73.8 & 0.76 & 9.43 & 130.9 & 10.3 \\
\hline \multirow{3}{*}{120} & 24 & 1.67 & 3.86 & & & & & & 90.6 & 73.2 & 0.81 & 10.56 & 128.1 & 8.6 \\
\hline & 28 & 2.29 & 5.29 & & & & & & 90.8 & 73.5 & 0.81 & 10.45 & 128.0 & 8.7 \\
\hline & 32 & 2.98 & 6.88 & & & & & & 90.9 & 73.6 & 0.81 & 10.44 & 127.9 & 8.7 \\
\hline
\end{tabular}


180 - Full Load - Performance Data

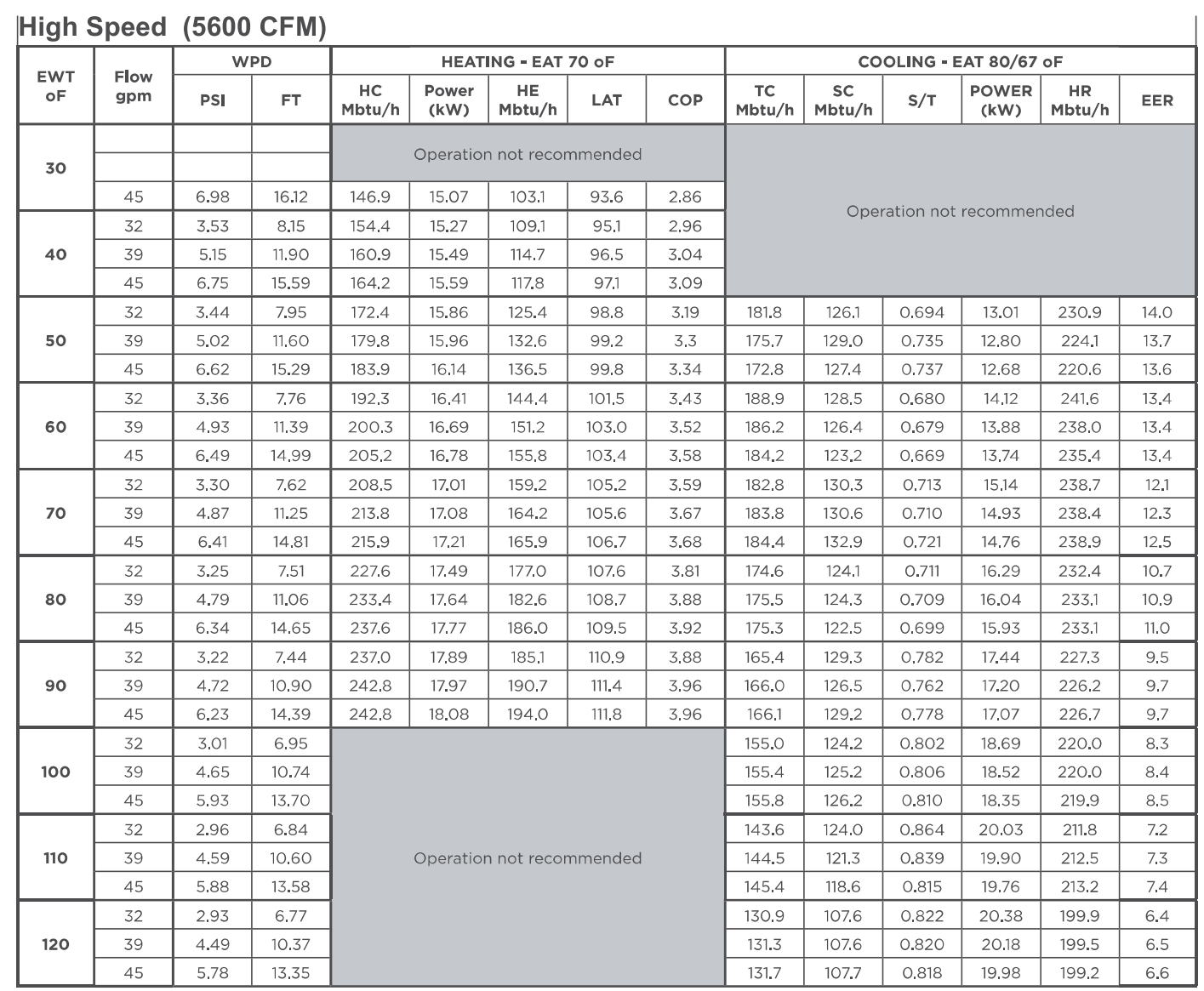




\section{APPENDIX C}

\section{AIR SOURCE HEAT PUMP PERFORMANCE DATA}

\begin{tabular}{|c|c|c|c|c|c|c|c|c|c|c|c|c|c|}
\hline \multicolumn{14}{|c|}{$\begin{array}{l}\text { 25VNA060/FE4BNBO06 Cooling EFFICIENCY Mode } \\
\text { Condenser Entering Air Temperature }{ }^{\circ} \mathrm{F}\left({ }^{\circ} \mathrm{C}\right)\end{array}$} \\
\hline \multirow{3}{*}{$\begin{array}{c}\text { EDB } \\
{ }^{\circ} F\left({ }^{\circ} \mathrm{C}\right)\end{array}$} & \multirow{3}{*}{$\begin{array}{l}\text { EVAP. AIR } \\
\text { EWB } \\
{ }^{\circ} \mathrm{F}\left({ }^{\circ} \mathrm{C}\right)\end{array}$} & \multicolumn{4}{|c|}{115} & \multicolumn{4}{|c|}{105} & \multicolumn{4}{|c|}{95} \\
\hline & & \multirow{2}{*}{ ID SCFM } & \multicolumn{2}{|c|}{ Capacity MBtuht } & \multirow{2}{*}{$\begin{array}{c}\text { Total Sys. } \\
\mathrm{KW}^{\star \star \star}\end{array}$} & \multirow{2}{*}{ ID SCFM } & \multicolumn{2}{|c|}{ Capacity MBtuht } & \multirow{2}{*}{$\begin{array}{c}\text { Total Sys. } \\
\kappa W^{\star \star *}\end{array}$} & \multirow{2}{*}{ ID SCFM } & \multicolumn{2}{|c|}{ Capacity MBtuht } & \multirow{2}{*}{$\begin{array}{c}\text { Total Sys. } \\
\mathrm{KW}^{* \star *}\end{array}$} \\
\hline & & & Total & Sens $\ddagger$ & & & Total & Sens $\ddagger$ & & & Total & Sensł & \\
\hline & & & & & & MAXIMUM & & & & & & & \\
\hline \multirow{4}{*}{$75(23.9)$} & $72(22.2)$ & \multirow{4}{*}{1300} & 55.12 & 22.16 & 5.31 & \multirow{4}{*}{1400} & 58.68 & 23.54 & 4.85 & \multirow{4}{*}{1500} & 62.00 & 24.82 & 4.45 \\
\hline & $67(19.4)$ & & 49.96 & 28.77 & 5.28 & & 53.17 & 30.59 & 4.81 & & 56.16 & 32.30 & 4.41 \\
\hline & $63(17.2)$ & & 46.11 & 33.91 & 5.25 & & 49.08 & 36.09 & 4.79 & & 51.85 & 38.15 & 4.38 \\
\hline & $57(13.9)$ & & 41.28 & 41.28 & 5.22 & & 43.98 & 43.98 & 4.76 & & 46.50 & 46.50 & 4.35 \\
\hline \multirow{4}{*}{$80(26.7)$} & $72(22.2)$ & \multirow{4}{*}{1300} & 54.92 & 28.76 & 5.31 & \multirow{4}{*}{1400} & 58.47 & 30.59 & 4.85 & \multirow{4}{*}{1500} & 61.78 & 32.30 & 4.45 \\
\hline & $67(19.4)$ & & 49.82 & 35.29 & 5.28 & & 53.02 & 37.56 & 4.81 & & 56.00 & 39.70 & 4.41 \\
\hline & $63(17.2)$ & & 46.04 & 40.40 & 5.25 & & 49.01 & 43.02 & 4.79 & & 51.78 & 45.49 & 4.38 \\
\hline & $57(13.9)$ & & 43.74 & 43.74 & 5.24 & & 46.59 & 46.59 & 4.77 & & 49.25 & 49.25 & 4.36 \\
\hline \multirow{5}{*}{$75(23.9)$} & & & & & & MEDIAN & & & & & & & \\
\hline & $72(22.2)$ & \multirow{4}{*}{1192} & 41.61 & 17.05 & 3.63 & \multirow{4}{*}{1265} & 44.37 & 18.14 & 3.28 & \multirow{4}{*}{1338} & 46.98 & 19.16 & 2.96 \\
\hline & $67(19.4)$ & & 37.68 & 23.11 & 3.63 & & 40.19 & 24.56 & 3.27 & & 42.55 & 25.93 & 2.95 \\
\hline & $63(17.2)$ & & 34.75 & 27.85 & 3.63 & & 37.07 & 29.58 & 3.27 & & 39.27 & 31.23 & 2.95 \\
\hline & $57(13.9)$ & & 32.25 & 32.25 & 3.63 & & 34.38 & 34.38 & 3.27 & & 36.38 & 36.38 & 2.94 \\
\hline & $72(22.2)$ & & 41.41 & 23.11 & 3.63 & & 44.16 & 24.55 & 3.28 & & 46.76 & 25.92 & 2.96 \\
\hline $80(26.7)$ & $67(19.4)$ & 1192 & 37.53 & 29.11 & 3.63 & 1265 & 40.04 & 30.90 & 3.27 & 1338 & 42.39 & 32.62 & 2.95 \\
\hline $00(20.7)$ & $63(17.2)$ & 1192 & 34.79 & 33.74 & 3.63 & 1200 & 37.12 & 35.81 & 3.27 & 1030 & 39.32 & 37.79 & 2.95 \\
\hline & $57(13.9)$ & & 34.35 & 34.35 & 3.63 & & 36.59 & 36.59 & 3.27 & & 38.71 & 38.71 & 2.95 \\
\hline & & & & & & MINIMUM & & & & & & & \\
\hline & $72(22.2)$ & & 16.15 & 1.63 & 2.08 & & 26.68 & 11.10 & 1.82 & & 28.33 & 11.75 & 1.59 \\
\hline $75(2399$ & $67(19.4)$ & 777 & 22.49 & 14.35 & 2.09 & 811 & 24.09 & 15.26 & 1.82 & 847 & 25.61 & 16.14 & 1.60 \\
\hline $75(23.9)$ & $63(17.2)$ & 775 & 20.68 & 17.44 & 2.10 & 811 & 22.18 & 18.50 & 1.83 & 847 & 23.59 & 19.53 & 1.60 \\
\hline & 57 (13.9) & & 19.58 & 19.58 & 2.10 & & 20.92 & 20.92 & 1.83 & & 22.21 & 22.21 & 1.60 \\
\hline & $72(22.2)$ & & 24.77 & 14.38 & 2.08 & & 26.53 & 15.28 & 1.82 & & 28.17 & 16.14 & 1.59 \\
\hline & $67(19.4)$ & & 22.42 & 18.29 & 2.09 & & 24.01 & 19.40 & 1.82 & & 25.52 & 20.47 & 1.60 \\
\hline $80(26.7)$ & $63(17.2)$ & 775 & 20.97 & 20.97 & 2.09 & 811 & 22.38 & 22.38 & 1.82 & 847 & 23.74 & 23.73 & 1.60 \\
\hline & $57(13.9)$ & & 20.93 & 20.93 & 2.09 & & 22.34 & 22.34 & 183 & & 23.69 & 23.69 & 160 \\
\hline
\end{tabular}


DETAILED COOLING CAPACITIES* - EFFICIENCY MODE (CONT.)

\begin{tabular}{|c|c|c|c|c|c|c|c|c|c|c|c|c|c|}
\hline \multicolumn{14}{|c|}{$\begin{array}{l}\text { 25VNA060/FE4BNBO06 Cooling EFFICIENCY Mode } \\
\text { Condenser Entering Air Temperature }{ }^{\circ} \mathrm{F}\left({ }^{\circ} \mathrm{C}\right)\end{array}$} \\
\hline \multirow{3}{*}{$\underset{{ }^{\circ} \mathrm{F}\left({ }^{\circ} \mathrm{C}\right)}{\mathrm{EDB}}$} & \multirow{3}{*}{$\begin{array}{l}\text { EVAP. AIR } \\
\text { EWB } \\
{ }^{\circ} \mathrm{F}\left({ }^{\circ} \mathrm{C}\right)\end{array}$} & \multicolumn{4}{|c|}{$85(29.4)$} & \multicolumn{4}{|c|}{75 (23.9) } & \multicolumn{4}{|c|}{$65(18.3)$} \\
\hline & & \multirow{2}{*}{ ID SCFM } & \multicolumn{2}{|c|}{ Capacity MBtuht } & \multirow{2}{*}{$\begin{array}{c}\text { Total Sys. } \\
\mathrm{KW}^{* *}\end{array}$} & \multirow{2}{*}{ ID SCFM } & \multicolumn{2}{|c|}{ Capacity MBtuht } & \multirow{2}{*}{$\begin{array}{c}\text { Total Sys. } \\
\mathrm{KW}^{* * \star}\end{array}$} & \multirow{2}{*}{ ID SCFM } & \multicolumn{2}{|c|}{ Capacity MBtuht } & \multirow{2}{*}{$\begin{array}{c}\text { Total Sys } \\
\mathrm{KW}^{* *}\end{array}$} \\
\hline & & & Total & Sens $\ddagger$ & & & Total & Sens‡ & & & Total & Sens: & \\
\hline & & & & & & MAXIMUM D & & & & & & & \\
\hline \multirow{4}{*}{75 (23.9) } & $72(22.2)$ & \multirow{4}{*}{1500} & 64.39 & 25.72 & 4.01 & \multirow{4}{*}{1675} & 67.43 & 26.88 & 3.76 & \multirow{4}{*}{1877} & 69.94 & 27.79 & 3.66 \\
\hline & $67(19.4)$ & & 58.31 & 33.16 & 3.96 & & 61.15 & 35.12 & 3.70 & & 63.57 & 36.95 & 3.58 \\
\hline & $63(17.2)$ & & 53.85 & 38.98 & 3.93 & & 56.52 & 41.57 & 3.65 & & 58.83 & 44.13 & 3.52 \\
\hline & $57(13.9)$ & & 48.25 & 47.46 & 3.89 & & 50.78 & 50.78 & 3.60 & & 53.42 & 53.42 & 3.46 \\
\hline \multirow{4}{*}{$80(26.7)$} & $72(22.2)$ & \multirow{4}{*}{1500} & 64.17 & 33.17 & 4.01 & \multirow{4}{*}{1675} & 67.19 & 35.08 & 3.76 & \multirow{4}{*}{1877} & 69.67 & 36.84 & 3.66 \\
\hline & $67(19.4)$ & & 58.15 & 40.52 & 3.96 & & 60.97 & 43.24 & 3.70 & & 63.37 & 45.92 & 3.58 \\
\hline & $63(17.2)$ & & 53.77 & 46.29 & 3.93 & & 56.45 & 49.62 & 3.65 & & 58.79 & 52.99 & 3.53 \\
\hline & $57(13.9)$ & & 50.74 & 50.74 & 3.91 & & 53.75 & 53.75 & 3.63 & & 56.56 & 56.56 & 3.50 \\
\hline \multirow{5}{*}{$75(23.9)$} & & & & & & MEDIAN D & & & & & & & \\
\hline & $72(22.2)$ & \multirow{4}{*}{1320} & 49.14 & 19.93 & 2.66 & \multirow{4}{*}{1382} & 51.12 & 20.71 & 2.48 & \multirow{4}{*}{1416} & 53.24 & 21.51 & 2.18 \\
\hline & $67(19.4)$ & & 44.50 & 26.61 & 2.65 & & 46.37 & 27.71 & 2.45 & & 48.28 & 28.67 & 2.16 \\
\hline & $63(17.2)$ & & 41.05 & 31.82 & 2.64 & & 42.84 & 33.19 & 2.44 & & 44.63 & 34.28 & 2.14 \\
\hline & $57(13.9)$ & & 37.63 & 37.63 & 2.63 & & 39.31 & 39.31 & 2.42 & & 40.82 & 40.82 & 2.12 \\
\hline & $72(22.2)$ & & 48.93 & 26.60 & 2.66 & & 50.90 & 27.67 & 2.48 & & 53.00 & 28.63 & 2.19 \\
\hline $80(26.7)$ & $67(19.4)$ & 1320 & 44.34 & 33.21 & 2.65 & 1382 & 46.21 & 34.60 & 2.45 & 1416 & 48.12 & 35.72 & 2.16 \\
\hline $80(20.7)$ & $63(17.2)$ & 1320 & 41.05 & 38.35 & 2.64 & 1382 & 42.85 & 39.99 & 2.44 & 1416 & 44.63 & 41.24 & 2.14 \\
\hline & $57(13.9)$ & & 40.00 & 40.00 & 2.64 & & 41.75 & 41.75 & 2.43 & & 43.32 & 43.32 & 2.13 \\
\hline & & & & & & MINIMUM D & & & & & & & \\
\hline & $72(22.2)$ & & 30.01 & 12.41 & 1.42 & & 31.50 & 12.96 & 1.25 & & 32.90 & 13.50 & 1.11 \\
\hline & $67(19.4)$ & 870 & 27.09 & 16.90 & 1.42 & & 28.43 & 17.49 & 1.25 & & 29.77 & 18.18 & 1.10 \\
\hline $75(23.9)$ & $63(17.2)$ & 870 & 24.96 & 20.41 & 1.42 & 875 & 26.19 & 21.04 & 1.25 & 894 & 27.42 & 21.81 & 1.10 \\
\hline & $57(13.9)$ & & 23.39 & 23.39 & 1.42 & & 24.37 & 24.37 & 1.25 & & 25.43 & 25.43 & 1.10 \\
\hline & $72(22.2)$ & & 29.84 & 16.92 & 1.42 & & 31.33 & 17.52 & 1.25 & & 32.81 & 18.21 & 1.11 \\
\hline & $67(19.4)$ & & 27.00 & 21.37 & 1.42 & & 28.33 & 22.00 & 1.25 & & 29.67 & 22.81 & 1.10 \\
\hline $80(26.7)$ & $63(17.2)$ & 870 & 25.07 & 24.80 & 1.42 & 875 & 26.26 & 25.50 & 1.25 & 894 & 27.49 & 26.40 & 1.10 \\
\hline & $57(13.9)$ & & 24.93 & 24.93 & 1.42 & & 25.96 & 25.96 & 1.25 & & 27.06 & 27.06 & 1.10 \\
\hline
\end{tabular}

+ Total and sensible capacities are net capacities. Blower motor heat has been subtracted

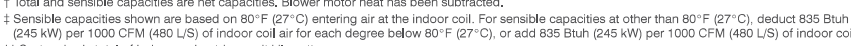

tystem wal

列 EWB - Entering Wet Bult

\section{HEAT PUMP HEATING PERFORMANCE - EFFICIENCY MODE}

\begin{tabular}{|c|c|c|c|c|c|c|c|c|c|c|c|c|c|c|c|c|}
\hline \multirow{4}{*}{$\begin{array}{c}\frac{\substack{\text { INDOOR } \\
\text { AlR }}}{} \\
\text { EDB }\end{array}$} & \multicolumn{16}{|c|}{ 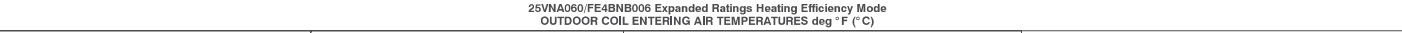 } \\
\hline & \multirow{3}{*}{$\underset{\text { ScFM }}{10}$} & \multicolumn{3}{|c|}{$-3(-19.4)$} & \multicolumn{4}{|c|}{$7(-13.9)$} & \multicolumn{4}{|c|}{$17(-8.3)$} & \multicolumn{4}{|c|}{$27(-2.8)$} \\
\hline & & \multicolumn{2}{|c|}{$\begin{array}{c}\substack{\text { capacaity } \\
\text { MBtuh }} \\
\text { M }\end{array}$} & \multirow{2}{*}{ Total Sys. KW† } & \multirow{2}{*}{$\begin{array}{l}\text { ID } \\
\text { ScFM }\end{array}$} & \multicolumn{2}{|c|}{ Capacity MBtuh } & \multirow{2}{*}{ Total Sys. KW $t$} & \multirow{2}{*}{$\begin{array}{l}\text { ID } \\
\text { sCFM }\end{array}$} & \multicolumn{2}{|c|}{ Capacity MBtuh } & \multirow{2}{*}{ Total Sys. KW $t$} & \multirow{2}{*}{$\begin{array}{l}\text { ID } \\
\text { scFM }\end{array}$} & \multicolumn{2}{|c|}{ Capacity MBtuh } & \multirow{2}{*}{ Total Sys. KWt } \\
\hline & & Total & Integ $\neq$ & & & Total & Integ $\neq$ & & & Total & Integf & & & Total & Integ $\neq$ & \\
\hline & \multirow{3}{*}{1067} & & & & & & & & MAXII & & & & & & & \\
\hline 年5 & & $\begin{array}{l}3.549 \\
34.90\end{array}$ & $\begin{array}{l}32.1 \\
32.11\end{array}$ & $\begin{array}{l}5.64 \\
5.64\end{array}$ & \multirow{2}{*}{1155} & $\begin{array}{r}42.75 \\
42.32\end{array}$ & $\begin{array}{l}39.28 \\
33.89\end{array}$ & $\frac{5.99}{6.22}$ & \multirow{2}{*}{1750} & 5.2 .80 & $\begin{array}{l}48.14 \\
47.87\end{array}$ & 6.63 & \multirow{2}{*}{1662} & 56.64 & 50.30 & 6.34 \\
\hline & & 34.27 & 31.53 & 5.80 & & 41.83 & 38.44 & 6.45 & & 52.19 & 47.58 & 7.23 & & 55.94 & 49.68 & 6.93 \\
\hline & & & & & & & & & MED & & & & & & & \\
\hline 65 & \multirow{3}{*}{867} & 31.48 & 28.96 & 3.58 & \multirow{3}{*}{916} & 37.31 & 34.28 & 3.95 & \multirow{3}{*}{1143} & 44.28 & 40.37 & 4.29 & \multirow{3}{*}{1342} & 47.77 & 42.43 & 4.17 \\
\hline 70 & & 30.97 & 28.49 & 3.72 & & 36.90 & 33.91 & 4.12 & & 43.95 & 40.07 & 4.51 & & 47.46 & 42.15 & 4.39 \\
\hline 75 & & 30.37 & 27.94 & 3.84 & & 36.44 & 33.49 & 4.29 & & 43.58 & 39.73 & 4.72 & & 47.14 & 41.87 & 4.62 \\
\hline & & & & & & & & & MINII & & & & & & & \\
\hline 65 & \multirow{3}{*}{667} & 23.63 & 21.74 & 2.07 & \multirow{3}{*}{689} & 27.55 & 25.32 & 2.30 & \multirow{3}{*}{800} & 31.24 & 28.48 & 2.43 & \multirow{3}{*}{945} & 34.52 & 30.66 & 2.08 \\
\hline 70 & & 23.21 & 21,35 & 2.16 & & 27.23 & 25.03 & 2.41 & & 30.96 & 28.23 & 2.57 & & 34.24 & 30.41 & 2.62 \\
\hline 75 & & 22.72 & 20.90 & 2.24 & & 26.87 & 24.69 & 2.53 & & 30.66 & 27.96 & 2.71 & & 33.96 & 30.16 & 2.78 \\
\hline
\end{tabular}

\begin{tabular}{|c|c|c|c|c|c|c|c|c|c|c|c|c|}
\hline \multirow{4}{*}{\begin{tabular}{|c|}
$\begin{array}{c}\text { INDOOR } \\
\text { AlR }\end{array}$ \\
EDB \\
\end{tabular}} & \multicolumn{12}{|c|}{$\begin{array}{l}\text { 25VNAO060/FEABNBoo6 Expanded Ratings Heating Efficiency Mode } \\
\text { OUTDOOR COIL ENTERING AIR TEMPERATURES deg }\end{array}$} \\
\hline & \multirow{2}{*}{\multicolumn{4}{|c|}{$\begin{array}{l}37(2.7) \\
\text { Capactly MBtuh }\end{array}$}} & & \multicolumn{4}{|c|}{$57(13.9)$} \\
\hline & \multirow{2}{*}{$\begin{array}{l}\text { ID } \\
\text { SCFM }\end{array}$} & \multirow{2}{*}{\multicolumn{2}{|c|}{\begin{tabular}{l|l} 
Capactly MBtuh \\
Total & Integł
\end{tabular}}} & \multirow{2}{*}{ Total Sys. KW† } & \multirow{2}{*}{$\begin{array}{l}\text { ID } \\
\text { SCFM }\end{array}$} & & Capacity MBtuh & \multirow{2}{*}{ Total Sys. KW +} & \multirow{2}{*}{$\begin{array}{l}\text { ID } \\
\text { SCFM }\end{array}$} & \multicolumn{2}{|c|}{ Capacity MBtuh } & \multirow{2}{*}{ Total Sys. KWt } \\
\hline & & & & & & & Integ & & & Total & Integ $\neq$ & \\
\hline 65 & \multirow{3}{*}{1649} & 54.45 & 49.55 & 5.03 & \multirow{3}{*}{1750} & 56.00 & 56.00 & 4.00 & \multirow{3}{*}{1725} & 50.08 & 50.08 & 3.00 \\
\hline 70 & & 54.03 & 49.17 & 5.28 & & 55.50 & 55.50 & 4.21 & & 49.57 & 49.57 & 3.17 \\
\hline 75 & & 53.59 & 48.77 & 5.54 & & 54.99 & 54.99 & 4.44 & & 49.04 & 49.04 & 3.33 \\
\hline 65 & \multirow{3}{*}{1468} & 44.69 & 40.67 & 336 & \multirow{3}{*}{1478} & 38.45 & 38.45 & 251 & \multirow{3}{*}{1500} & 39.22 & 39.22 & 240 \\
\hline 70 & & 44,32 & 40,33 & 3.56 & & 38.07 & 38.07 & 2.67 & & 38.76 & 39.726 & $\frac{2.40}{2.54}$ \\
\hline 75 & & 43.95 & 40.00 & 3.76 & & 37.69 & 37.69 & 2.83 & & 38.32 & 38.32 & 2.69 \\
\hline 65 & \multirow{3}{*}{814} & 30.39 & 27.66 & 2.08 & \multirow{3}{*}{1125} & 25.08 & 25.08 & 1.43 & \multirow{3}{*}{1125} & 26.98 & 26.98 & 1.51 \\
\hline 70 & & 30.14 & 27.42 & 2.21 & & 24.80 & 24.80 & 1.53 & & 26.61 & 26.61 & 1.61 \\
\hline 75 & & 29.86 & 27.17 & 2.34 & & 24.51 & 24.51 & 1.63 & & 26.25 & 26.25 & 1.71 \\
\hline
\end{tabular}

NOTES:

The $\mathrm{kW}$ values include the compressor, outdoor fan motor, and indoor blower motor. The $\mathrm{kW}$ from supplement heaters should be added to these values to obtain Total Sys. kilowatts.

fThe Btuh heating capacity values shown are net integrated values from which the defrost effect has been subtracted. The Btuh heating from supplement heaters should be added to those values to obtain Total Sys. capacity. NOTE: When the required data falls between the published data, interpolation may be performed. Extrapolation is not an acceptable practice.

EDB - Entering Dry Bulb 


\section{APPENDIX D}

\section{UMASS ENERGY PRICE FORECAST}

\begin{tabular}{|c|c|c|c|c|c|c|c|c|c|c|c|c|c|}
\hline \multicolumn{14}{|c|}{ Total Volumetric Retail Electricity Charges ( $\$ / \mathrm{MWh})$} \\
\hline Year & Jan & Feb & Mar & Apr & May & Jun & Jul & Aug & Sep & Oct & Nov & Dec & Avg. \\
\hline 2020 & 5 & 95.84 & 81.42 & 75. & 3 & 27 & 69.92 & 89 & 5.06 & 64.91 & 77.28 & 7.97 & 76.55 \\
\hline 2021 & 101.13 & 97.95 & 83.21 & 77.42 & 70.86 & 2.09 & 9.34 & 77.32 & 1.58 & 72.27 & 83.11 & 93.05 & 81.61 \\
\hline 2022 & 107.43 & 104.21 & 85.69 & 80.55 & 73.98 & 76.13 & 82.43 & 80.66 & 78.19 & 75.84 & 84.83 & 97.69 & 85.64 \\
\hline 2023 & 110.59 & 107.18 & 90.42 & 82.61 & 77.23 & 79.39 & 85.65 & 83.89 & 81.47 & 79.09 & 85.30 & 9.41 & 88.52 \\
\hline 2024 & 113.39 & 109.82 & 89.86 & 82.32 & 76.77 & 78.86 & 03 & 8 & 4 & 78.35 & 88.12 & 2.37 & 89.07 \\
\hline 2025 & 118.88 & 114.67 & 92.26 & 81.94 & 76.09 & 78.19 & 84.39 & 82.52 & 80.12 & 77.79 & 87.83 & 101.59 & 89.69 \\
\hline 2026 & 119.03 & 114.84 & 92.64 & 82.35 & 76.41 & 78.52 & 84.76 & 82.96 & 0.58 & 78.16 & 88.23 & 101.83 & 90.03 \\
\hline 2027 & 117.54 & 113.40 & 91.47 & 81.35 & 75.48 & 77.55 & 83.80 & 81.99 & 79.69 & 77.28 & 87.28 & 100.66 & 88.96 \\
\hline 2028 & 118.55 & 14.35 & 92.49 & 82.40 & 76.46 & 78.56 & 84.91 & 83.08 & 0.84 & 78.50 & 88.41 & 51 & 90.01 \\
\hline 2029 & 116.19 & 112.01 & 90.42 & 80.26 & דונדו & 76.46 & 82.79 & 80.97 & 78.74 & (1.0. & 86.29 & 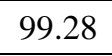 & 87.85 \\
\hline 2030 & 117.72 & 113.60 & 92.33 & 82.21 & 76.34 & 78.47 & 84 & 83.28 & 08 & . & 88 & 36 & 89.89 \\
\hline 2031 & & & & 8 & & & & & & & & & 33 \\
\hline 2032 & 12 & 11 & 6 & 8 & 8 & 1 & 0 & 5 & 0 & 33 & 8 & 57 & 94.46 \\
\hline 2033 & 123.36 & 119.26 & 98.84 & 89.08 & 83.34 & 85.54 & 92.18 & 90.53 & 88.26 & 85.88 & 95.33 & 107.58 & 96.60 \\
\hline 2034 & 125.25 & 121.17 & 100.94 & 91.27 & 85.57 & 87.79 & 94.49 & 92.82 & 90.54 & 88.14 & 97.51 & 109.61 & 98.76 \\
\hline 2035 & 127.17 & 123.10 & 103.05 & 93.48 & 87.82 & 90.06 & 96.82 & 95.13 & 92.84 & 90.43 & 99.71 & 111.65 & 100.94 \\
\hline 2036 & 129.11 & 125.04 & 105.19 & 95.71 & 90.10 & 92.36 & 99.17 & 97.46 & 95.17 & 92.73 & 101.93 & 113.73 & 103.14 \\
\hline 2037 & 131.08 & 127.02 & 107.36 & 97.97 & 92.40 & 94.68 & 101.55 & 99.82 & 97.52 & 95.07 & 104.17 & 115.83 & 105.37 \\
\hline 2038 & & & & 100.26 & 94 & 97 & & 102.20 & (7) & 3 & $4 \mathrm{~J}$ & 95 & 7.63 \\
\hline 2039 & & & & 102.57 & & & & & & 93 & .75 & 11 & 109.91 \\
\hline 2040 & & & & 104.92 & & 101.81 & & 107.07 & & 102.24 & 111.09 & .30 & 112.23 \\
\hline 2041 & & 134.59 & & 106.68 & & 103.63 & & 108.93 & & 104.08 & 112.84 & 123.90 & 113.97 \\
\hline 2042 & 140.75 & 136.73 & 118.03 & 109.10 & 103.74 & 106.11 & 113.27 & 111.45 & 109.11 & 106.57 & 115.25 & 126.16 & 116.36 \\
\hline 2043 & 133.82 & 129.81 & 111.30 & 102.46 & 97.14 & 99.54 & 106.76 & 104.92 & 102.57 & 100.01 & 108.61 & 119.36 & 109.69 \\
\hline 2044 & 134.04 & 130.04 & 111.72 & 102.97 & 97.69 & 100.11 & 107.39 & 105.53 & 103.17 & 100.60 & 109.11 & 119.71 & 110.17 \\
\hline 2045 & 135.75 & 131.76 & 113.63 & 104.97 & 99.74 & 102.17 & 109.51 & 107.63 & 105.27 & 102.67 & 111.11 & 121.56 & 112.15 \\
\hline 2046 & 138.14 & & 116.23 & 107.66 & 102.46 & 104.92 & & 110.42 & 108.05 & 105.44 & 113.79 & 124.09 & 114.81 \\
\hline 2047 & 139.38 & 135.41 & & 109.19 & 104.04 & 106.52 & 113.97 & 112.05 & 109.67 & 107.04 & 115.31 & 125.46 & 116.31 \\
\hline 2048 & 141.13 & 137.16 & 119.61 & 111.23 & 106.11 & 108.62 & 116.12 & 114.19 & 111.81 & 109.16 & 117.35 & 127.34 & 118.32 \\
\hline 2049 & 143.03 & 139.07 & 121.71 & 113.41 & 108.34 & 110.86 & 118.43 & 116.48 & 114.09 & 111.42 & 119.53 & 129.37 & 120.48 \\
\hline 2050 & 144.75 & 140.81 & 123.64 & 115.43 & 110.40 & 112.94 & 120.57 & 118.60 & 116.20 & 113.52 & 121.54 & 131.23 & 122.47 \\
\hline
\end{tabular}




\begin{tabular}{|c|c|c|c|c|c|c|c|c|c|c|c|c|c|}
\hline \multicolumn{14}{|c|}{ Blended CHP Fuel Rate (\$/MMBtu) } \\
\hline Year & Jan & Feb & Mar & Apr & May & Jun & Jul & Aug & Sep & Oct & Nov & Dec & Avg. \\
\hline 2020 & 11.700 & .634 & 7.2391 & 5.2175 & 336 & 4.5482 & 4.7536 & 7532 & 4.4772 & 4.6263 & 5.6252 & 8.2171 & 7.9683 \\
\hline 2021 & 11.796 & 11.730 & .3356 & 140 & 5301 & 4.6531 & 336 & 4.8296 & 4915 & 7008 & 5374 & .7730 & .9585 \\
\hline 2022 & 9.2003 & 8 & 6.5010 & 5.40 & 43 & 4.7083 & 4.9059 & 4.8872 & 4.5837 & 6999 & 0064 & 9893 & 1104 \\
\hline 2023 & 9.3980 & 9.3530 & 6.8494 & 5.5354 & 4.8966 & 4.9312 & 5.0998 & 5.0783 & 4.8123 & 4.9650 & 5.9212 & 8.0164 & 7.2603 \\
\hline 2024 & 9.8796 & 9.8356 & 6.9237 & 5.6246 & 4.9849 & 5.0121 & 5.1741 & 5.1460 & 4.8753 & 5.0280 & 6.3158 & 8.4972 & 7.5689 \\
\hline 2025 & 10.703 & 10.622 & 7.3463 & 5.7269 & 5.1593 & 5.2371 & 5.3157 & 5.3223 & 5.2698 & 5.2520 & 6.4322 & 8.5826 & 7.9694 \\
\hline 2026 & 10.796 & 10.714 & 7.4394 & 5.8097 & 5.2299 & 5.3095 & 5.3910 & 5.4041 & 5.3526 & 5.3273 & 6.5187 & 8.6691 & 8.0563 \\
\hline 2027 & 10.800 & 0.122 & 7.4551 & 0205 & 2484 & 5.3234 & 3.4011 & 5.4151 & . & .3505 & 6.5456 & דר 0.0 & 8.0719 \\
\hline 2028 & 10.895 & 10.809 & 7.5276 & 5.8894 & 3012 & 5.3790 & 5.4642 & 5.4783 & 5.4399 & .4249 & 6.6219 & 8.7555 & 8.1469 \\
\hline 2029 & 10.958 & 10.872 & 7.6006 & 5.9437 & 5.3527 & 5.4333 & 5.5185 & 5.5326 & 5.4942 & 5.4792 & 6.6818 & 8.8182 & 8.2084 \\
\hline 2030 & 11.029 & 10.947 & 7.6902 & 6.0230 & 5.4320 & 5.5125 & 5.5978 & 5.6352 & 5.6015 & 5.5968 & 6.8004 & 8.9368 & 8.3009 \\
\hline 2031 & 11.122 & 11.040 & 7.7802 & 6.1084 & 5.5161 & 5.5973 & 5.6833 & 5.7215 & 5.6880 & 5.6842 & 6.8891 & 9.0284 & 8.3906 \\
\hline 2032 & 11.216 & 11.133 & 7.8719 & 6.1945 & 5.6017 & 5.6836 & 5.7703 & 5.8093 & 5.7761 & 5.7732 & 6.9795 & 9.1217 & 8.4818 \\
\hline 2033 & 10.909 & 10.825 & 7.5622 & 5.8791 & 5.2859 & 5.3684 & 5.4560 & 5.4957 & 5.4629 & 5.4608 & 6.6685 & 8.8138 & 8.1717 \\
\hline 2034 & 11.006 & 10.922 & 7.6573 & 5.9683 & 5.3746 & 5.4579 & 5.5462 & 5.5868 & 5.5542 & 5.5531 & 6.7622 & 8.9106 & 8.2663 \\
\hline 2035 & 11.106 & 11.021 & 7.7541 & 6.0591 & 5.4650 & 5.5490 & 5.6381 & 5.6795 & 5.6472 & 5.6470 & 6.8576 & 9.0091 & 8.3626 \\
\hline 2036 & 11.207 & 11.121 & 7.8527 & 6.1516 & 5.5571 & 5.6418 & 5.7317 & 5.7739 & 5.7420 & 5.7427 & 6.9548 & 9.1095 & 8.4607 \\
\hline 2037 & 11.310 & 11.224 & 7.9531 & 6.2458 & 5.6508 & 5.7362 & 5.8270 & 5.8701 & 5.8384 & 5.8402 & 7.0537 & 9.2117 & 8.5605 \\
\hline 2038 & 11.415 & 11.328 & 8.0554 & 6.3417 & 5.7462 & 5.8324 & 5.9241 & 5.9680 & 5.9367 & 5.9394 & 7.1545 & 9.3158 & 8.6623 \\
\hline 2039 & & & & & & & & 6.0677 & 67 & 404 & & 9.4219 & 8.7659 \\
\hline 2040 & 11.631 & 11.543 & 8.2656 & 6.5389 & 5.9424 & 6.0301 & 6.1236 & 6.1692 & 6.1386 & 1433 & 7.3617 & 9.5299 & 8.8714 \\
\hline 2041 & 11.742 & 11.653 & 8.3736 & 6.6401 & 6.0432 & 6.1317 & 6.2261 & 6.2727 & 6.2424 & 6.2482 & 7.4681 & 9.6399 & 8.9788 \\
\hline 2042 & 11.855 & 11.765 & 8.4836 & 6.7433 & 6.1458 & 6.2352 & 6.3305 & 6.3780 & 6.3480 & 6.3549 & 7.5765 & 9.7519 & 9.0883 \\
\hline 2043 & 11.970 & 11.879 & 8.5957 & 6.8483 & 6.2504 & 6.3405 & 6.4368 & 6.4852 & 6.4556 & 6.4636 & 7.6869 & 9.8660 & 9.1997 \\
\hline 2044 & 12.088 & 11.996 & 8.7098 & 6.9553 & 6.3568 & 6.4478 & 6.5450 & 6.5945 & 6.5652 & 6.5743 & 7.7994 & 9.9822 & 9.3132 \\
\hline 2045 & 12.207 & 12.114 & 8.8261 & 7.0643 & 6.4652 & 6.5571 & 6.6553 & 6.7057 & 6.6769 & 6.6871 & 7.9139 & 10.101 & 9.4289 \\
\hline 2046 & 12.329 & 12.235 & 8.9445 & 7.1752 & 6.5756 & 6.6684 & 6.7676 & 6.8190 & 6.7905 & 6.8019 & 8.0306 & 10.221 & 9.5466 \\
\hline 2047 & 12.453 & 12.358 & 9.0651 & 7.2882 & 6.6881 & 6.7817 & 6.8820 & 6.9344 & 6.9063 & 6.9189 & 8.1494 & 10.344 & 9.6666 \\
\hline 2048 & 12.579 & 12.484 & 9.1879 & 7.4033 & 6.8026 & 6.8972 & 6.9984 & 7.0519 & 7.0242 & 7.0380 & 8.2704 & 10.469 & 9.7887 \\
\hline 2049 & 12.708 & 12.611 & 9.3130 & 7.5206 & 6.9192 & 7.0147 & 7.1171 & 7.1716 & 7.1443 & 7.1593 & 8.3937 & 10.596 & 9.9132 \\
\hline 2050 & 12.839 & 12.741 & 9.4404 & 7.6399 & 7.0380 & 7.1345 & 7.2379 & 7.2936 & 7.2667 & 7.2829 & 8.5192 & 10.726 & 10.040 \\
\hline
\end{tabular}




\begin{tabular}{|c|c|c|}
\hline \multicolumn{3}{|c|}{ Electricity Demand } \\
\hline & Monthly Demand & Annual Capacity Charge \\
\hline Year & $\$ / \mathrm{kW} / \mathrm{month}$ & \$/kW/year \\
\hline 2020 & 11.53 & 95.40 \\
\hline 2021 & 11.99 & 79.45 \\
\hline 2022 & 12.35 & 63.84 \\
\hline 2023 & 12.72 & 33.60 \\
\hline 2024 & 13.10 & 70.81 \\
\hline 2025 & 13.50 & 86.88 \\
\hline 2026 & 13.83 & 102.94 \\
\hline 2027 & 14.18 & 135.07 \\
\hline 2028 & 14.53 & 137.10 \\
\hline 2029 & 14.90 & 139.15 \\
\hline 2030 & 15.27 & 141.24 \\
\hline 2031 & 15.65 & 143.36 \\
\hline 2032 & 16.04 & 145.51 \\
\hline 2033 & 16.44 & 147.69 \\
\hline 2034 & 16.85 & 149.91 \\
\hline 2035 & 17.28 & 152.16 \\
\hline 2036 & 17.71 & 154.44 \\
\hline 2037 & 18.15 & 156.76 \\
\hline 2038 & 18.60 & 159.11 \\
\hline 2039 & 19.07 & 161.49 \\
\hline 2040 & 19.55 & 163.92 \\
\hline 2041 & 20.03 & 166.38 \\
\hline 2042 & 20.54 & 168.87 \\
\hline 2043 & 21.05 & 171.40 \\
\hline 2044 & 21.57 & 173.98 \\
\hline 2045 & 22.11 & 176.59 \\
\hline 2046 & 22.67 & 179.23 \\
\hline 2047 & 23.23 & 181.92 \\
\hline 2048 & 23.81 & 184.65 \\
\hline 2049 & 24.41 & 187.42 \\
\hline 2050 & 25.02 & 190.23 \\
\hline
\end{tabular}




\section{APPENDIX E}

CHCRC DEMAND DATA (kW)

\begin{tabular}{|c|c|c|c|c|c|c|c|}
\hline Month & $\begin{array}{c}\text { GSHP } \\
\text { System } \\
\text { Only }\end{array}$ & $\begin{array}{c}\text { Conventional } \\
\text { System Only }\end{array}$ & $\begin{array}{c}\text { GSHP Total } \\
\text { No Electric } \\
\text { Generation }\end{array}$ & $\begin{array}{c}\text { Conventional } \\
\text { Total No Electric } \\
\text { Generation }\end{array}$ & $\begin{array}{c}\text { GSHP Total } \\
\text { with Electric } \\
\text { Generation }\end{array}$ & $\begin{array}{c}\text { Conventional Total } \\
\text { with Electric } \\
\text { Generation }\end{array}$ & $\begin{array}{c}\text { ASHP Total } \\
\text { No Electric } \\
\text { Generation }\end{array}$ \\
\hline 1 & 711 & 0 & 1,248 & 542 & 1,029 & 318 & 1,458 \\
\hline 2 & 602 & 0 & 1,200 & 603 & 809 & 213 & 1,344 \\
\hline 3 & 574 & 0 & 1,172 & 607 & 783 & 218 & 1,368 \\
\hline 4 & 356 & 0 & 958 & 608 & 569 & 225 & 986 \\
\hline 5 & 264 & 231 & 573 & 541 & 318 & 271 & 709 \\
\hline 6 & 246 & 233 & 545 & 532 & 201 & 188 & 620 \\
\hline 7 & 318 & 304 & 704 & 699 & 274 & 269 & 810 \\
\hline 8 & 318 & 289 & 655 & 626 & 205 & 177 & 763 \\
\hline 9 & 396 & 301 & 978 & 883 & 526 & 431 & 1,017 \\
\hline 10 & 278 & 187 & 787 & 713 & 416 & 330 & 919 \\
\hline 11 & 397 & 0 & 966 & 569 & 540 & 143 & 934 \\
\hline 12 & 533 & 0 & 997 & 464 & 599 & 66 & 1,009 \\
\hline $\begin{array}{c}\text { Annual } \\
\text { Capacity } \\
\text { Charge }\end{array}$ & 447 & 369 & 846 & 730 & 322 & 213 & 992 \\
\hline
\end{tabular}




\section{BIBLIOGRAPHY}

Battocletti, E. C., \& Glassley, W. E. (2013). Measuring the Costs and Benefits of Nationwide Geothermal Heat Pump Deployment. https://doi.org/10.15121/1154918

Breger, D. S., Hubbell, J. E., El Hasnaoui, H., \& Sunderland, J. E. (1996). Thermal energy storage in the ground: Comparative analysis of heat transfer modeling using U-tubes and boreholes. Solar Energy, 56(6), 493-503. https://doi.org/10.1016/0038092X(96)00013-8

Cacabelos, A., Eguía, P., Míguez, J. L., Granada, E., \& Arce, M. E. (2015). Calibrated simulation of a public library HVAC system with a ground-source heat pump and a radiant floor using TRNSYS and GenOpt. Energy and Buildings, 108, 114-126. https://doi.org/10.1016/j.enbuild.2015.09.006

Elhasnaoui, H. (1991). The Design of a Central Solar Heating Plant with Seasonal Storage. University of Massachusetts Dissertation, 122.

Garber, D., Choudhary, R., \& Soga, K. (2013). Risk based lifetime costs assessment of a ground source heat pump (GSHP) system design: Methodology and case study. Building and Environment, 60, 66-80. https://doi.org/10.1016/j.buildenv.2012.11.011

Hellstrom, G. (1989). DUCT GROUND HEAT STORAGE MODEL Manual for Computer Code. TRNSYS Manual, 49.

IGSHPA Standards Committee 2017. (2017). Closed-Loop / Geothermal Heat Pump Systems Design and Installation Standards. INTERNATIONAL GROUND SOURCE HEAT PUMP ASSOCIATION. https://igshpa.org/wpcontent/uploads/2019/01/2017_IGSHPA_Standards-restricted.pdf

Integral Group. (2019). Amherst College Zero Carbon Energy System Study.

ISO New England. (2018). 2018 ISO New England Electric Generator Air Emissions Report. May, 1-44. https://www.iso-ne.com/staticassets/documents/2020/05/2018_air_emissions_report.pdf

Lanahan, M., \& Tabares-Velasco, P. C. (2017). Seasonal thermal-energy storage: A critical review on BTES systems, modeling, and system design for higher system efficiency. Energies, 10(6). https://doi.org/10.3390/en10060743

Lowe, J. W., Koester, R. J., \& Sachtleben, P. J. (2010). Embracing the Future: The Ball State University Geothermal Project. In W. Leal Filho (Ed.), Universities and Climate Change: Introducing Climate Change to University Programmes (pp. 205220). Springer Berlin Heidelberg. https://doi.org/10.1007/978-3-642-10751-1_17

Marmaras, J. M. (2014). Measurement and Verification - Retro- Commissioning of a LEED Gold Rated Building Through Means of an Energy Model : Are Aggressive 
Energy Simulation Models Reliable? Masters Theses, 31.

https://scholarworks.umass.edu/masters_theses_2/31

Massachusetts Clean Energy Center. (2020). Ground-Source Heat Pump Program Residential \& Small-Scale Projects. http://filescdn.masscec.com/ResidentialandSmallScaleGSHPProjectDatabase.xlsx

McDaniel, B., \& Kosanovic, D. (2016). Modeling of combined heat and power plant performance with seasonal thermal energy storage. Journal of Energy Storage, 7, 13-23. https://doi.org/10.1016/j.est.2016.04.006

Mustafa Omer, A. (2008). Ground-source heat pumps systems and applications. Renewable and Sustainable Energy Reviews, 12(2), 344-371. https://doi.org/10.1016/j.rser.2006.10.003

Quiggin, D., \& Buswell, R. (2016). The implications of heat electrification on national electrical supply-demand balance under published 2050 energy scenarios. Energy, 98, 253-270. https://doi.org/10.1016/j.energy.2015.11.060

Rees, S. J., Spitler, J. D., Deng, Z., Orlo, C. D., \& Johnson, C. N. (2004). A study of geothermal heat pump and standing column well performance. 2004 Winter Meeting - Technical and Symposium Papers, American Society of Heating, Refrigerating and Air-Conditioning Engineers, 109, 1-10.

Safa, A. A., Fung, A. S., \& Kumar, R. (2015). Heating and cooling performance characterisation of ground source heat pump system by testing and TRNSYS simulation. Renewable Energy, 83, 565-575. https://doi.org/10.1016/j.renene.2015.05.008

Sanner, B., Karytsas, C., Mendrinos, D., \& Rybach, L. (2003). Current status of ground source heat pumps and underground thermal energy storage in Europe. Geothermics, 32(4), 579-588. https://doi.org/10.1016/S0375-6505(03)00060-9

Suresh, S. (2012). Thermodynamic Analysis of Combined Cycle District Heating. Masters Theses 1911, February 2014. https://scholarworks.umass.edu/theses/955

Veldman, E., Gibescu, M., Slootweg, H., \& Kling, W. L. (2011). Impact of electrification of residential heating on loading of distribution networks. 2011 IEEE PES Trondheim PowerTech: The Power of Technology for a Sustainable Society, POWERTECH 2011, 1-7. https://doi.org/10.1109/PTC.2011.6019179 